\title{
EXPERIMENTAL TESTING OF ROOF TO WALL CONNECTIONS IN WOOd FRAME HOUSES
}

Michael A. Riley and Fahim Sadek

Building and Fire Research Laboratory

Gaithersburg, MD 20899-8611

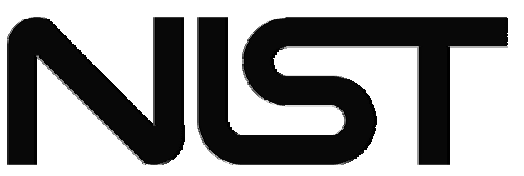

United States Department of Commerce Technology Administration

National Institute of Standards and Technology 



\section{EXPERIMENTAL TESTING OF ROOF TO WALL CONNECTIONS IN WoOd Frame Houses}

Michael A. Riley and Fahim Sadek

April 2003

Building and Fire Research Laboratory National Institute of Standards and Technology Gaithersburg, MD 20899-8611

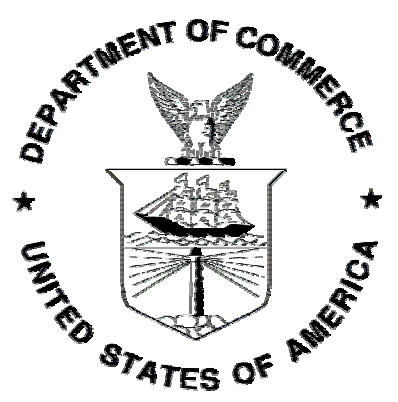

United States Department of Commerce Donald L. Evans, Secretary

Technology Administration

Phillip J. Bond, Under Secretary for Technology

National Institute of Standards and Technology Arden L. Bement, Jr., Director 



\section{ABSTRACT}

The majority of residential construction in the United States is wood-frame construction. These buildings perform well under gravity loads, but considerable damage has been observed in such structures after significant earthquakes and major hurricanes. This is due to weaknesses inherent in current wood-frame construction and underscores the need for improving the structural performance of typical homes. To enhance the resistance of houses to natural disasters and to reduce the risk to life and property, the behavior of wood-frame buildings subjected to dynamic and lateral loads needs to be better understood. These buildings are typically constructed from diaphragms that are joined by inter-component connections, which can greatly influence the overall behavior of the structure. An understanding of the behavior of each of the structural components and connections is essential to accurately predict the performance of a housing unit under different types of loading.

While the response of many of the components of wood-frame houses are well documented, there is a lack of performance data for inter-component connections between intersecting walls, roofs and walls, and walls and foundations. Since post-event investigations of several recent disasters indicate that failure of inter-component connections played a large role in the failure of many structures, the response of such connections needs to be better understood. To achieve this, experiments are needed to investigate how these connections respond as they are loaded to failure. The resulting experimental data can be used to develop improved analytical models of wood-frame structures, which can be used to design houses that are better able to resist extreme loads.

This report describes the results of a series of tests on two types of roof to wall connections. These test results show how the connections are likely to perform when subjected to strong winds or seismic loads. The results of the tests provide data necessary for the development of improved analytical models of the connection response, which could in turn lead to improved design tools for wood-frame construction, and to stronger and more structurally efficient residential buildings. 


\section{ACKNOWLEDGEMENTS}

This effort was supported by the Materials and Construction Research Division, Building and Fire Research Laboratory, National Institute of Standards and Technology, U.S. Department of Commerce. The authors wish to thank Frank Davis, Andre Witcher, Mark Kile, and Max Peltz who provided valuable assistance in the laboratory testing. Jason McCormick's assistance in analyzing the experimental data is greatly appreciated. 


\section{CONTENTS}

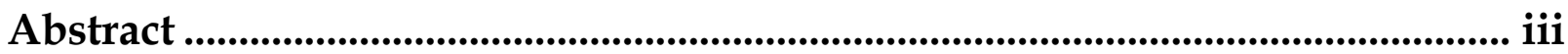

Acknowledgements ............................................................................................................... v

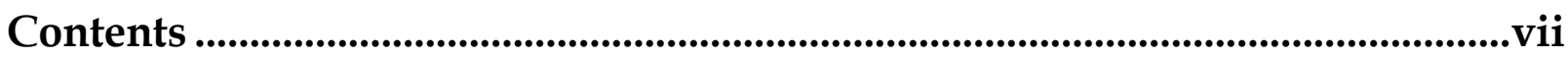

List of Figures ............................................................................................................... ix

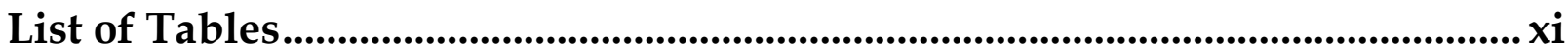

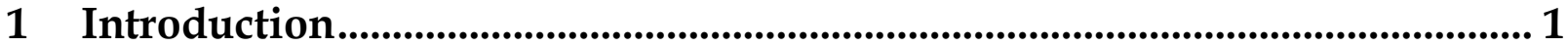

1.1 Background.......................................................................................................................... 2

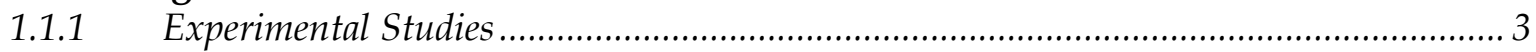

1.1.2 Analytical Studies........................................................................................ 3

1.2 Research Objectives............................................................................................................ 3

1.3 Scope of Current Effort .................................................................................................................. 4

2 Overview of Test Program.................................................................................... 5

$2.1 \quad$ Test Specimens ........................................................................................................... 5

2.1.1 Roof to Wall Connections Tested ...................................................................... 7

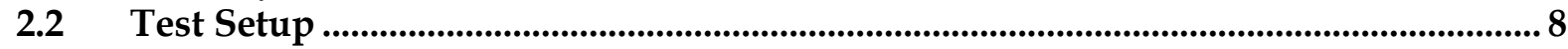

2.3 Instrumentation and Data Acquisition ...............................................................................10

$2.4 \quad$ Test Protocols ....................................................................................................................... 14

3 Results of Uplift Load Tests................................................................................... 17

3.1 Response with Toe-nailed Connections ............................................................................17

3.2 Response with Hurricane Clips............................................................................................. 18

3.3 Comparison of Responses ....................................................................................... 18

4 Results of Monotonic Lateral Load Tests .......................................................... 27

4.1 Response with Toe-nailed Connections .............................................................................. 27

4.2 Response with Hurricane Clips............................................................................................. 27

4.3 Comparison of Responses ............................................................................................... 33

$5 \quad$ Results of Cyclic Lateral Load Tests....................................................................... 39

$5.1 \quad$ Response with Toe-nailed Connections ..................................................................................39

5.2 Response with Hurricane Clips........................................................................................ 39

5.3 Comparison of Responses ................................................................................................... 47

6 Results of Combined Uplift and Lateral Load Tests....................................... 49

6.1 Response with Toe-nailed Connections ............................................................................49

6.2 Response with Hurricane Clips...................................................................................49

6.3 Comparison of Responses ................................................................................................... 55

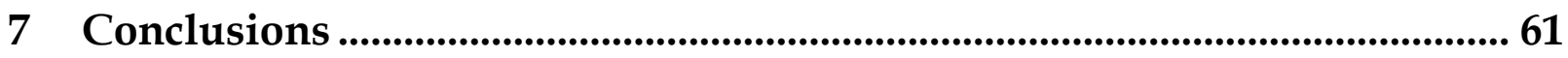

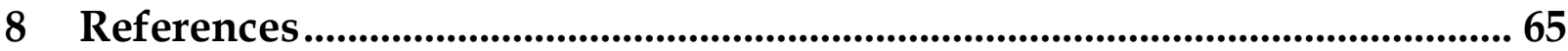




\section{LIST OF FIGURES}

Figure 2.1. Sketch of a typical test specimen. ........................................................................ 5

Figure 2.2. Typical test specimen before instrumentation.......................................................... 6

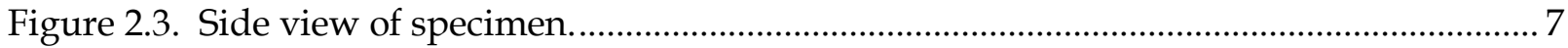

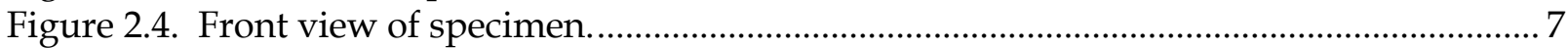

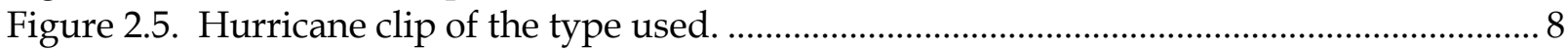

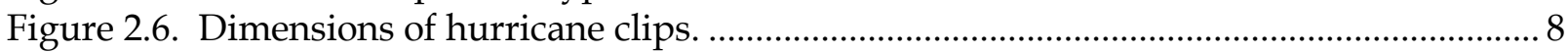

Figure 2.7. Sketch of specimen for lateral load test ............................................................ 10

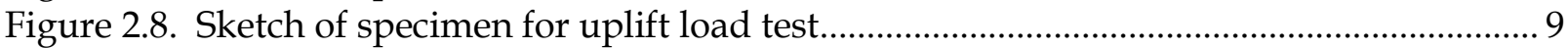

Figure 2.9. Sketch of specimen for combined vertical and lateral load test.............................. 11

Figure 2.10. Locations of displacement sensors and load cells on the specimens. .................... 13

Figure 2.11. Generic lateral displacement curve for cyclic lateral load tests. ............................ 16

Figure 3.1. Failure of toe-nailed truss to wall connection......................................................... 17

Figure 3.2. Vertical displacement applied to specimen with toe-nailed connections................. 19

Figure 3.3. Vertical load applied to specimen with toe-nailed connections. .............................. 19

Figure 3.4. Connection deformation response of specimen with toe-nailed connections. ......... 20

Figure 3.5. Load-deformation response of specimen with toe-nailed connections. .................. 20

Figure 3.6. Failure of hurricane clip connection................................................................... 21

Figure 3.7. Vertical displacement applied to specimen with hurricane clips............................ 22

Figure 3.8. Vertical load applied to specimen with hurricane clips......................................... 22

Figure 3.9. Connection deformation response of first test with hurricane clips........................ 23

Figure 3.10. Load-deformation response of first test with hurricane clips. ............................... 23

Figure 3.11. Connection deformation response of second test with hurricane clips.................. 24

Figure 3.12. Load-deformation response of second test with hurricane clips........................... 24

Figure 3.13. Comparison of responses with toe-nailed connections and hurricane clips.......... 25

Figure 4.1. Failure of toe-nailed connection with lateral load. ................................................ 28

Figure 4.2. Lateral displacement applied to specimen with toe-nailed connections................... 29

Figure 4.3. Lateral load applied to specimen with toe-nailed connections................................. 29

Figure 4.4. Lateral displacement responses for trusses with toe-nailed connections................. 30

Figure 4.5. Uplift displacement responses for trusses with toe-nailed connections....................30

Figure 4.6. Lateral force-displacement responses for trusses with toe-nailed connections........ 31

Figure 4.7. Uplift force-displacement responses for trusses with toe-nailed connections.......... 31

Figure 4.8. Comparison of lateral and vertical responses for inner truss with toe-nailed

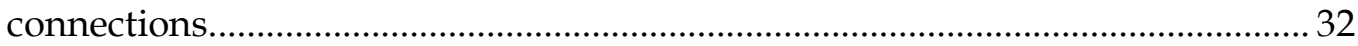

Figure 4.9. Comparison of lateral and vertical responses for outer truss with toe-nailed

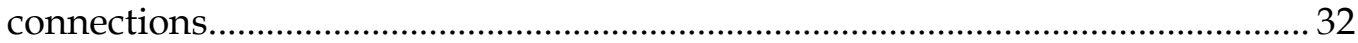

Figure 4.10. Failure of hurricane clip connection with lateral load.............................................33

Figure 4.11. Lateral displacement applied to specimen with hurricane clips .......................... 34

Figure 4.12. Lateral load applied to specimen with hurricane clips ......................................... 34

Figure 4.13. Lateral displacement responses for trusses with hurricane clips. ......................... 35

Figure 4.14. Uplift displacement responses for trusses with hurricane clips............................ 35

Figure 4.15. Lateral force-displacement responses for trusses with hurricane clips.................. 36

Figure 4.16. Uplift force-displacement responses for trusses with hurricane clips................... 36

Figure 4.17. Lateral and vertical responses for inner truss with hurricane clips. ...................... 37

Figure 4.18. Lateral and vertical responses for outer truss with hurricane clips....................... 37

Figure 4.19. Comparison of responses of inner trusses. ............................................................. 38 


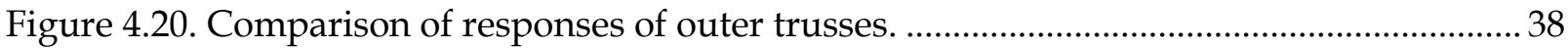

Figure 5.1. Failure of toe-nailed connection with cyclic load.................................................. 40

Figure 5.2. Lateral displacement applied to specimen with toe-nailed connections.................. 41

Figure 5.3. Lateral load applied to specimen with toe-nailed connections..................................41

Figure 5.4. Lateral displacement responses for trusses with toe-nailed connections................. 42

Figure 5.5. Uplift displacement responses for trusses with toe-nailed connections.................... 42

Figure 5.6. Lateral force-displacement responses for trusses with toe-nailed connections........ 43

Figure 5.7. Uplift force-displacement responses for trusses with toe-nailed connections.......... 43

Figure 5.8. Lateral displacement applied to specimen with hurricane clips. ............................ 44

Figure 5.9. Lateral load applied to specimen with hurricane clips. ............................................. 44

Figure 5.10. Lateral displacement responses for trusses with hurricane clips. ......................... 45

Figure 5.11. Uplift displacement responses for trusses with hurricane clips........................... 45

Figure 5.12. Lateral force-displacement responses for trusses with hurricane clips..................46

Figure 5.13. Uplift force-displacement responses for trusses with hurricane clips................... 46

Figure 6.1. Failure of toe-nailed connection with combined load............................................ 50

Figure 6.2. Displacements applied to specimen with toe-nailed connections. ........................... 51

Figure 6.3. Loads applied to specimen with toe-nailed connections. .........................................51

Figure 6.4. Lateral displacement responses for trusses with toe-nailed connections................. 52

Figure 6.5. Uplift displacement responses for trusses with toe-nailed connections.................. 52

Figure 6.6. Lateral force-displacement responses for trusses with toe-nailed connections........ 53

Figure 6.7. Uplift force-displacement responses for trusses with toe-nailed connections......... 53

Figure 6.8. Lateral and vertical responses for inner truss with toe-nailed connections.............. 54

Figure 6.9. Lateral and vertical responses for outer truss with toe-nailed connections..............54

Figure 6.10. Failure of hurricane clip connection with combined load......................................55

Figure 6.11. Displacements applied to specimen with hurricane clips. ....................................56

Figure 6.12. Loads applied to specimen with hurricane clips..................................................56

Figure 6.13. Lateral displacement responses for trusses with hurricane clips. ........................ 57

Figure 6.14. Uplift displacement responses for trusses with hurricane clips........................... 57

Figure 6.15. Lateral force-displacement responses for trusses with hurricane clips..................58

Figure 6.16. Uplift force-displacement responses for trusses with hurricane clips. .................. 58

Figure 6.17. Lateral and vertical responses for inner truss with hurricane clips......................59

Figure 6.18. Lateral and vertical responses for outer truss with hurricane clips.......................59

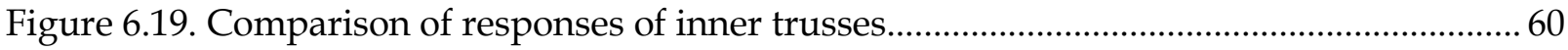

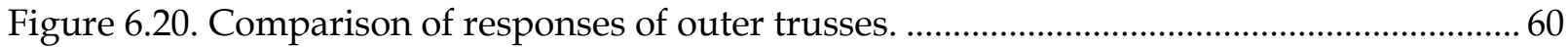




\section{LIST OF TABLES}

Table 2.1. Displacement sensors used to measure the specimen motion................................... 12

Table 2.2. Load cells used to measure the uplift loads applied to the roof sheathing............... 14

Table 2.3. Additional sensors measured during the tests.......................................................... 14 


\section{INTRODUCTION}

The majority of residential construction in the United States is wood-frame buildings. These buildings perform well under gravity loads, but considerable damage has been observed after significant earthquakes and major hurricanes. Recent natural disasters have caused major damage to them, which has resulted in large economic losses. As examples, the tornado that struck Oklahoma City on 3 May 1999 demolished more than 2200 homes and damaged over 7000 more, while losses to residential construction represented about $72 \%$ of the $\$ 15.3$ billion in total insured losses from the 1994 Northridge earthquake.

Such disasters highlight the weaknesses inherent in current wood-frame construction and underscore the need for improving the structural performance of typical homes. To enhance the resistance of houses to natural disasters and to reduce the risk to life and property, the behavior of wood-frame buildings subjected to dynamic and lateral loads needs to be better understood.

Wood-frame buildings are constructed from several diaphragms such as walls, floors, and roofs; joined by inter-component connections such as nails, anchor bolts, metal plates, and other proprietary connectors. The structural performance of these buildings is influenced by the behavior of their individual components and connections. Therefore, an understanding of the behavior of the different structural components and connections is essential to accurately predict the performance of a housing unit under different types of loading.

Analysis of the structural response of woodframe building components subjected to lateral loads is a difficult task due to several sources of nonlinearity, the complex nature of the connections, and a wide variability in material properties and construction techniques. Since shear walls are the most important elements for resisting lateral loads, they have been experimentally and analytically studied since the early 1970s. Simplified methods of wall analysis and finite element models have been developed to predict the behavior of the walls under static and dynamic lateral loading.

The development of tools for analyzing complete wood-frame houses started in the mid-eighties, but few investigators have attempted to analyze the different structural components and the inter-component connections in an assembled model. This is due, in part, to the lack of performance data for inter-component connections between intersecting walls, roof and walls, and walls and foundations. Since post-event investigations of several recent disasters indicated that in many cases failure of the intercomponent connections played a large role in the failure of the structure, such connections need to be incorporated into the performance models. To achieve this, experiments are needed to investigate how these connections behave, as they are loaded to failure.

The NIST research plan is to develop experimentally validated, three-dimensional, analytical models to predict the performance of housing units during natural disasters. Such models can be used to establish performance characteristics of conventional and innovative housing systems. The current effort consisted of testing the intercomponent connections between roof trusses and walls, in a full-scale roof and wall assembly. The intent is to determine the performance of the connections when they are part of a complete system. The results of these tests can be combined with the 
results of sub-component tests to develop more accurate analytical models.

\subsection{Background}

Although recent earthquakes and hurricanes in the United States have resulted in few casualties, they have caused substantial damage, significant economic loss, and disruption of social and commercial activities. The performance of residential housing during such events has shown that wood-frame construction generally meets the life safety objective. Many houses, however, have experienced structural and nonstructural damage that prevented immediate occupancy, and resulted in expensive repairs.

Post-earthquake investigations have indicated that much of the seismic damage can be attributed to construction flaws or inadequate quality assurance, including missing fasteners, overdriving of nails, improper placement of anchor bolts, and misplaced nails. The preference for more open interior spaces, hillside homes, soft stories due to garage openings, and more irregularly shaped structures may also be contributing factors. Poor soil conditions (liquefaction, excessive settlement) and location (building on a hill-side) have been also cited as causes of damage. Houses built in accordance with seismic codes were generally found to perform well.

In general, poor seismic performance of wood-frame houses has been observed when the house did not respond as a unit, due to discontinuous load paths. Common practices that lead to a lack of integrity include:

- Insufficient or poorly detailed intercomponent connections (anchorage to foundation, wall-to-wall connections, wall-to-roof or floor connections).
- Inadequate bracing (cripple walls, total absence of shear walls, large wall openings, inadequate let-in bracing).

- Component separation (masonry fireplaces and chimneys, masonry veneers, porch roofs and other overhangs, different house sections).

- Non-uniform or irregular distribution of stiffness, due to irregular plans and elevations (split level house, setbacks), which leads to torsional movements.

- Poor detailing or quality of construction.

- Lack of continuous load path from roof to foundation.

In past hurricanes, the main cause of severe damage to wood-frame houses has been roof damage, due to inadequate anchorage of the roof framing to the wall, damage to the shingles and other roof coverings, and loss of roof sheathing. Foundation failure and inadequate anchorage of the structure to the foundation have also caused failures. Similar to earthquake performance, issues such as continuous load path and structural integrity are crucial for hurricane resistance, particularly because water damage from roof failures is a major contributor toward the economic losses. In addition to water damage, the internal pressure in a house is increased due to breaches in the building envelope from missiles, thereby contributing to roof failures. Properly installed plywood boards over windows or storm shutters, doors, and garage doors can alleviate this problem, but improperly installed boards and shutters can contribute to the damage from wind-borne debris.

NIST has published a comprehensive stateof-the-art report on the structural performance of single-family, wood-frame housing (Yancey et al., 1998), which includes a detailed literature review of experimental and 
analytical studies conducted on complete houses, in addition to wood subassemblies, such as shear wall diaphragms, and various connections. While some of the salient findings are summarized below, greater detail may be found in the NIST report.

\subsubsection{Experimental Studies}

Shear wall behavior under lateral loads has been the focus of a significant number of studies. Tests have been conducted under monotonic, cyclic, and dynamic loads to investigate the response characteristics of the walls. Several additional studies have tested the sheathing-to-framing connections to determine their response characteristics, determine their resistance, and provide data for analytical modeling, since they have been shown to be a critical element in the wall performance.

A relatively small number of full-scale houses have been tested. Tests have been performed on single- and two-story houses under field and laboratory conditions.

Very few experimental studies have been conducted on inter-component connections. See, for example, Rosowsky et al. (1998) and Reed et al. (1996, 1997). Testing of these connections is important, since they are key elements for the wood-frame buildings, and they must perform well for the structure to respond in an integrated fashion. An invitational workshop on seismic testing, analysis, and design of wood-frame construction (Seible et al., 1999) recognized that the behavior of inter-component connections is not well understood and recommended further testing of such connections.

\subsubsection{Analytical Studies}

Analyzing the structural components of a wood-frame building subjected to lateral loads is essential to understand their performance during natural disasters. Since shear walls are the most important elements in resisting lateral loads, several investigators have extensively studied them since the early 1970s. Simplified analysis methods and finite element models were developed to predict the nonlinear behavior of the walls under static lateral loading. A few researchers also attempted to predict the dynamic behavior of the walls subjected to earthquake ground motion.

The development of analytical tools for analyzing complete wood-frame houses started in the mid 1980s. This work included analyzing the different structural components, as well as the inter-component connections in an assembled model. Comparisons with experimental studies were performed to assess the validity of the proposed models and analyses. To date, only limited research has been directed toward the analysis of a complete building or to the response of the inter-component connections (Polensek and Schimel, 1986, 1988; Groom and Leichti, 1991, 1994).

\subsection{Research Objectives}

The long term objective of the NIST research is to develop the metrics and predictive tools necessary for evaluating the structural performance of housing systems during natural disasters, including earthquakes and strong winds. The program is expected to lead to buildings that can better resist extreme loads and a reduction in construction costs for the housing industry.

To reach this objective, experimentally validated, three-dimensional finite element models of typical systems and structural performance criteria for complete houses need to be developed. The analytical models will need to include the interaction of the various diaphragms such as shear walls, floors, and roof, as well as inter-component connections. Data from prior testing con- 
ducted on wood diaphragms can be used in the models, but as mentioned above, there are minimal data on the performance of inter-component connections. Therefore, experimental testing of various connections under monotonic and cyclic loads is necessary to characterize their performance and provide the necessary data for modeling.

\subsection{Scope of Current Effort}

The current research is intended to fill one of the gaps in the understanding of the structural behavior of wood frame buildings by experimentally testing two types of roof to wall connections to determine their behavior and performance. The test results will provide data that are now lacking, but are necessary to develop analytical models of the connections. Such models will lead to improved design tools for wood-frame construction, and to stronger and more structurally efficient residential buildings.

The two types of connections tested were toe-nailed connections and hurricane clips. The simple toe-nailed connections are the most common type of roof to wall connection used in regions that are not routinely subjected to hurricanes. The hurricane clips are one of the lightest and simplest versions of a wide range of clips and straps that can be used to increase the strength of roof to wall connections.

In the current work, the specimens were subjected to four types of loading. Monotonic uplift and monotonic lateral loads were applied to determine the general failure response curves. Combined uplift and lateral load, and cyclic lateral loading were applied to obtain specific data on how these connections will respond when loaded to failure by strong winds and seismic loads, respectively.

The objectives of these tests are to understand the in-situ behavior of the wall-to-roof connections in the structure, explore the failure mechanisms, and determine the displacements and forces that occur in the individual connections. The results of the experimental tests will allow more accurate sub-component connection testing and lead to improved analytical models. 


\section{OVerview of Test Program}

This phase of the NIST effort consisted of experimental tests of full-scale wall-to-roof connections. Tests will be performed on specimens with toe-nailed connections and specimens with hurricane clips. The objectives of this testing were to understand the in-situ behavior of the wall-to-roof connections in the structure, explore the failure mechanisms, and determine the displacements and forces that occur in the individual connections, so as to allow more accurate component connection testing and modeling in the future.

\subsection{Test Specimens}

The specimens represent a center cut through a simple wood-frame house. Each

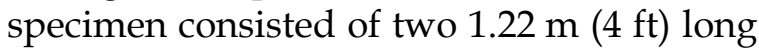

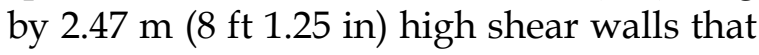
supported four roof trusses with spans of $4.88 \mathrm{~m}(16 \mathrm{ft})$. A sketch of a test specimen is shown in Figure 2.1, and a photo of one specimen is shown in Figure 2.2

As can be seen in Figures 2.3 and 2.4, the framing for each shear wall consisted of double top plates, a single bottom plate, and

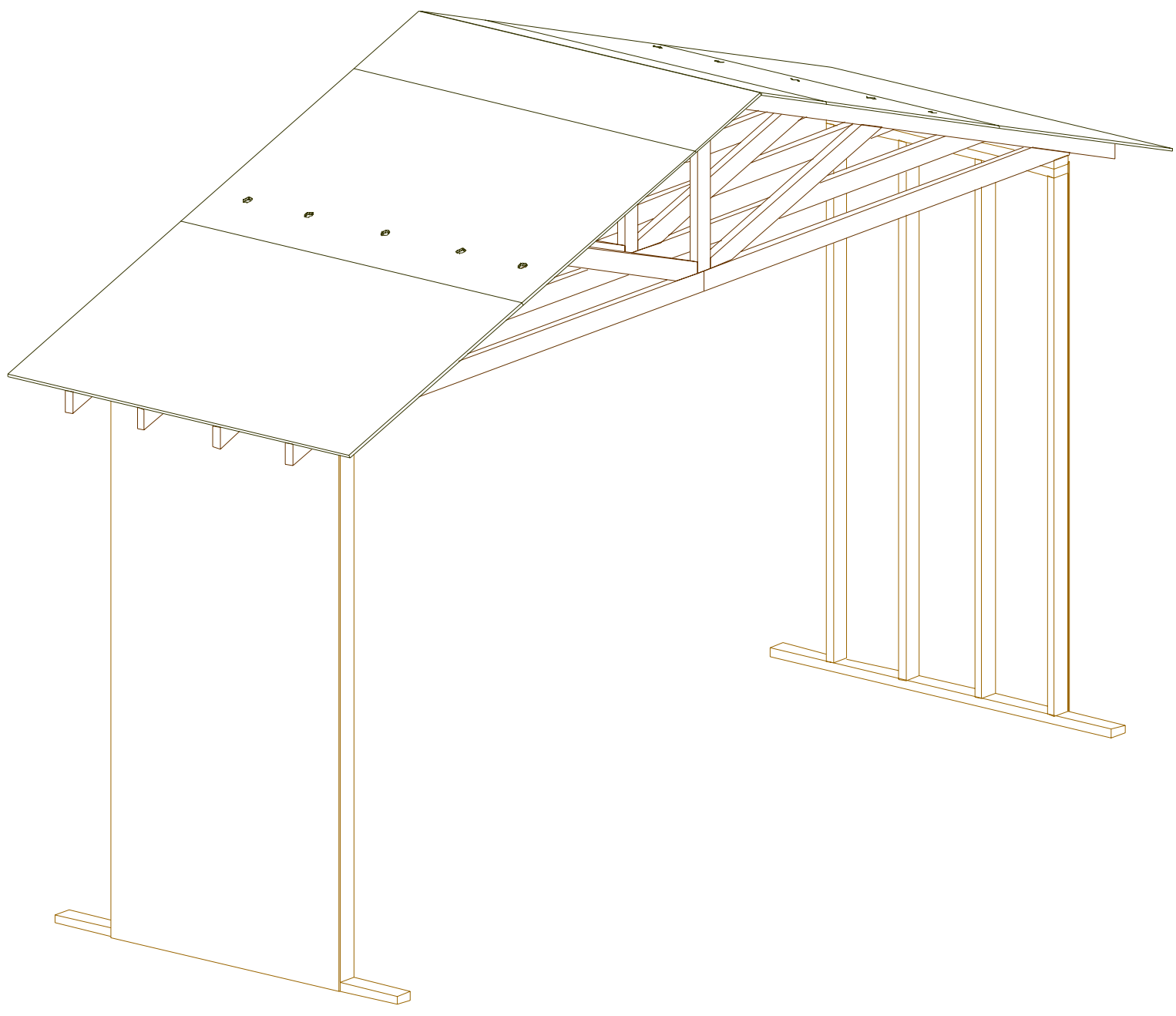

Figure 2.1. Sketch of a typical test specimen. 
four vertical studs spaced $0.40 \mathrm{~m}$ (16 in) on center. All framing members were constructed from $38 \mathrm{~mm} \times 89 \mathrm{~mm}$ (2 by 4 nominal) spruce-pine-fir, grade No. 2 lumber. The outer wall sheathing was $11 \mathrm{~mm}$ (7/16 in) thick oriented strand board (OSB) panels. These were connected to the framing with $38 \mathrm{~mm}$ (1.5 in) cement coated staples spaced $76 \mathrm{~mm}$ ( 3 in) on perimeter and $152 \mathrm{~mm}$ (6 in) on intermediate studs.

The pre-fabricated roof trusses, which are shown in Figure 2.4, had a top chord slope of 4:12, and were spaced $0.41 \mathrm{~m}$ (16 in) apart. All truss elements were $38 \mathrm{~mm} \mathrm{x}$ $89 \mathrm{~mm}$ ( 2 by 4 nominal) members. The roof sheathing consisted of $11 \mathrm{~mm}$ (7/16 in) thick OSB panels attached to the trusses us- ing 8d-common nails spaced $102 \mathrm{~mm}$ (4 in) apart.

Toe-nailed connections and hurricane clips were used to tie the roof trusses to the shear walls in these tests. Details about the connections are given in Section 2.1.1.

The shear walls and roof trusses were purchased pre-fabricated from a local supplier. They were thus fairly typical examples, in both the material and quality, of woodframe construction in central Maryland. The quantity, spacing, length of the staples used to connect the OSB to the wall framing were all standard, with respect to similar sized wood frame construction. The construction quality of these walls was gener-

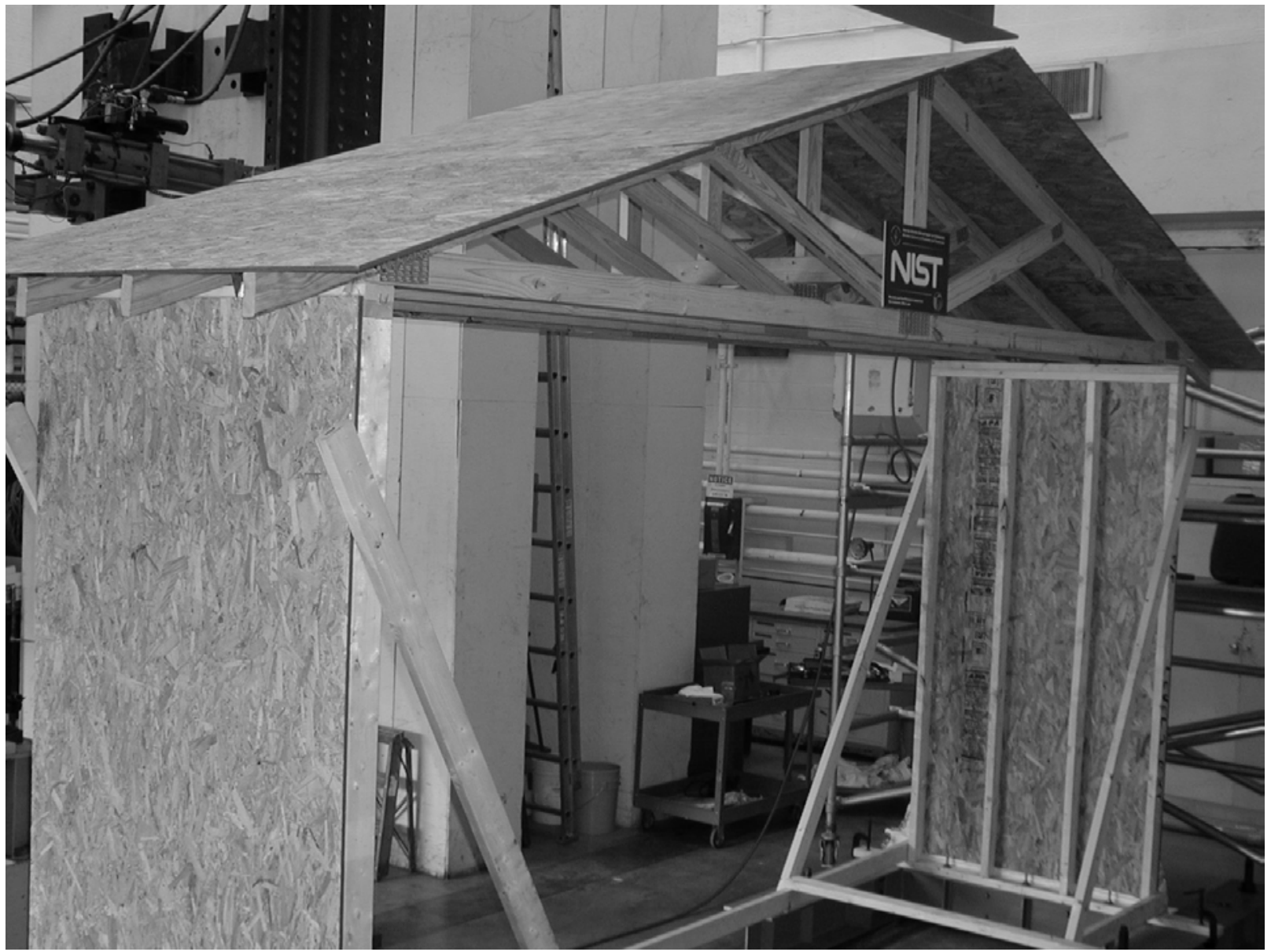

Figure 2.2. Typical test specimen before instrumentation. 
ally very good. The manufacturing techniques guaranteed that the quantity and spacing of the staples was consistent. The only aspect that was subject to human error and variability was the positioning of the staples relative to the studs. While the staples were properly driven in most cases, a few cases were observed where some of the staples had missed a stud.

\subsubsection{Roof to Wall Connections Tested}

Two types of roof to wall connections were tested - toe-nailed connections and hurricane clips.

For the cases of the toe-nailed connections, each of the roof trusses were connected to each wall using three $16 \mathrm{~d}$-common nails driven at approximately a $45^{\circ}$ angle through the truss and into the top plate of the wall. Two of the nails were driven into one side of the truss, while the third nail was driven into the other side such that the nails crossed at a $90^{\circ}$ angle.

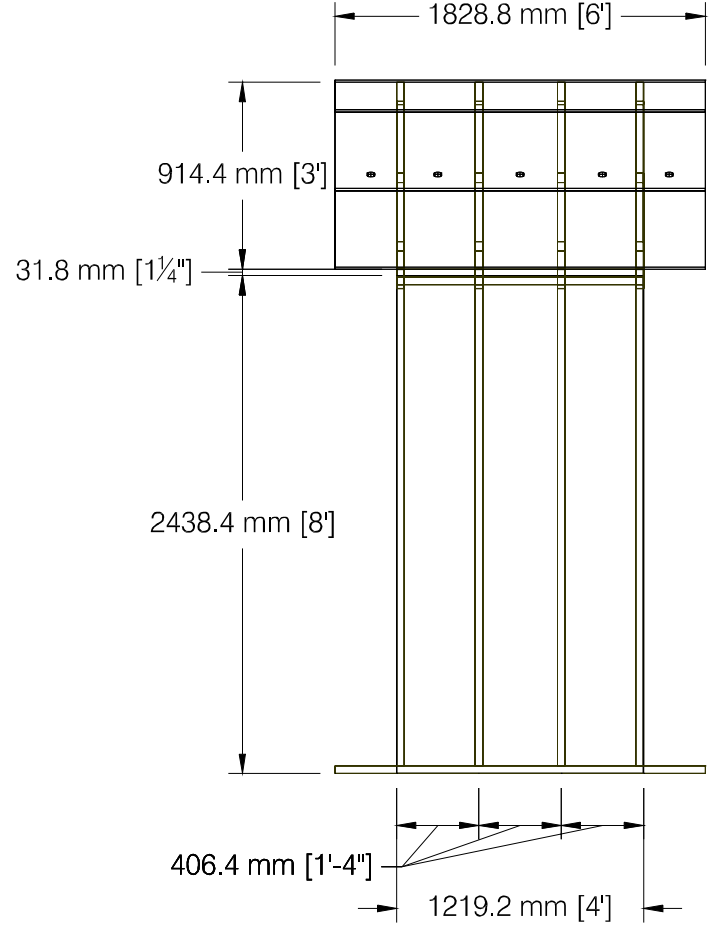

Figure 2.3. Side view of specimen.

For the hurricane clip connections, two nails

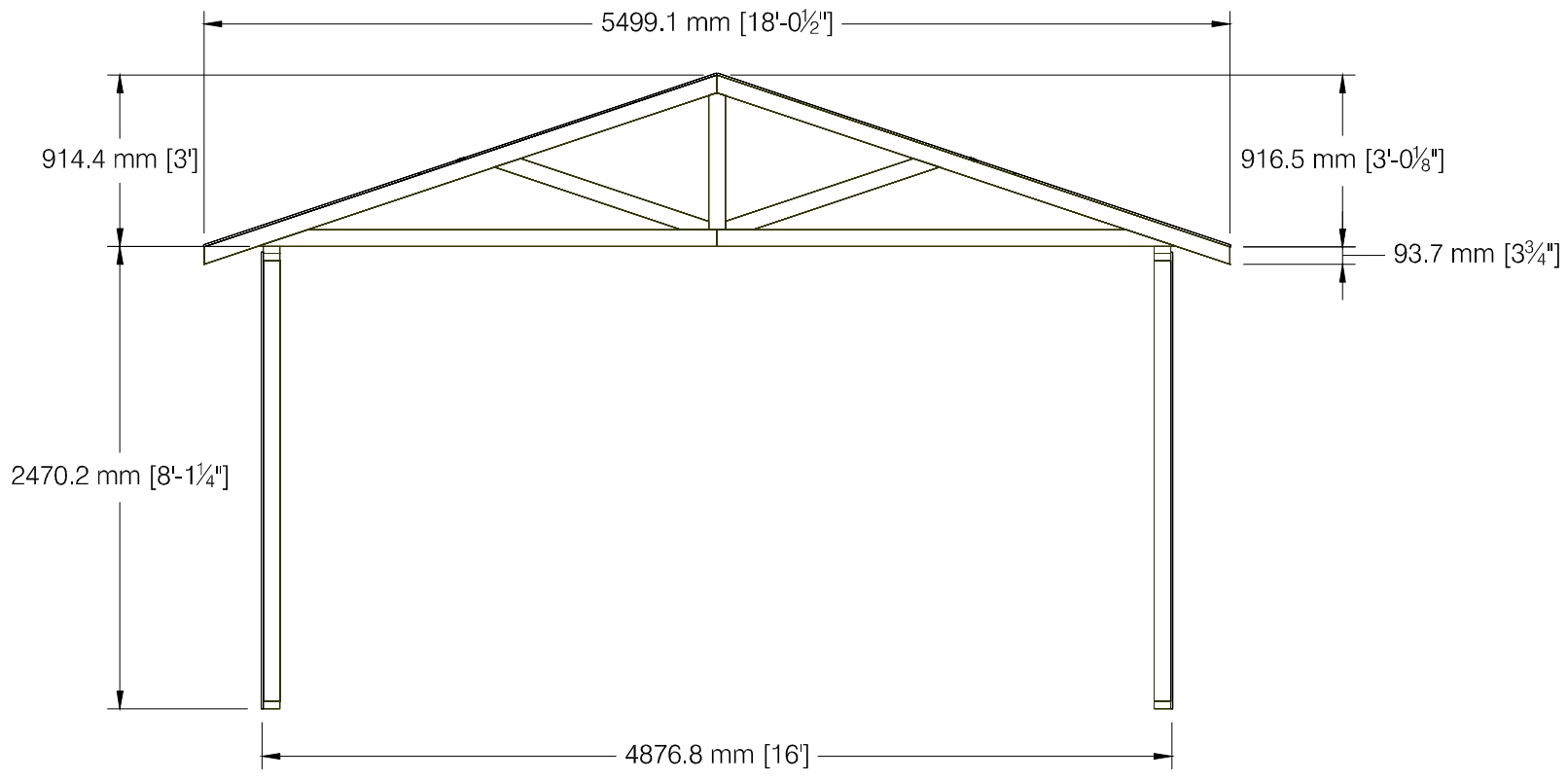

Figure 2.4. Front view of specimen. 
were toe-nailed through the truss and into the top plate of the wall for erection purposes. Then a simple, sheet metal hurricane clip of the type shown in Figure 2.5 was added to provide the primary load path between the truss and the walls. The standard dimensions of the clips used are shown in Figure 2.6. These clips were attached to the trusses and the top plate of the wall using four $8 \mathrm{~d}$ common nails.

\subsection{Test Setup}

The shear walls were supported on steel foundation frames rigidly attached to the

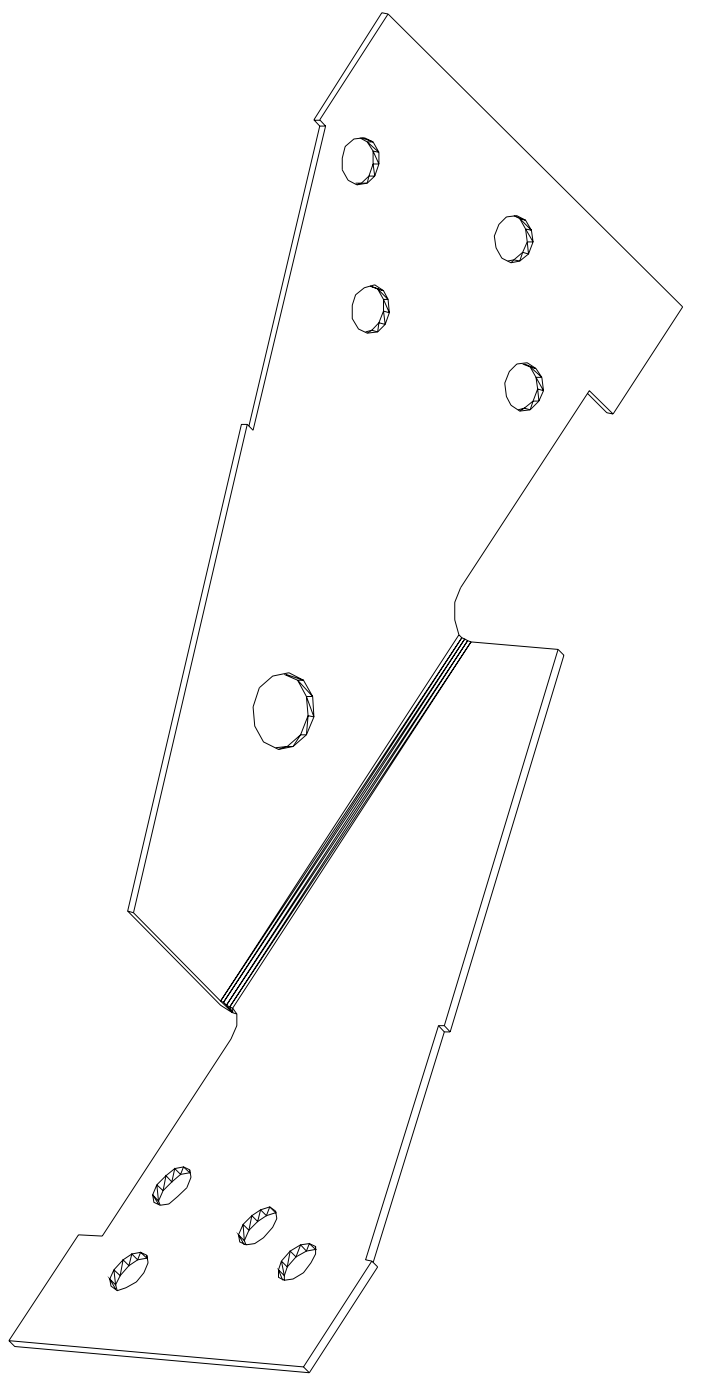

Figure 2.5. Hurricane clip of the type used. laboratory strong floor. The bottom plates of each of the walls were anchored to the foundation frames with five $12.7 \mathrm{~mm}$ (1/2 in) diameter bolts, spaced $400 \mathrm{~mm}$ (16 in) on center.

The specimens were subjected to monotonic uplift, monotonic lateral, cyclic lateral, and combined uplift and lateral loads.

The uplift loads were applied using a vertical actuator with a steel load tree that distributed the load to ten points on the roof sheathing, as shown in Figure 2.7. The uplift point loads were further distributed using $38 \mathrm{~mm} \times 184 \mathrm{~mm}$ ( 2 by 8 nominal) lumber members that were connected to the roof sheathing, but not the trusses. These boards spread the load over a larger area, and prevented local failure of the sheathing.

The lateral loads were applied using a horizontal actuator connected to a transfer beam, which was in turn connected to two steel pipes that were bolted to a pair of

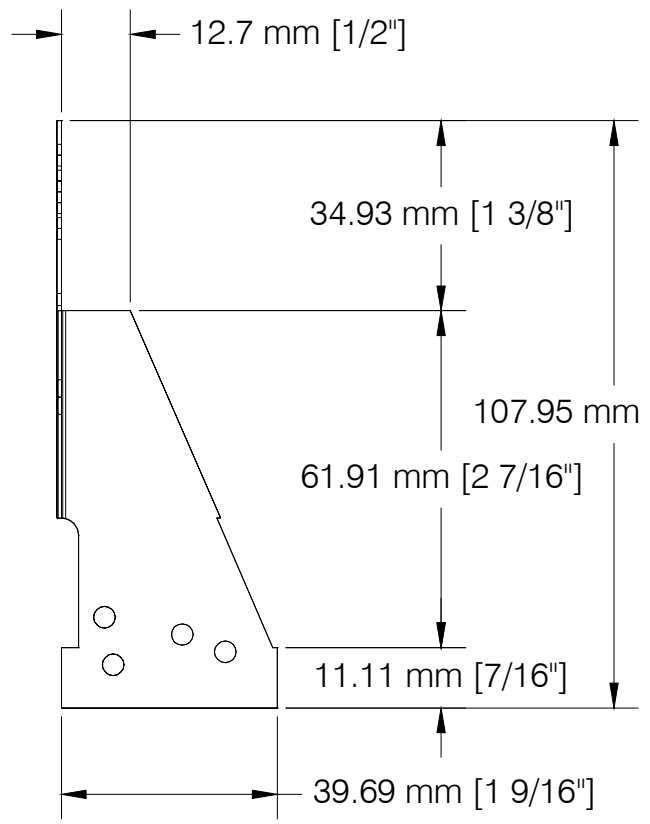

Figure 2.6. Dimensions of hurricane clips. 
$38 \mathrm{~mm} \times 184 \mathrm{~mm}$ ( 2 by 8 nominal) lumber members that were screwed to the roof sheathing on either side of the ridge. This configuration, shown in Figure 2.8, allowed the load to be applied through the roof's center of mass, without applying any un- usually large lateral loads to any truss members.

For the tests with combined lateral and uplift loads, the two loading systems were

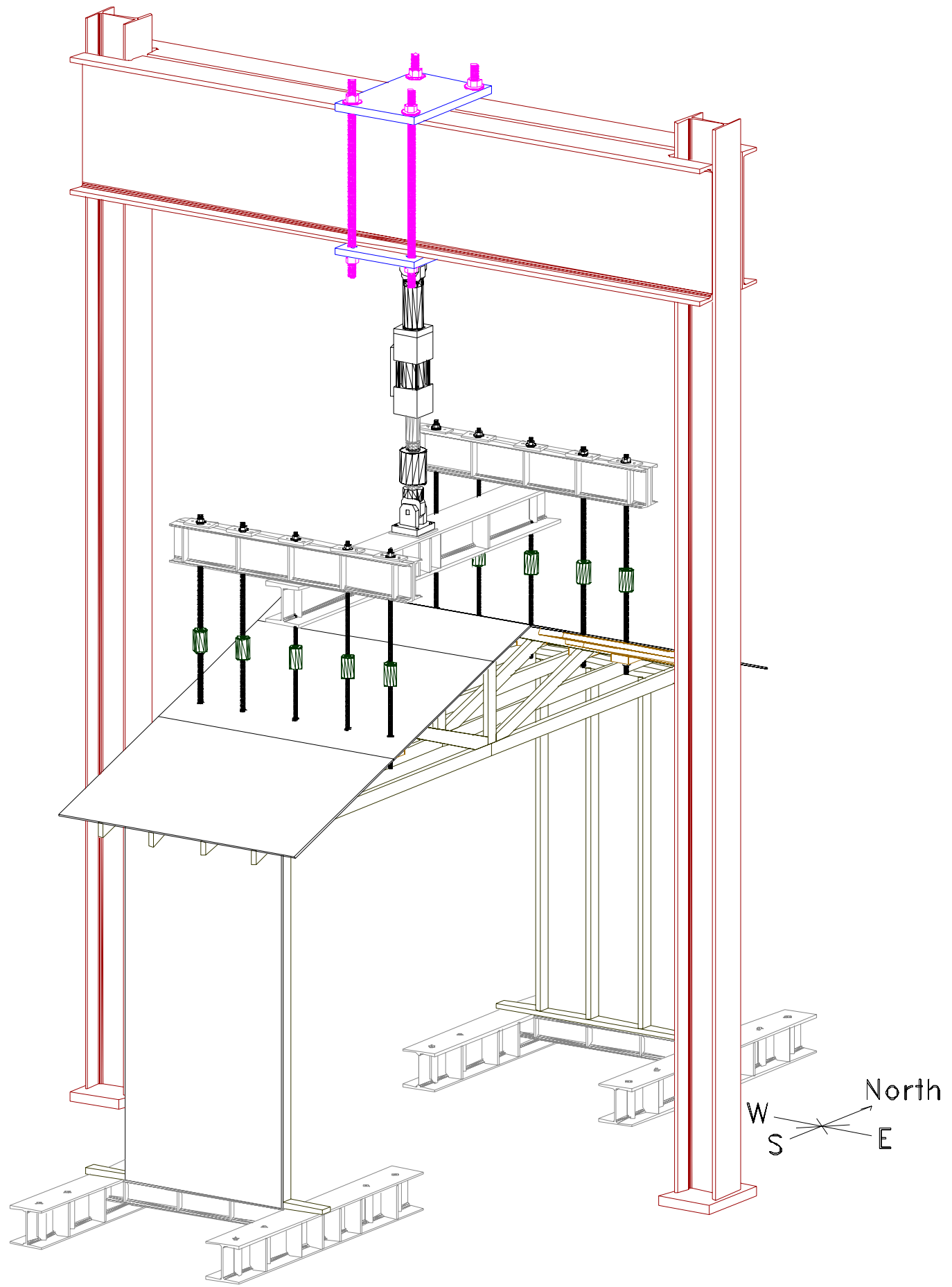

Figure 2.7. Sketch of specimen for uplift load test 
combined, as shown in Figure 2.9.

Both the vertical and horizontal actuators push against a steel reaction frame, which can be seen in Figures 2.7 through 2.9. For the uplift loads an actuator with a $152 \mathrm{~mm}$
(6 in) stroke and a $222 \mathrm{kN}$ (50 kip) capacity was used, while for the lateral loads a smaller actuator with a $152 \mathrm{~mm}$ (6 in) stroke and a $45 \mathrm{kN}$ (10 kip) capacity was used.

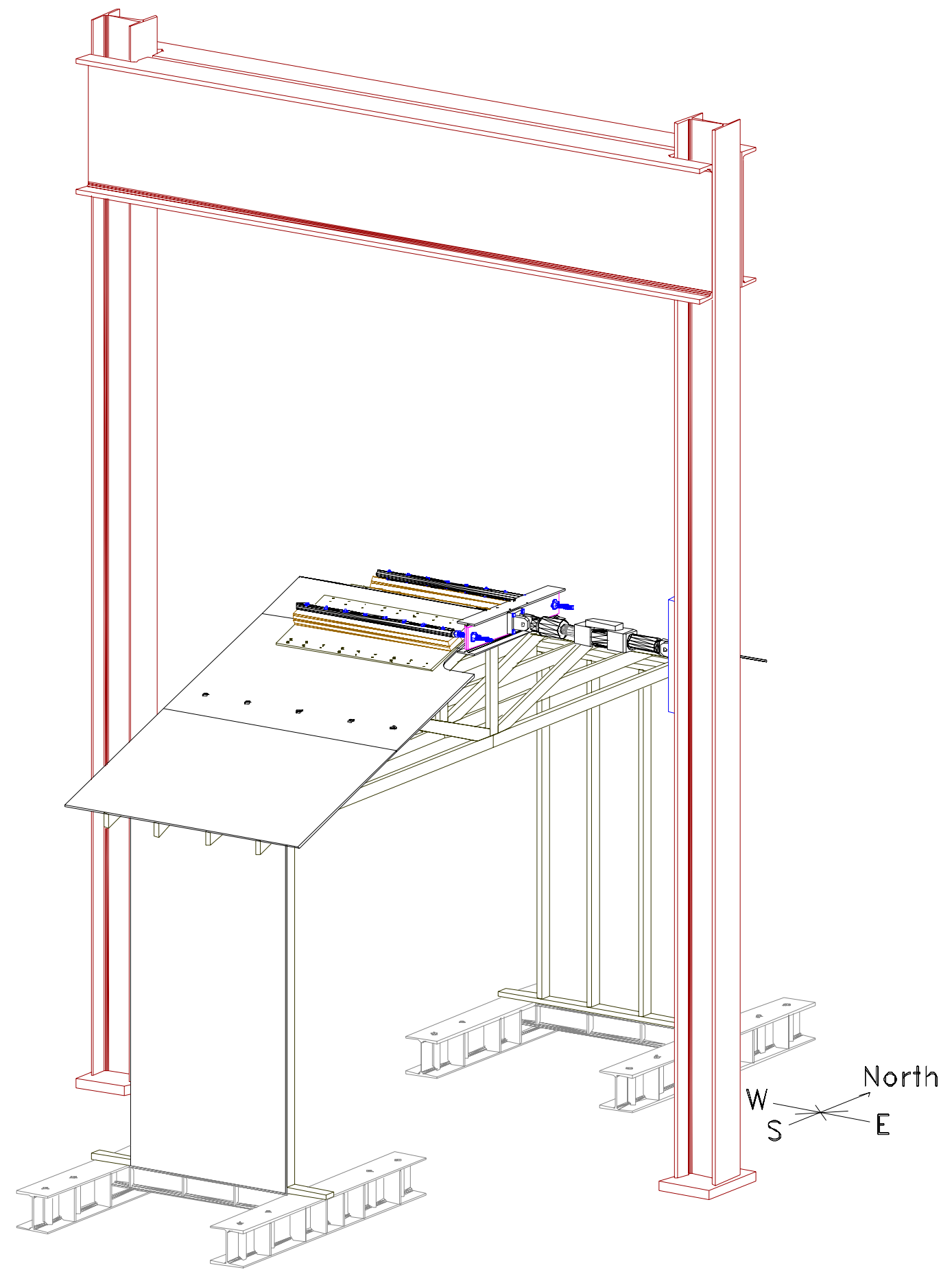

Figure 2.8. Sketch of specimen for lateral load test 


\subsection{Specimen Instrumentation}

The specimens were highly instrumented with displacement transducers and load cells to gain maximum information about the response characteristics of the speci- mens. The sensors consisted of twelve load cells and forty-eight displacement sensors.

The displacement sensors consisted of fortysix linear variable differential transformers (LVDT) mounted on the specimen or one of

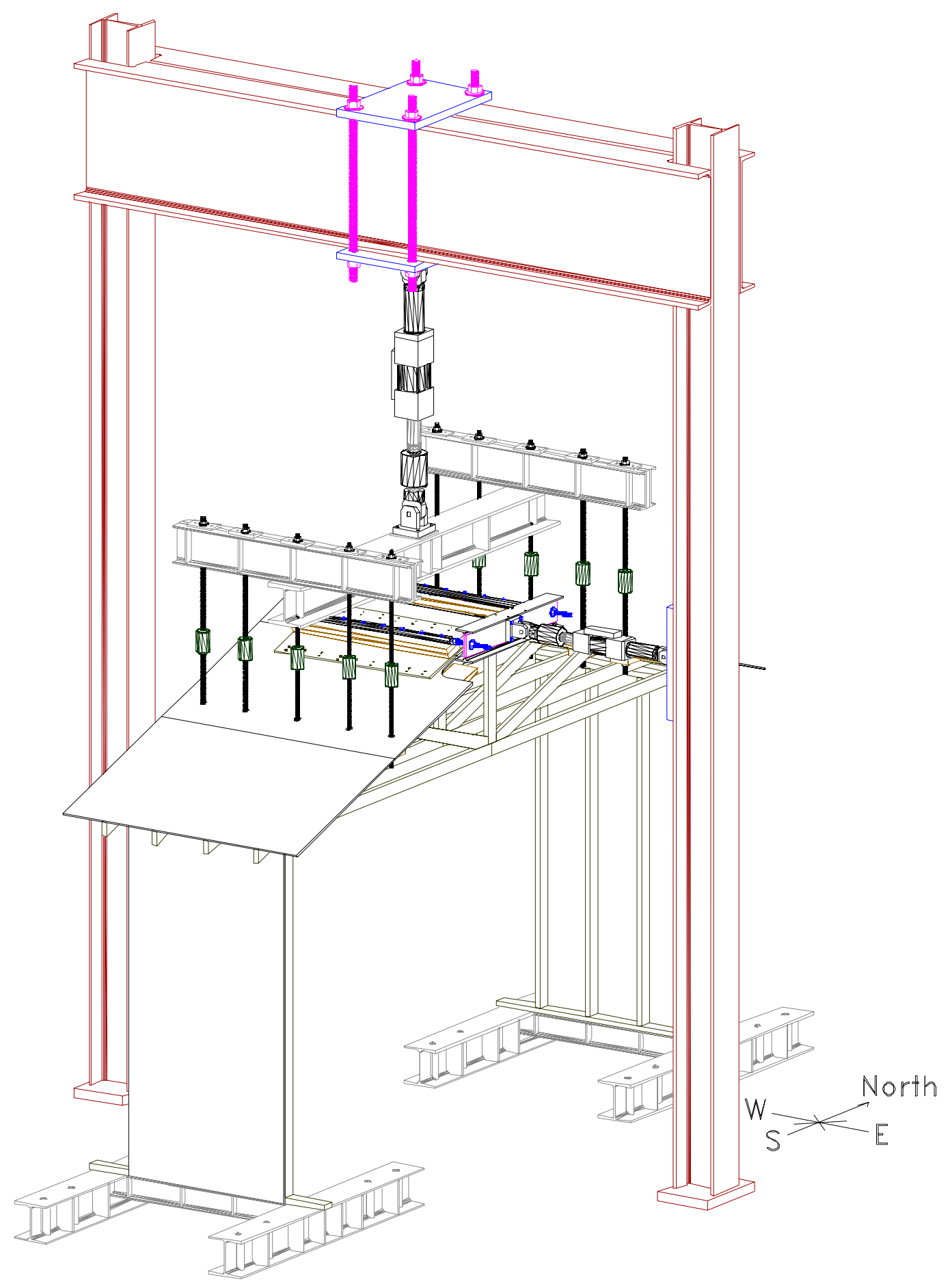

Figure 2.9. Sketch of specimen for combined vertical and lateral load test. 
Table 2.1. Displacement sensors used to measure the specimen motion.

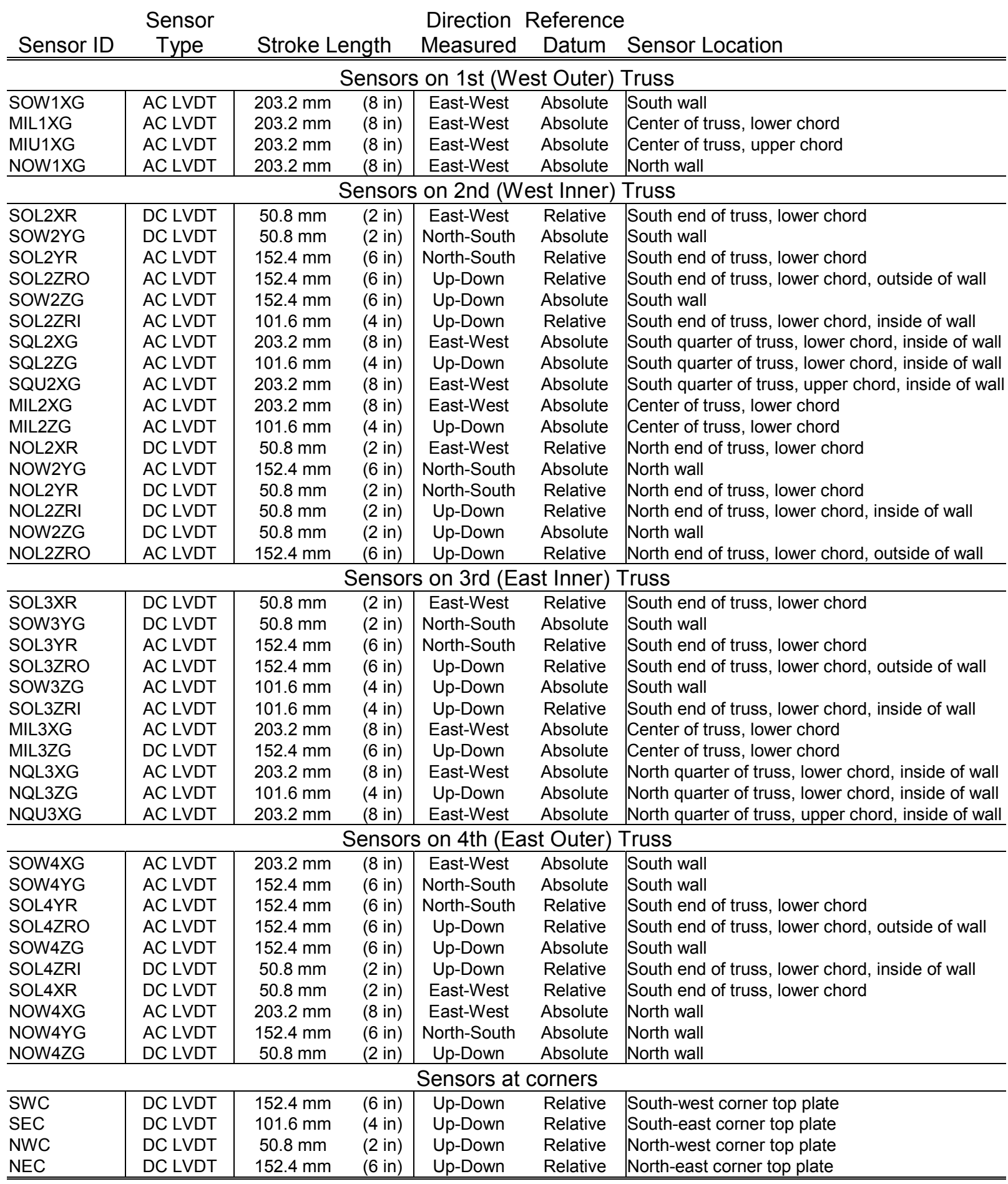

three reference frames located next to the specimen. These sensors were used to measure the displacements of the trusses and walls, and the deformation that occurred in the roof to wall connections. 
As listed in Table 2.1, twenty-six of the sensors measured the absolute motion of the specimen, while twenty sensors measured the relative motion within the specimen. Twenty-one of the sensors were used to measure the vertical motions, and sixteen were used to measure the lateral motion in the east-west direction, which was the primary direction of motion during the lateral loading tests. The remaining nine sensors measured out-of-plane motions in the north-south direction. The positions of these sensors are shown in Figure 2.10.

Two additional LVDTs, permanently mounted inside the hydraulic actuators, were used to measure the displacements applied to the specimen.

Ten strain gage-based load cells were used to measure the uplift forces applied to the roof of the specimen. These sensors were

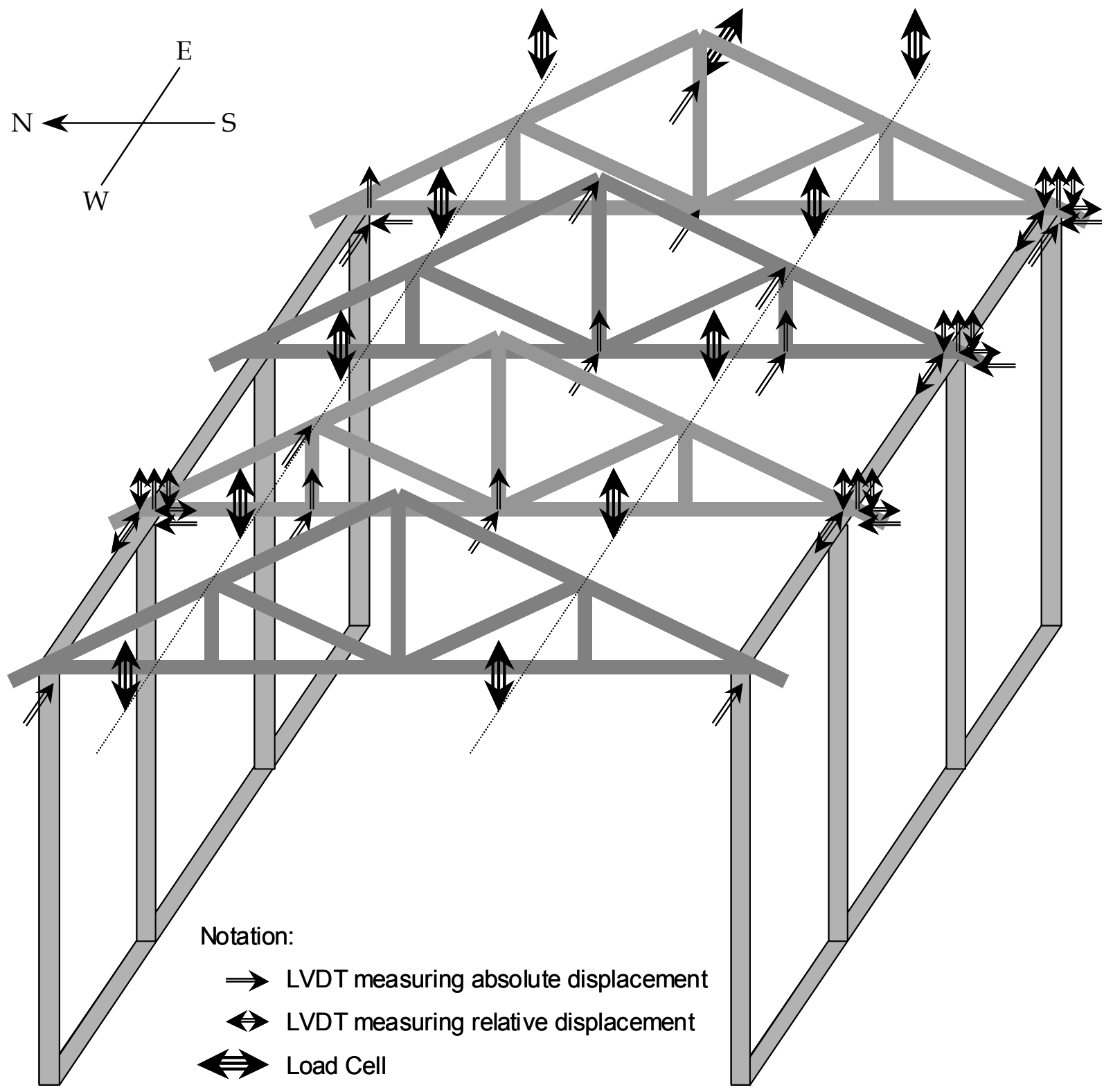

Figure 2.10. Locations of displacement sensors and load cells on the specimens. 
Table 2.2. Load cells used to measure the uplift loads applied to the roof sheathing.

\begin{tabular}{|c|c|c|c|c|c|c|}
\hline Sensor ID & $\begin{array}{c}\text { Sensor } \\
\text { Type }\end{array}$ & \multicolumn{2}{|c|}{ Capacity } & $\begin{array}{l}\text { Direction } \\
\text { Measured }\end{array}$ & $\begin{array}{c}\text { Reference } \\
\text { Datum }\end{array}$ & Sensor Location \\
\hline LCS01 & Load Cell & $44.5 \mathrm{kN}$ & (10 kip) & Up-Down & Absolute & South side, west end, outside \\
\hline LCN01 & Load Cell & $44.5 \mathrm{kN}$ & (10 kip) & Up-Down & Absolute & North side, west end, outside \\
\hline LCS02 & Load Cell & $44.5 \mathrm{kN}$ & (10 kip) & Up-Down & Absolute & South side, west end, inside \\
\hline LCN02 & Load Cell & $44.5 \mathrm{kN}$ & (10 kip) & Up-Down & Absolute & North side, west end, inside \\
\hline LCS03 & Load Cell & $44.5 \mathrm{kN}$ & (10 kip) & Up-Down & Absolute & South side, center \\
\hline LCN03 & Load Cell & $44.5 \mathrm{kN}$ & (10 kip) & Up-Down & Absolute & North side, center \\
\hline LCS04 & Load Cell & $44.5 \mathrm{kN}$ & (10 kip) & Up-Down & Absolute & South side, east end, inside \\
\hline LCN04 & Load Cell & $44.5 \mathrm{kN}$ & (10 kip) & Up-Down & Absolute & North side, east end, inside \\
\hline LCS05 & Load Cell & $44.5 \mathrm{kN}$ & (10 kip) & Up-Down & Absolute & South side, east end, outside \\
\hline LCN05 & Load Cell & $44.5 \mathrm{kN}$ & (10 kip) & Up-Down & Absolute & North side, east end, outside \\
\hline
\end{tabular}

Table 2.3. Additional sensors measured during the tests.

\begin{tabular}{|c|c|c|c|c|}
\hline Sensor ID & Type & \multicolumn{2}{|c|}{ Stroke or Capacity } & Sensor Location \\
\hline$\overline{\text { CmdVAct }}$ & Command Signal & $10 \mathrm{~V}$ & & Vertical actuator command signal \\
\hline DispVAct & AC LVDT & $152.4 \mathrm{~mm}$ & (6 in) & Vertical actuator displacement \\
\hline LCVAct & Load Cell & $222.4 \mathrm{kN}$ & (50 kip) & Vertical actuator applied load \\
\hline CmdHAct & Command Signal & $10 \mathrm{~V}$ & & Horizontal actuator command signal \\
\hline DispHAct & AC LVDT & $152.4 \mathrm{~mm}$ & (6 in) & Horizontal actuator displacement \\
\hline LCHAct & Load Cell & $44.5 \mathrm{kN}$ & (10 kip) & Horizontal actuator applied load \\
\hline
\end{tabular}

located along the rods that transferred the loads from the load tree to the roof sheathing. As listed in Table 2.2, each of these load cells had a capacity of $45 \mathrm{kN}$ (10 kip).

Two additional load cells, attached to the rods of the hydraulic actuators, were used to directly measure the forces generated by the actuators.

Table 2.3 lists the additional response signals that were recorded during testing. As mentioned above, the forces and loads generated by each of the actuators were measured and recorded. The command signals that were used to drive the actuators were also monitored. Each of these signals was a direct current voltage, with a $10 \mathrm{~V}$ full scale. Since each of the actuators was driven in displacement control, the $10 \mathrm{~V}$ corresponded to the maximum displacement of the actuator.

\subsection{Test Protocols}

As described above, specimens were subjected to either monotonic uplift, monotonic lateral, cyclic lateral, or combined uplift and lateral loads. The loads were applied with the actuator driven in displacement control. During the monotonic load tests a constant rate of deformation was applied.

For the uplift loading tests, a number of small deformation tests were performed to verify that the sensors were properly measuring the response, followed by a large deformation test to fail the connections. During the first small deformation test, a vertical deformation was applied at a constant rate of $2.54 \mathrm{~mm} / \mathrm{min}(0.10 \mathrm{in} / \mathrm{min})$ to a peak of $2.54 \mathrm{~mm}$ (0.10 in). A second small deformation test was performed with a vertical deformation applied at a constant rate of $5.08 \mathrm{~mm} / \mathrm{min}(0.20 \mathrm{in} / \mathrm{min})$ to a peak of $5.08 \mathrm{~mm}(0.20 \mathrm{in})$. If the results of these initial tests appeared reasonable, the specimen was tested to failure. During the failure test, the vertical deformation was applied at a constant rate of $6.35 \mathrm{~mm} / \mathrm{min}$ (0.25 in/min), until the connections on one side of the roof failed.

The lateral loading test sequence was similar to the vertical test sequence. Again, a 
number of small deformation tests were performed to verify that the sensors were working properly, followed by a large deformation test to failure. Because the specimens were more flexible in the lateral direction, larger deformations and rates were used. During the first small deformation test, the lateral deformation was applied at a constant rate of $6.35 \mathrm{~mm} / \mathrm{min}$ $(0.25 \mathrm{in} / \mathrm{min})$ to a peak of $6.35 \mathrm{~mm}(0.25 \mathrm{in})$. During the second small deformation test, the deformation was applied at a constant rate of $12.7 \mathrm{~mm} / \mathrm{min}(0.50 \mathrm{in} / \mathrm{min})$ to a peak of $12.7 \mathrm{~mm}(0.50 \mathrm{in})$. Again if the results of these tests appeared to be reasonable, the specimen was tested to failure. During the failure test of the specimen with toe-nailed connections, the lateral deformation was applied at a constant rate of $12.7 \mathrm{~mm} / \mathrm{min}$ $(0.50 \mathrm{in} / \mathrm{min})$. This rate of loading resulted in a relatively long test. So, to reduce the test length and to make the amount of data recorded more manageable, during the failure test of the specimen with hurricane clips, the lateral deformation was applied at a constant rate of $25.4 \mathrm{~mm} / \mathrm{min}$ (1.0 in/ $\mathrm{min})$.

The combined lateral and uplift load tests were performed by applying a vertical deformation at a constant rate, and calculating in real-time the lateral deformation that would cause a lateral load that was proportional to the load caused by the vertical deformation. Based on the shape of the truss and the tributary area of the roof, the ratio between the uplift load and the lateral load that would occur during a strong windstorm was estimated as 0.295. The control system attempted to maintain the ratios between the uplift and lateral forces at this level throughout the test; however, due to limitations in the speed of the control computer, nonlinearities in the specimen response, and changes in the stiffness of the specimen as it deformed, the actual load ratio varied slightly over the course of each test. As in the case of the monotonic load test, small deformation tests were performed to validate the sensor operation. During the failure test, the vertical deformation was applied at a rate of $6.35 \mathrm{~mm} / \mathrm{min}$ (0.25 in/min).

The fourth test series was the cyclic lateral loading, which was intended to simulate the effects of earthquake motion on the connections. The applied motion was a constant velocity (CV) deformation waveform with increasing amplitudes over time. The generic version of this waveform is shown in Figure 2.11. This waveform is based on the work of Krawinkler et al. (2001). For application in a test, the waveform is scaled such that the unit amplitude of the generic waveform is equal to $60 \%$ of the deformation in a specimen subjected to monotonic lateral loading at the point in the test after the peak capacity has been exceeded and the response force has dropped to $80 \%$ of the peak value.

For the current tests, the period of the waveform was $30 \mathrm{~s}$. The unit amplitude was scaled to $37.24 \mathrm{~mm}$ (1.466 in) for the specimen with toe-nailed connections and to $50.19 \mathrm{~mm}$ (1.976 in) for the specimen with hurricane clips. In both cases, the absolute peak amplitude was limited to $73.7 \mathrm{~mm}$ (2.90 in), due to the actuator stroke limits. 


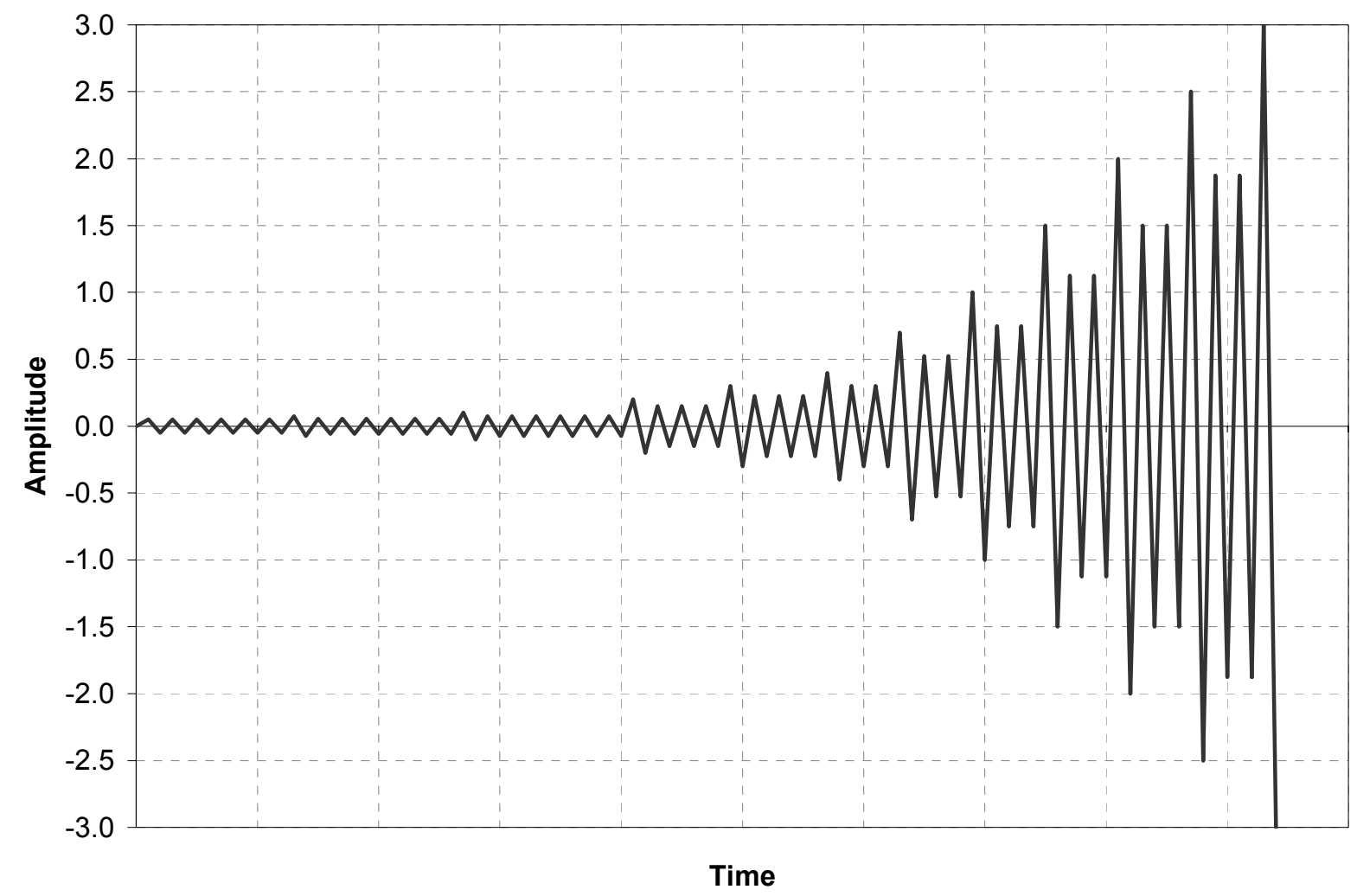

Figure 2.11. Generic (dimensionless) lateral displacement curve for cyclic lateral load tests. 


\section{Results Of Uplift LoAd Tests}

Two specimens were tested under uplift load to simulate the wind effects on the structure, without any lateral component to the load. The first specimen used the toenailed connection (three $16 \mathrm{~d}$-common nails) to tie the bottom chord of the roof trusses to the walls, while the second used the stronger hurricane clip to connect the bottom chord of the trusses to the upper plate of the walls' top plate.

\subsection{Response with Toe-nailed Con- nections}

As described in section 2.4, a constantly increasing uplift deformation was applied to the roof of the toe-nailed connection specimen at a rate of $6.35 \mathrm{~mm} / \mathrm{min}(0.25 \mathrm{in} / \mathrm{min})$ for a period of approximately $360 \mathrm{~s}$. This deformation is shown in Figure 3.2 and the resulting loads are shown in Figure 3.3. The specimen failed on one side at the connection between the trusses and the top plate of the wall after about $125 \mathrm{~s}$. The failure mode was characterized as the nails withdrawing from the top plate, which resulted in separation in the bottom wood fibers of the bottom chord as can be seen in Figure 3.1. The specimen continued to exhibit some resistance, although the strength was relatively small after $200 \mathrm{~s}$, and continued to decrease as all of the connections on one side of the

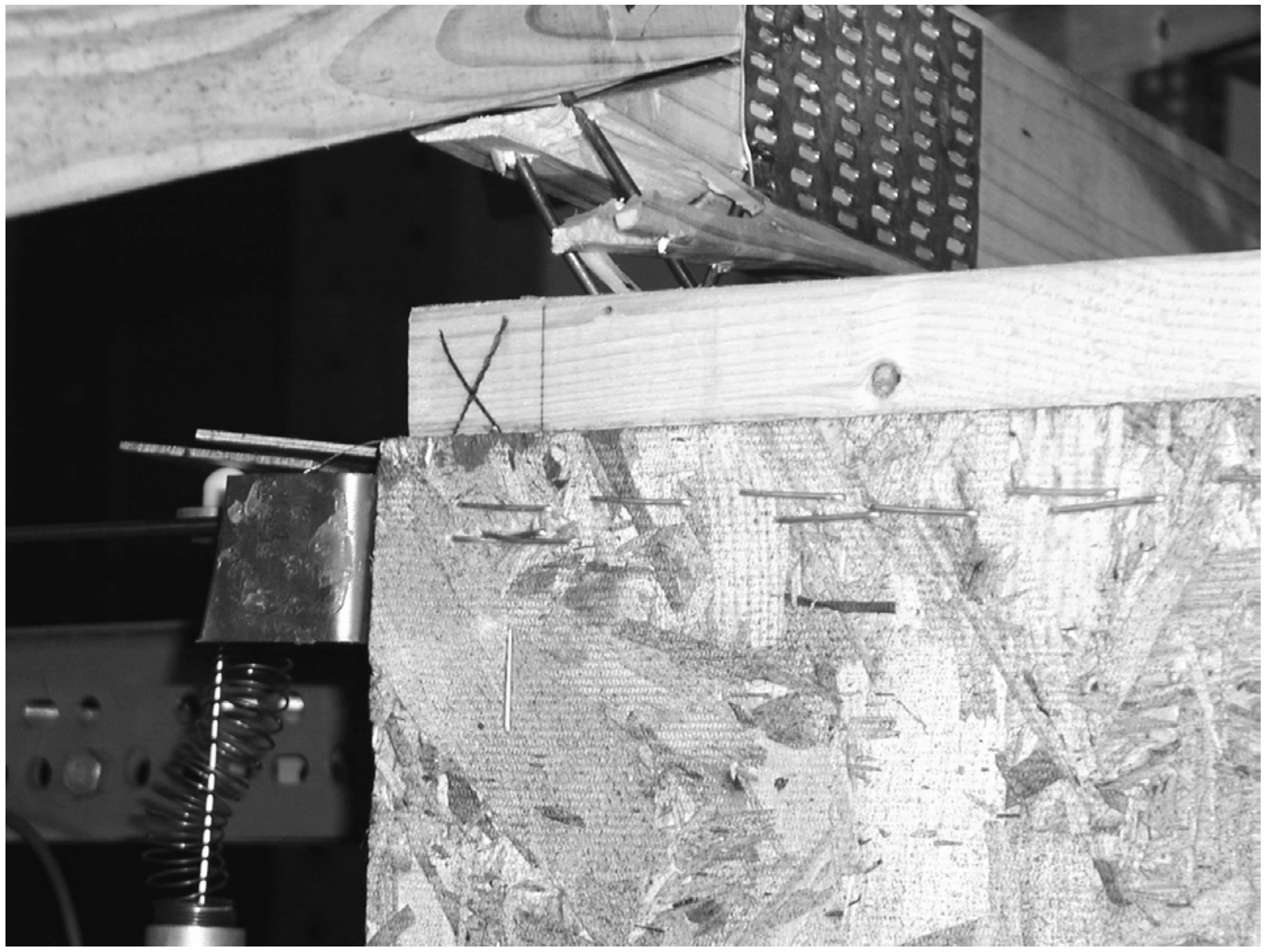

Figure 3.1. Failure of toe-nailed truss to wall connection. 
specimen failed completely.

Figure 3.4 shows the deformation that occurred at two connections during the test. The outer connection, truss 4 , failed first. The drop in the deformation for this truss occurred near the end of the test, when the opposite outer connection finally failed. Truss 2 is an inner truss, and was the third of the four connections to separate completely. The load-deformation curves for these two connections are shown in Figure 3.5.

\subsection{Response with Hurricane Clips}

The specimen with the stronger hurricane clip connections was tested twice. The first failure occurred on the lightly instrumented side of the specimen, and consisted of the entire top plate pulling loose from the wall studs and cladding. The specimen was repaired and retested. During the second test, failure was observed on the other side in the walls' top plate, as can be seen in Figure 3.6. The hurricane clip remained attached to the upper member of the top plate and the truss, while the upper member of the top plate and a portion of the lower member separated from the rest of the wall. This failure mode clearly illustrated the improved strength of the hurricane clip connection.

During both tests, this specimen was loaded in the same way as the toe-nailed connection specimen, except that the loading period was increased and, as can be seen in Figure 3.7, the applied deformation increased proportionally. During the first test, the connections began to lose stiffness after about $150 \mathrm{~s}$, but they did not fail until approximately $225 \mathrm{~s}$. Due to the nature of the failure, the resistance of the specimen dropped by about half when the first failure occurred. This response can be observed in Figure 3.8.
The deformation that occurred at one of the inner truss connections during the first test is shown in Figure 3.9, while the deformation at three connections during the second test is shown in Figure 3.11. The corresponding load-deformation curves are shown in Figure 3.10 (first test) and Figure 3.12 (second test). As can be seen in these two figures, the hurricane clip connections showed good ductility, continuing to carry significant, but reduced, load at relatively large levels of deformation.

\subsection{Comparison of Responses}

A direct comparison of the responses with the two types of connections is shown in Figure 3.13. The behavior of both of these types of connections is highly nonlinear, and once either of these connections reaches their ultimate load they lose a significant portion of their resistance. However, Figure 3.13 clearly shows that the hurricane clip connection has a significantly higher uplift capacity, and in most cases a larger failure deformation than the toe-nailed connections. In addition, the residual strength of the hurricane clip connection tended to be greater than the capacity of the toe-nailed connection. 


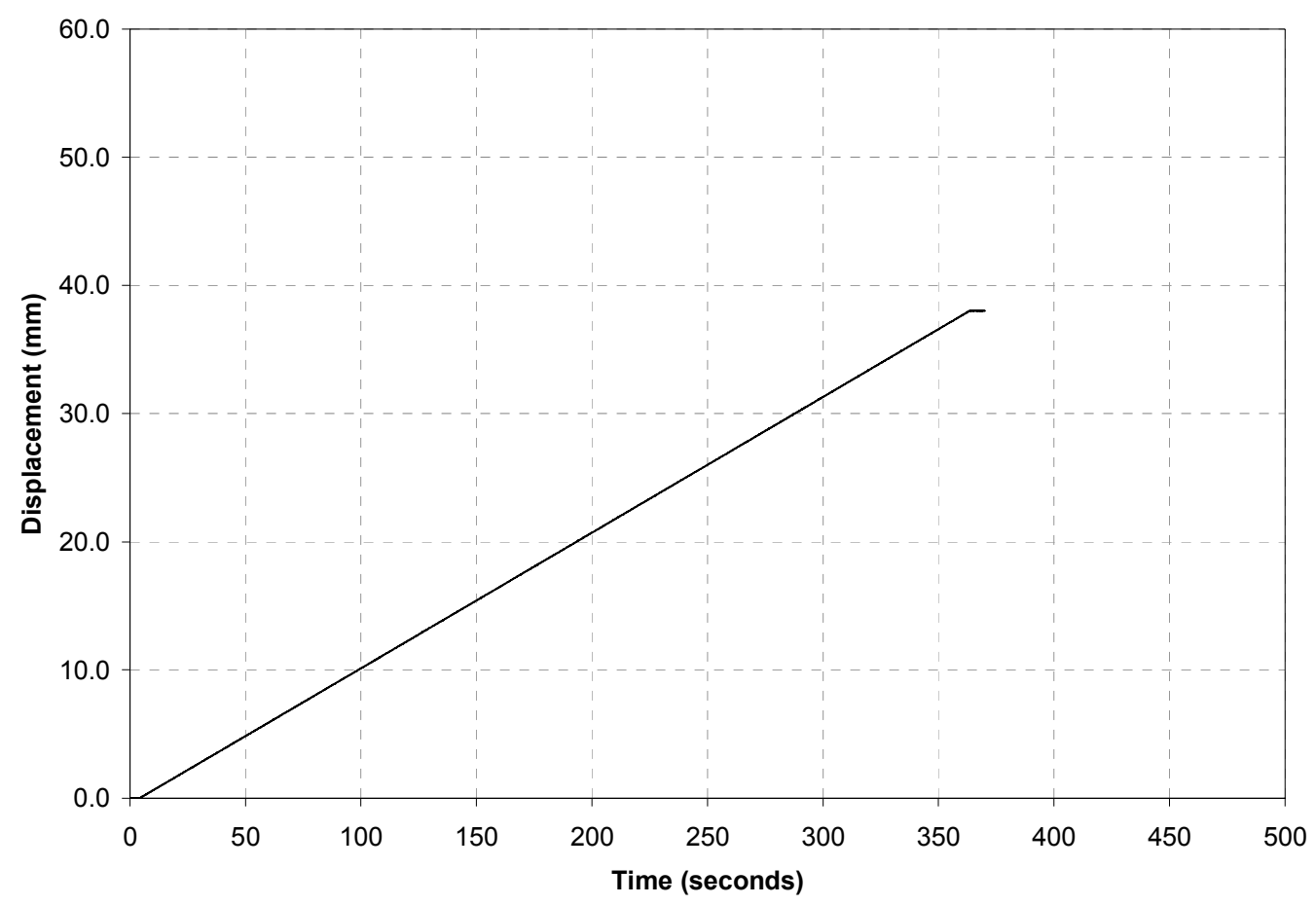

Figure 3.2. Vertical displacement applied to specimen with toe-nailed connections.

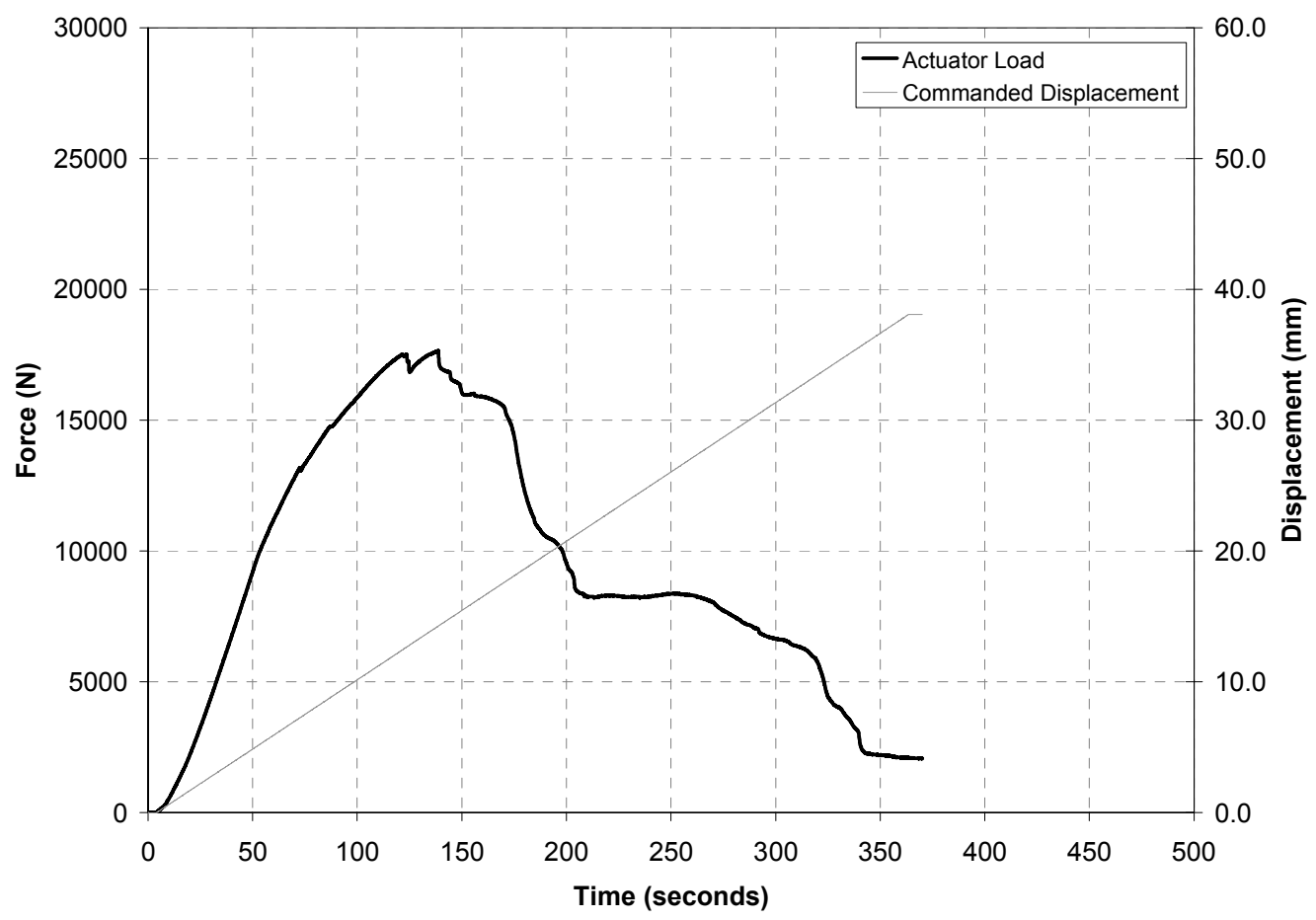

Figure 3.3. Vertical load applied to specimen with toe-nailed connections. 


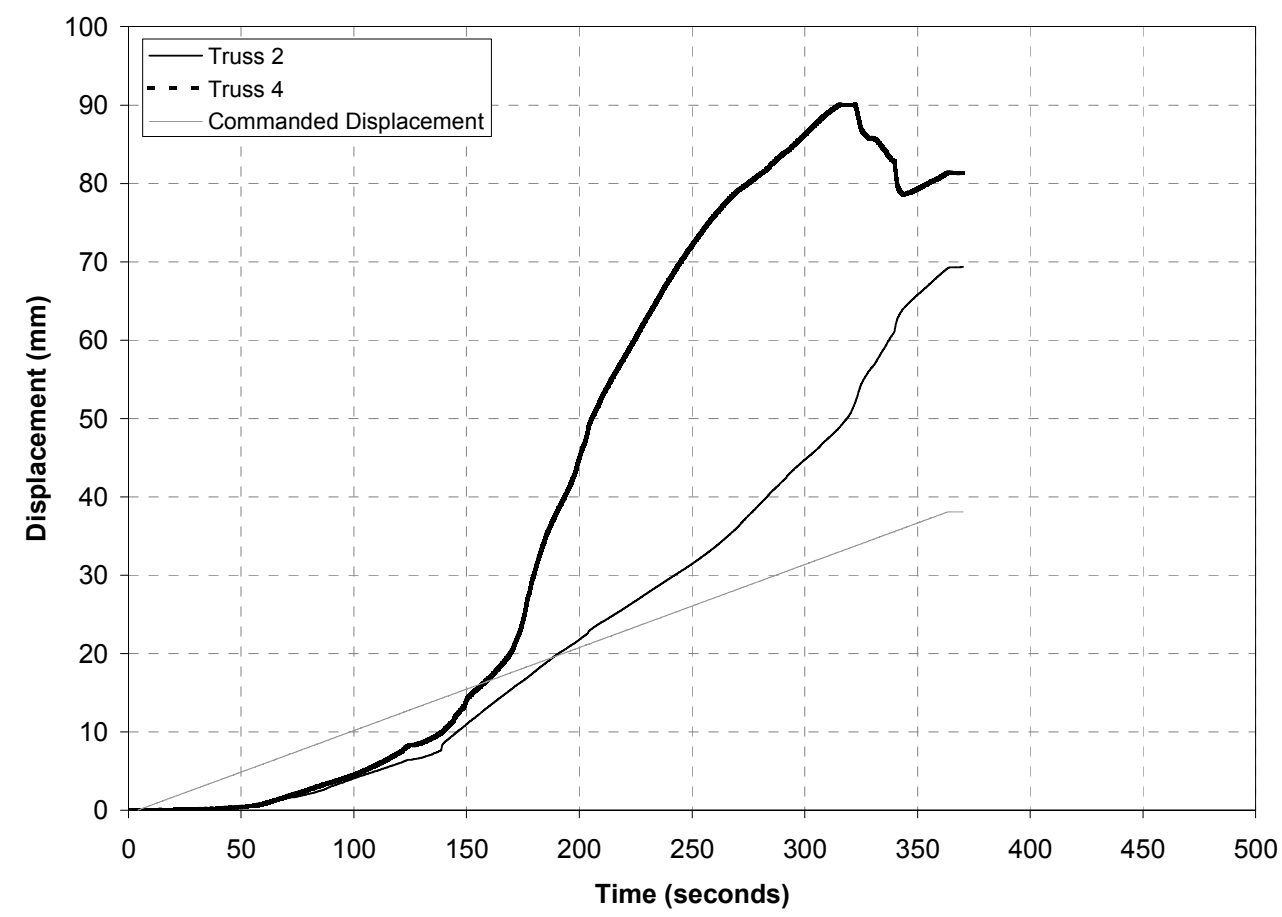

Figure 3.4. Connection deformation response of specimen with toe-nailed connections.

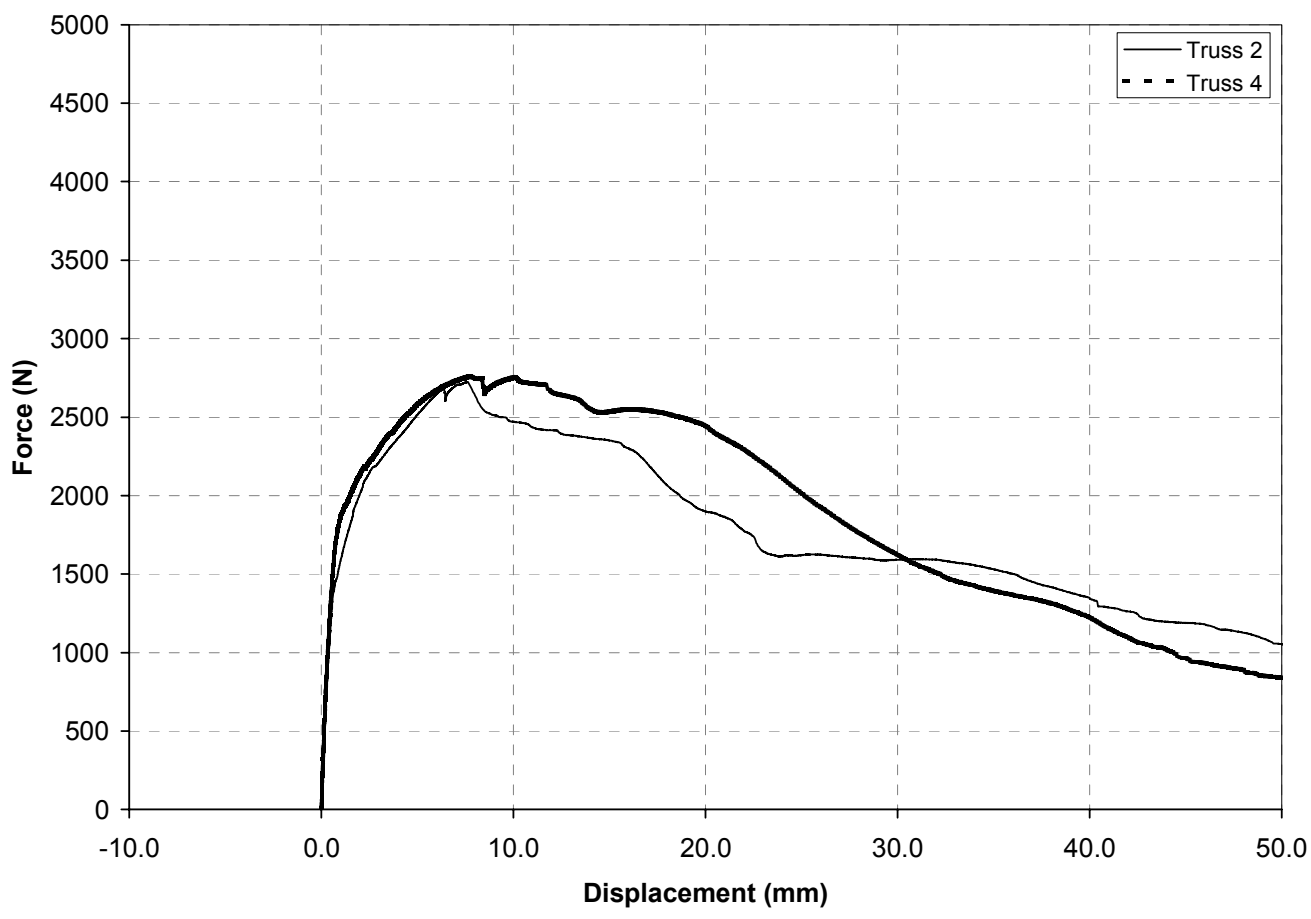

Figure 3.5. Load-deformation response of specimen with toe-nailed connections. 


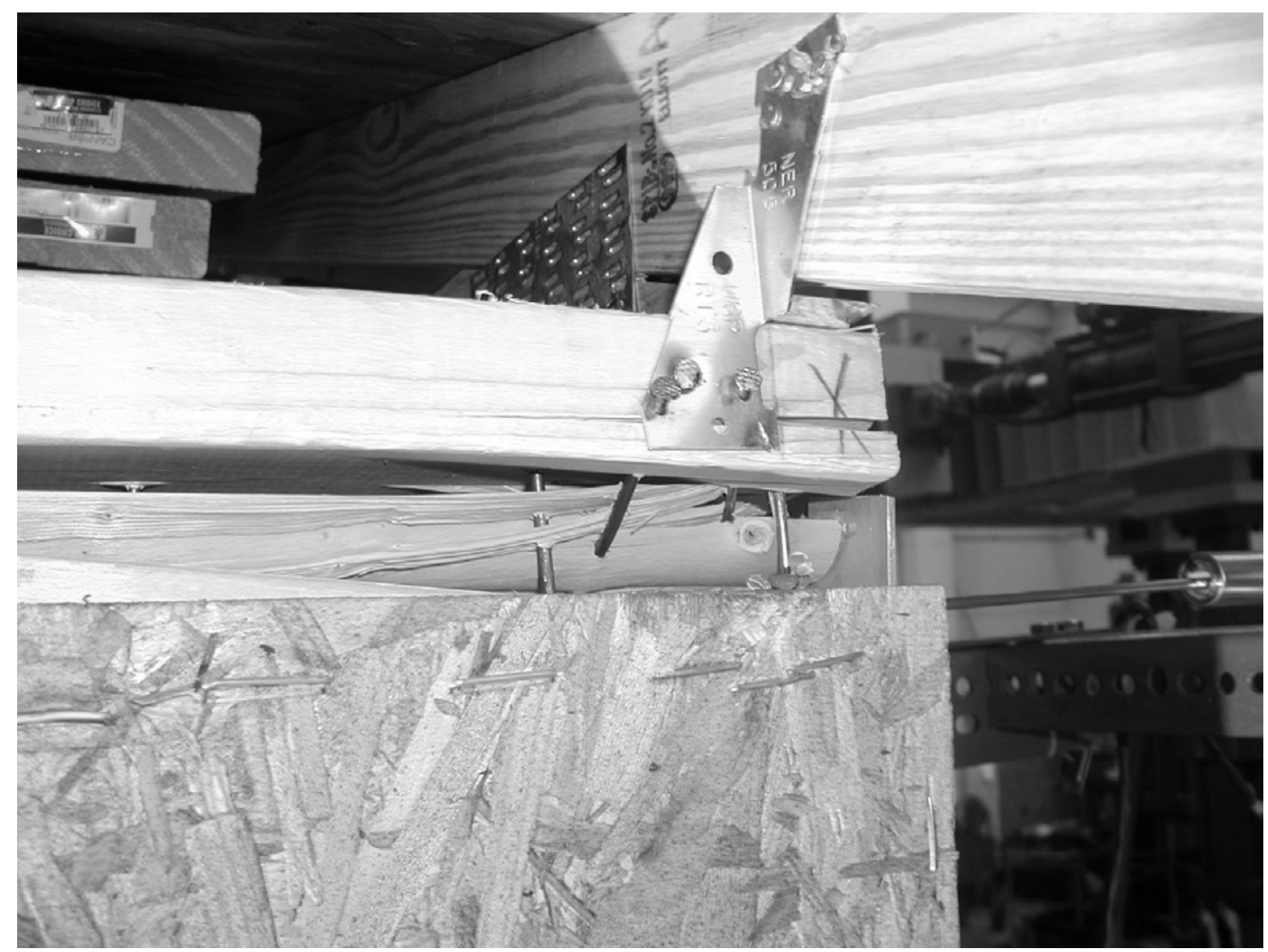

Figure 3.6. Failure of hurricane clip connection. 


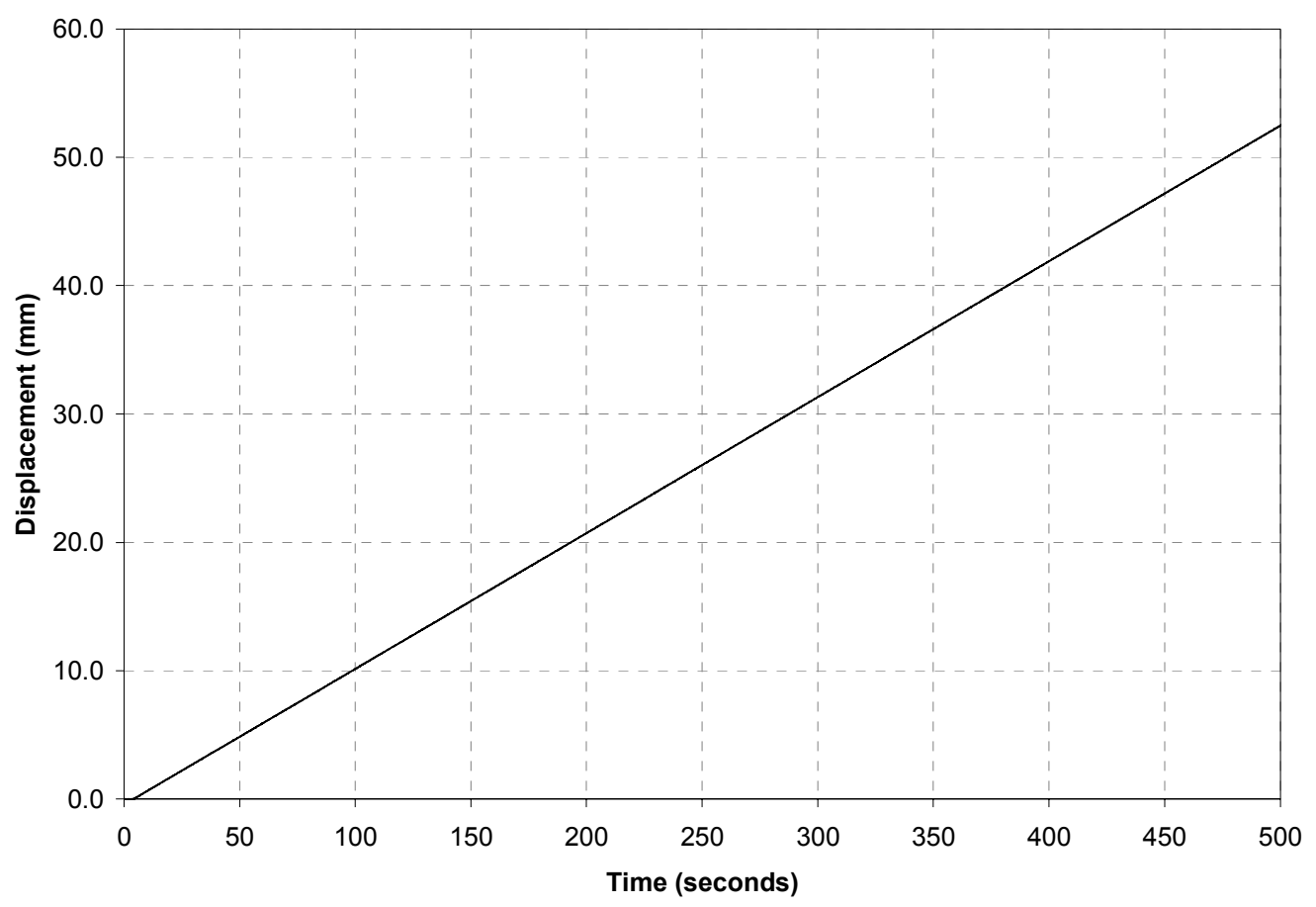

Figure 3.7. Vertical displacement applied to specimen with hurricane clips.

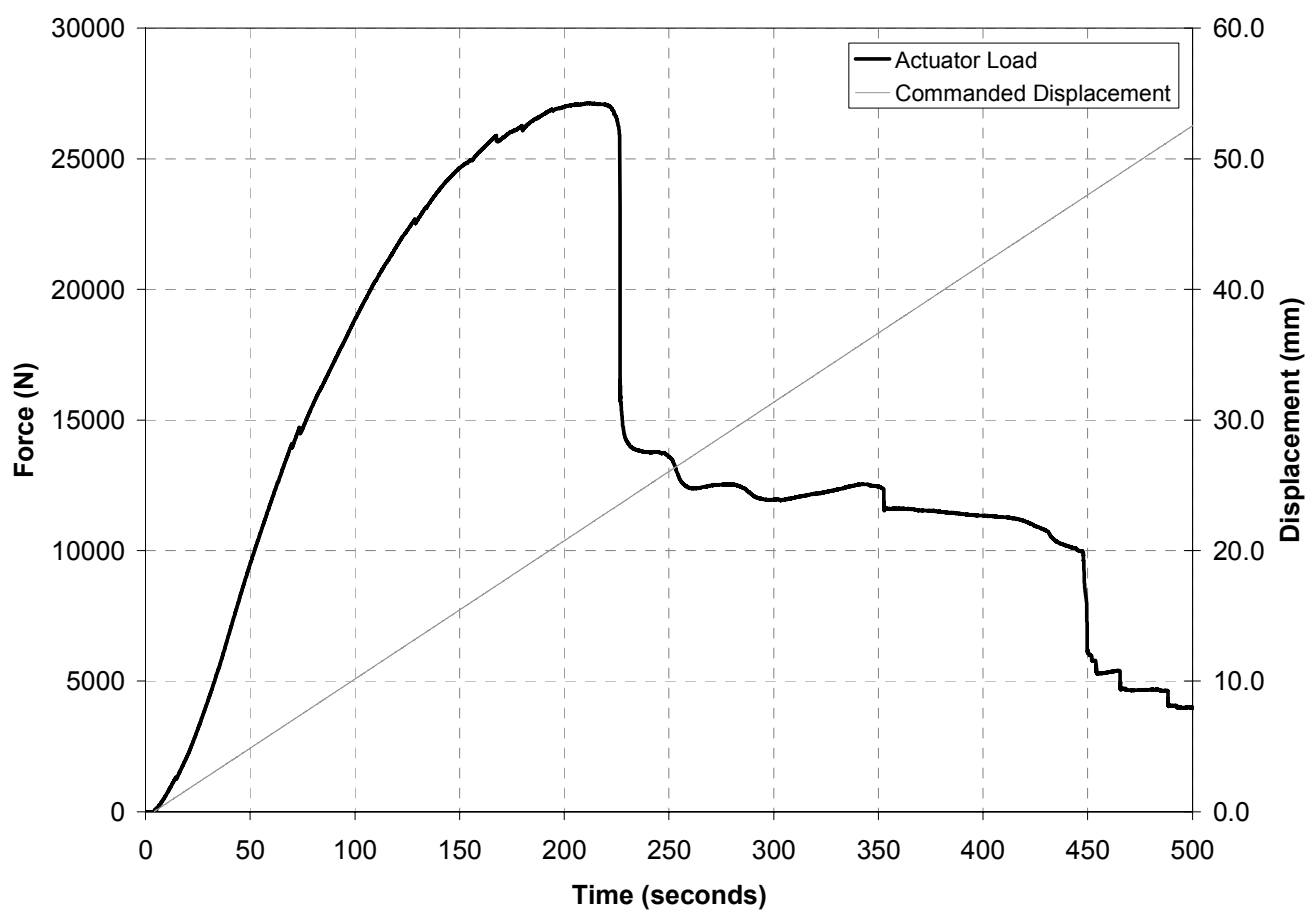

Figure 3.8. Vertical load applied to specimen with hurricane clips. 


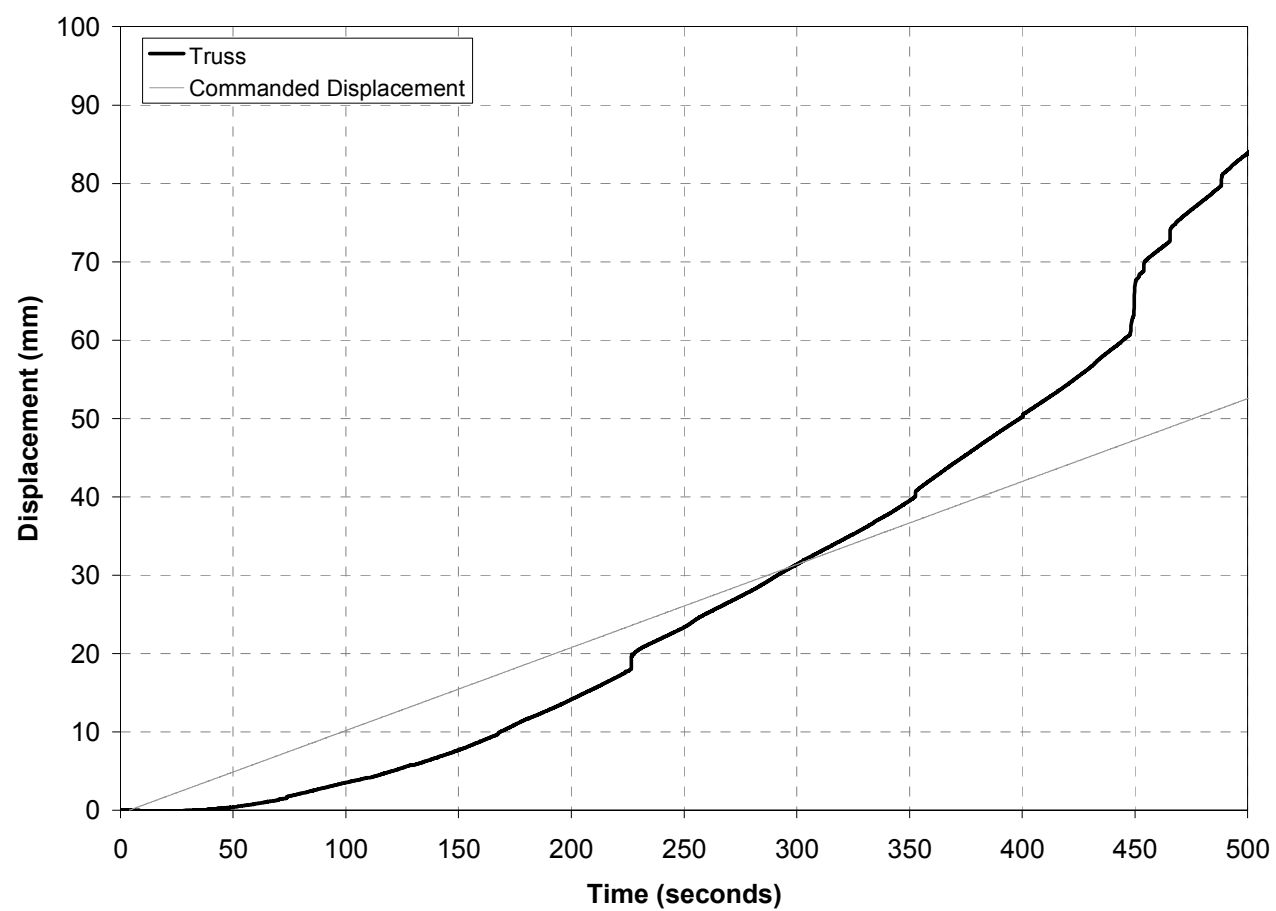

Figure 3.9. Connection deformation response of first test with hurricane clips.

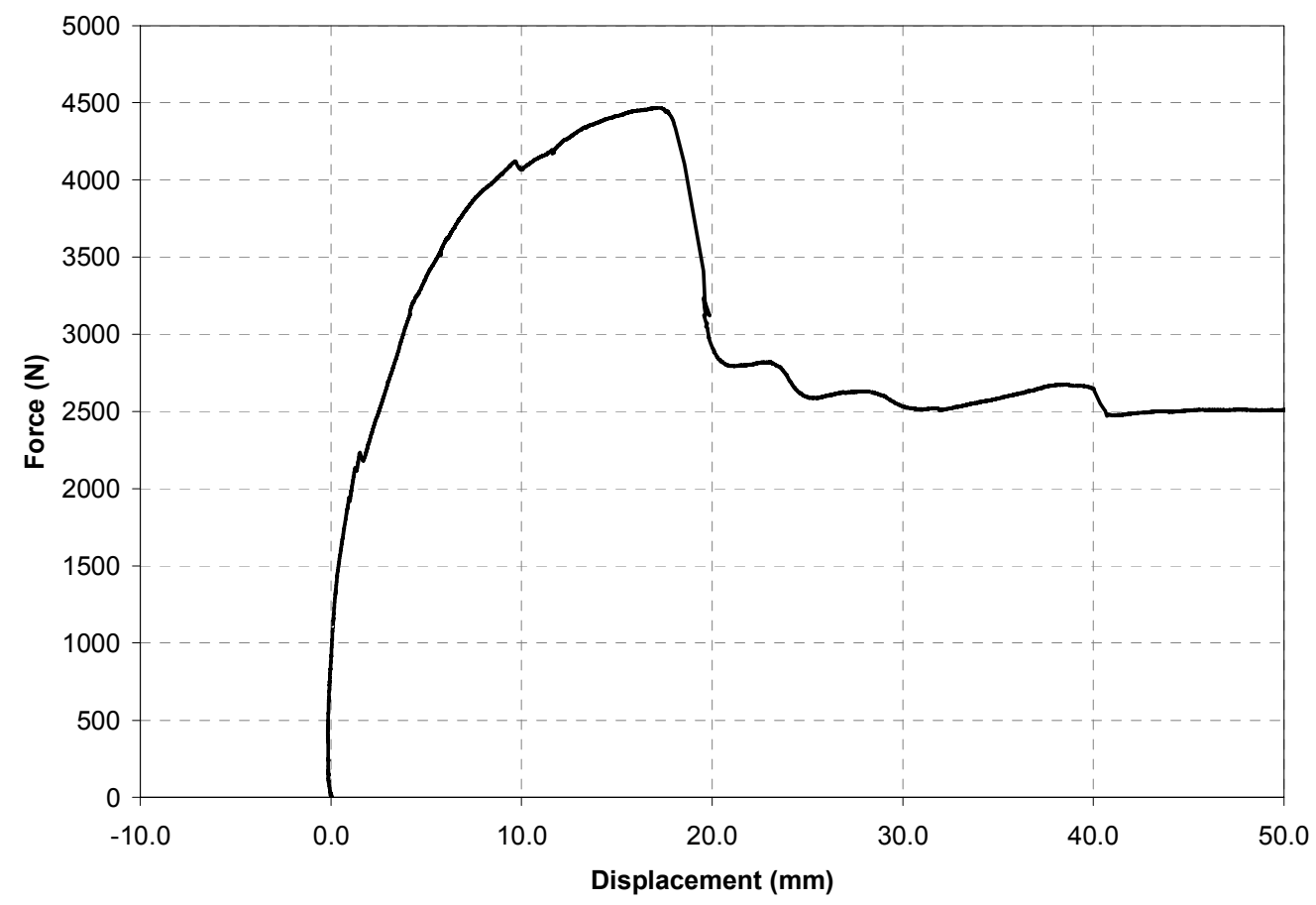

Figure 3.10. Load-deformation response of first test with hurricane clips. 


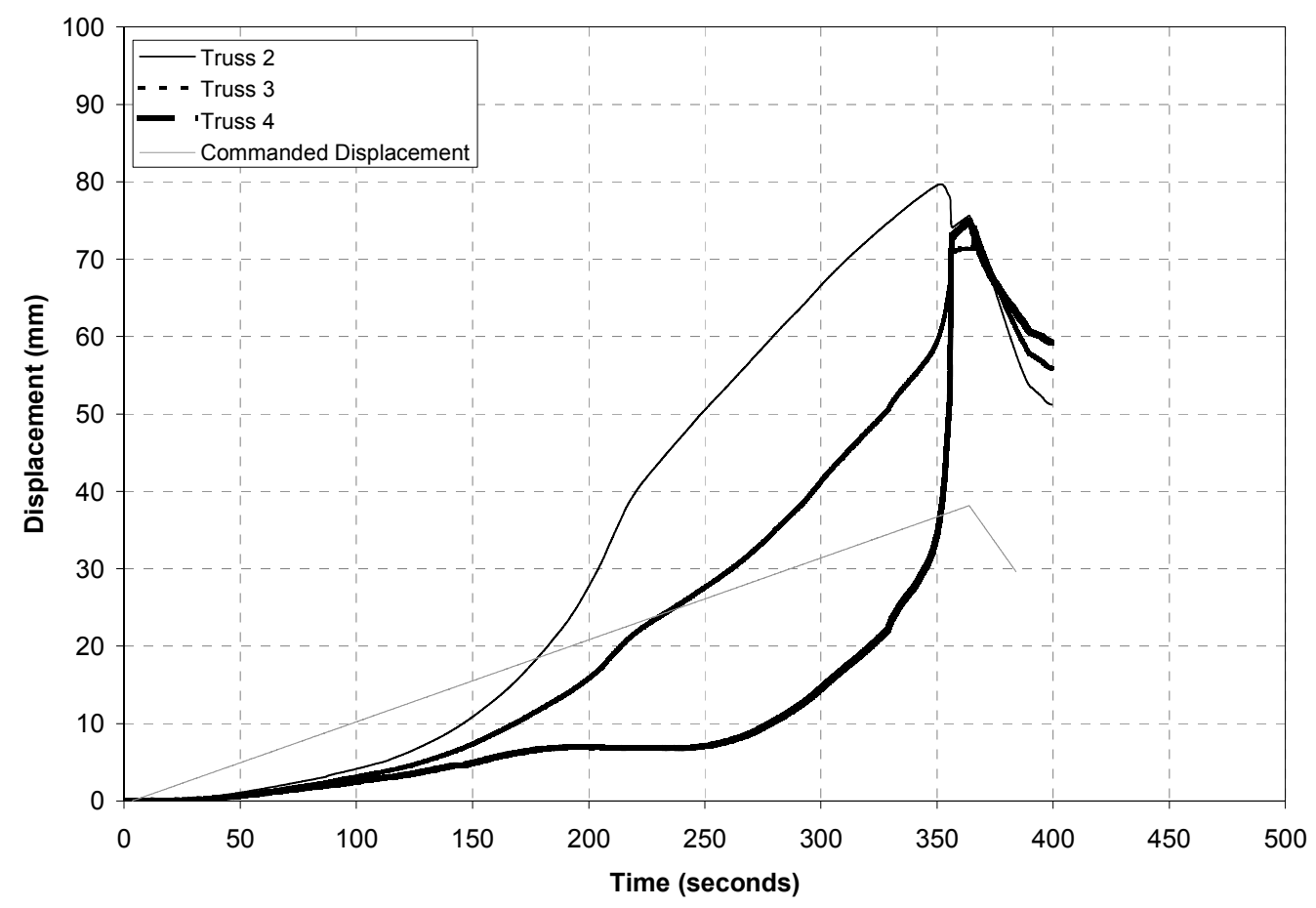

Figure 3.11. Connection deformation response of second test with hurricane clips.

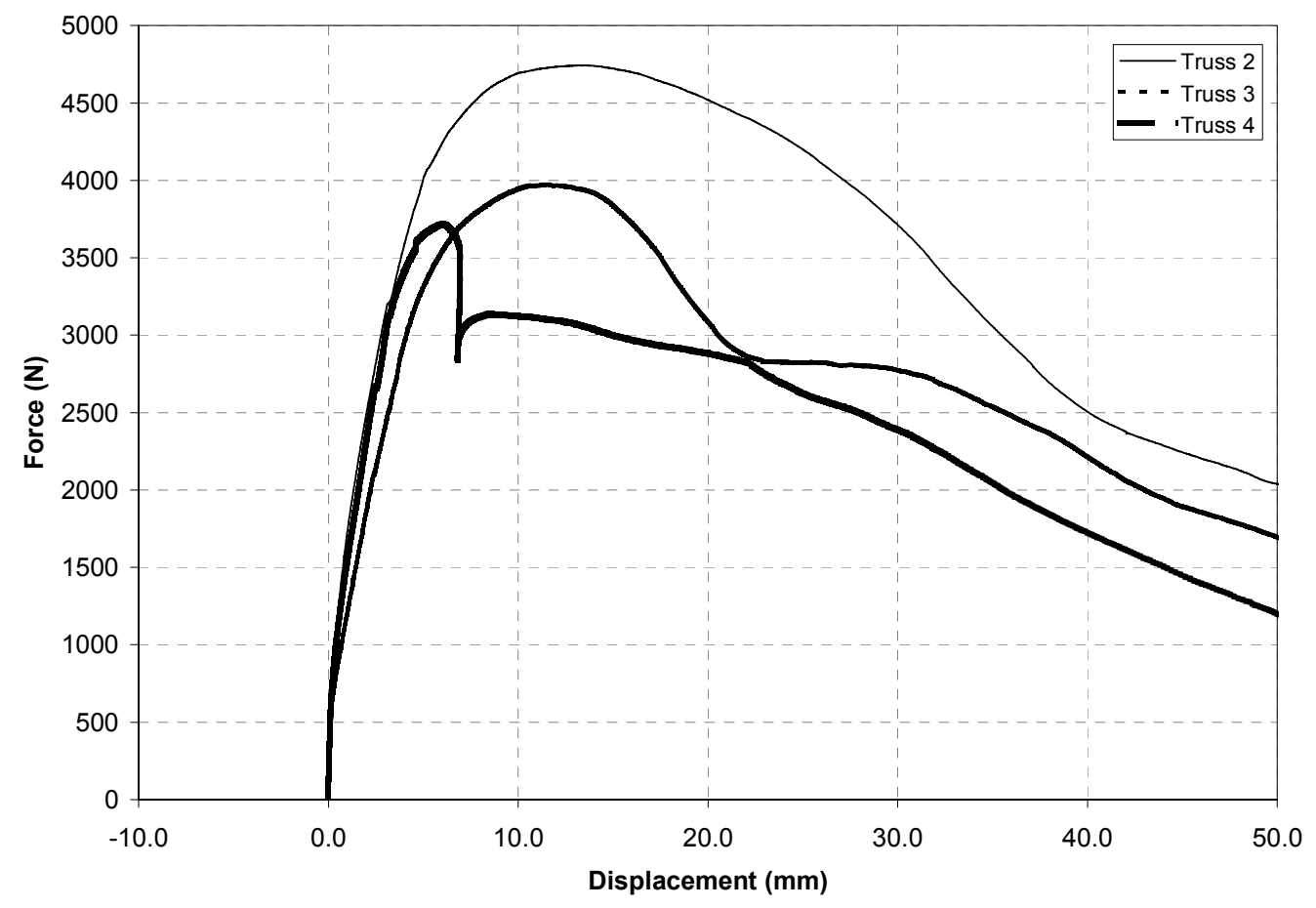

Figure 3.12. Load-deformation response of second test with hurricane clips. 


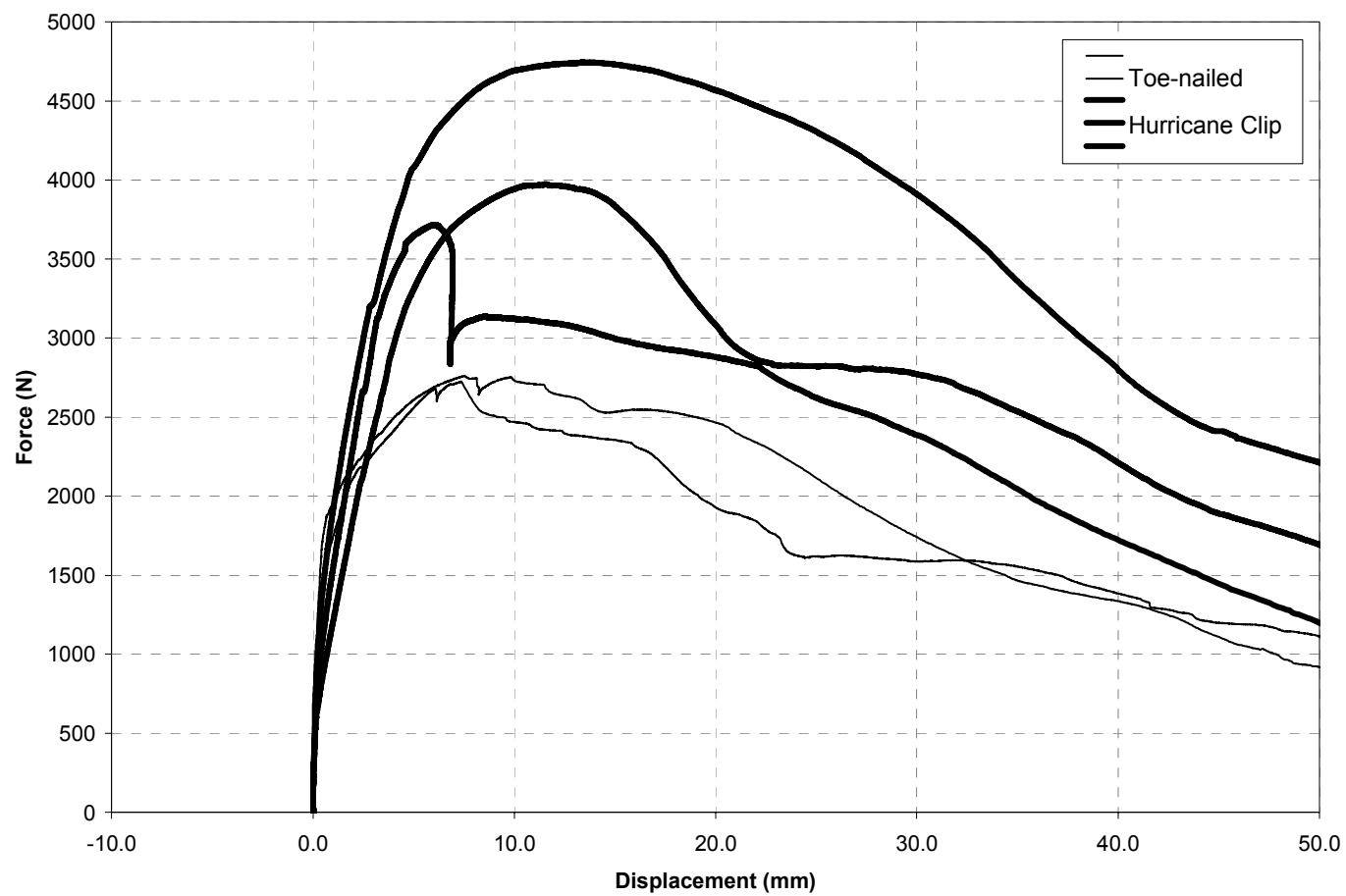

Figure 3.13. Comparison of responses with toe-nailed connections and hurricane clips. 
This page intentionally left blank. 


\section{Results of Monotonic LATERAL LoAd TESTS}

Two specimens were tested with a monotonic lateral load to determine the ultimate shear capacity of the connections and their pushover response. As in the case of the monotonic uplift tests, in one specimen the bottom chord of each roof truss was connected to the walls with toe-nailed connection, while in the other specimen hurricane clips were used.

\subsection{Response with Toe-nailed Con- nections}

For the specimen with toe-nailed connections, the lateral deformation was applied at a constant rate of $12.7 \mathrm{~mm} / \mathrm{min}$ ( $0.50 \mathrm{in} / \mathrm{min}$ ) for a period of about $330 \mathrm{~s}$, as can be observed in Figure 4.2. The resulting load is shown in Figure 4.3. The specimen resisted the applied load with constantly decreasing stiffness, until about $270 \mathrm{~s}$ into the test. At this point, the tension, due to the overturning moments, in the connections at one end caused the outer truss to pull free of the top plate. This failure can be seen in Figure 4.1. As in the case of the uplift loading, the failure mode can be characterized as nail withdrawal from the top plate. This failure resulted in the wood splitting in the bottom chord of one inner truss, but little damage to the wood of the outer truss.

The lateral deformations in the toe-nailed connections of three of the trusses are shown in Figure 4.4, while the uplift deformations in the same connections are shown in Figure 4.5. From these results it is clear that the connections were quite stiff in shear, but more flexible in tension. The corresponding force displacement responses are shown in Figures 4.6 and 4.7. The responses of all three connections were quite similar in shear, but the outer connection, which failed first, was clearly carrying greater tension due to the overturning moments.

The lateral and vertical components of the response of the east inner truss are shown in Figure 4.8. These curves clearly show a difference in the lateral and vertical stiffness of the connection, and how much more deformation occurred in the vertical direction than the lateral. Figure 4.9 shows the same response for the east outer truss. In this case the difference in the stiffnesses before failure is not as great, but again the vertical deformation is much greater than the lateral deformation. It is notable that the peak vertical load carried by this connection is nearly as large as the load carried by the toe-nailed connections tested with uplift loading.

\subsection{Response with Hurricane Clips}

For the specimen with hurricane clips, the lateral deformation was applied at a constant rate of $25.4 \mathrm{~mm} / \mathrm{min}(1.0 \mathrm{in} / \mathrm{min})$ for a period of about $250 \mathrm{~s}$, as can be observed in Figure 4.11. The load that resulted is shown in Figure 4.12. The specimen resisted the applied load with a near constant stiffness, until about $170 \mathrm{~s}$ into the test. At this point, the outer truss pulled free of the top plate. As in the case of the toe-nailed connections, the tension due to the overturning moments appeared to play a major role in the failure, which can be seen in Figure 4.10. Also as in the prior test, the failure mode can be characterized as nail withdrawal from the top plate.

The lateral deformations in the connections of three of the trusses are shown in Figure 4.13, and the uplift deformations in these connections are shown in Figure 4.14. From these results it is clear that like the toenailed connections, the hurricane clip con- 
nections were quite stiff in shear, but relatively flexible in tension. The corresponding force displacement responses are shown in Figures 4.15 and 4.16. Again, the responses of all three connections were quite similar in shear, but the outer connection, which failed first, was clearly carrying greater tension due to the overturning moments, and the westernmost connection never reached its failure capacity.

Figure 4.17 shows the lateral and vertical components of the response of the east inner truss. These curves clearly show a difference in the lateral stiffness of the connection was greater than the vertical stiffness, and how much more deformation occurred in the vertical direction than the lateral. Figure 4.18 shows the same response for the east outer truss. In this case, the stiffnesses are similar to the inner truss, and again the vertical deformation is much greater than the lateral deformation. While the peak vertical load carried by this connection is nearly twice as large as the peak lateral load, it is somewhat smaller than the load carried by the hurricane clip connections tested with uplift loading. One reason for this last result may be the difference in the failure modes between the two tests.

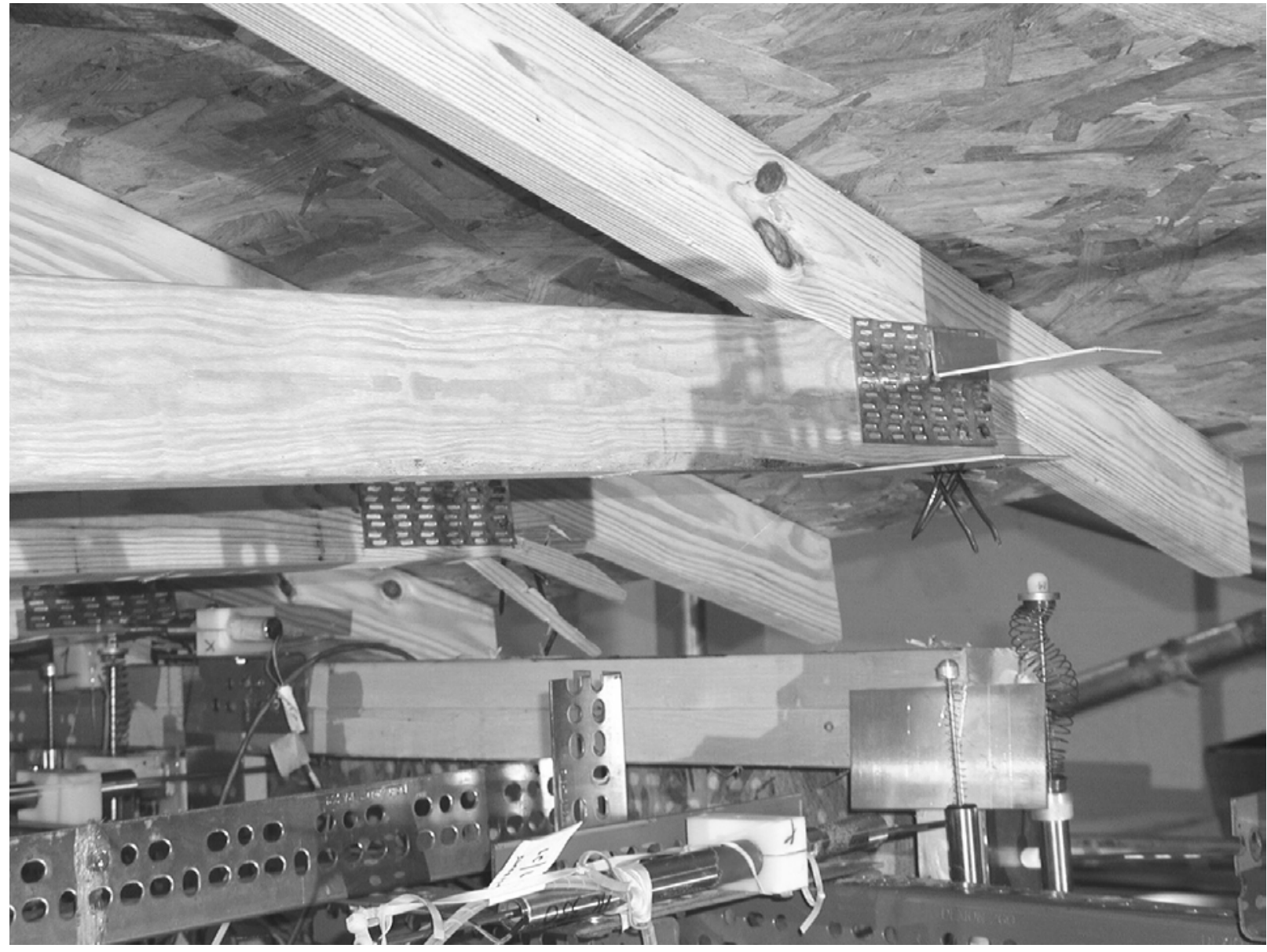

Figure 4.1. Failure of toe-nailed connection with lateral load. 


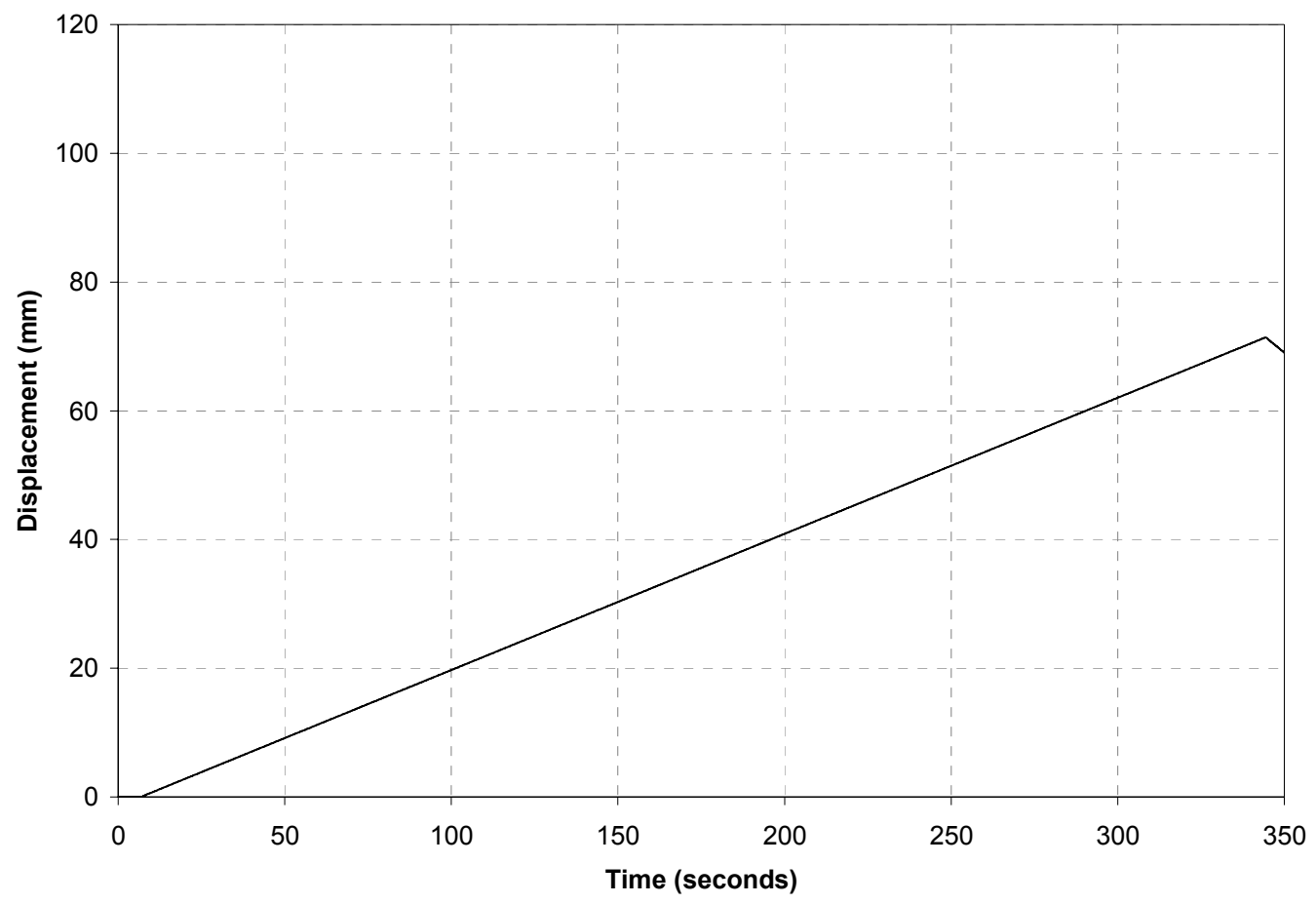

Figure 4.2. Lateral displacement applied to specimen with toe-nailed connections.

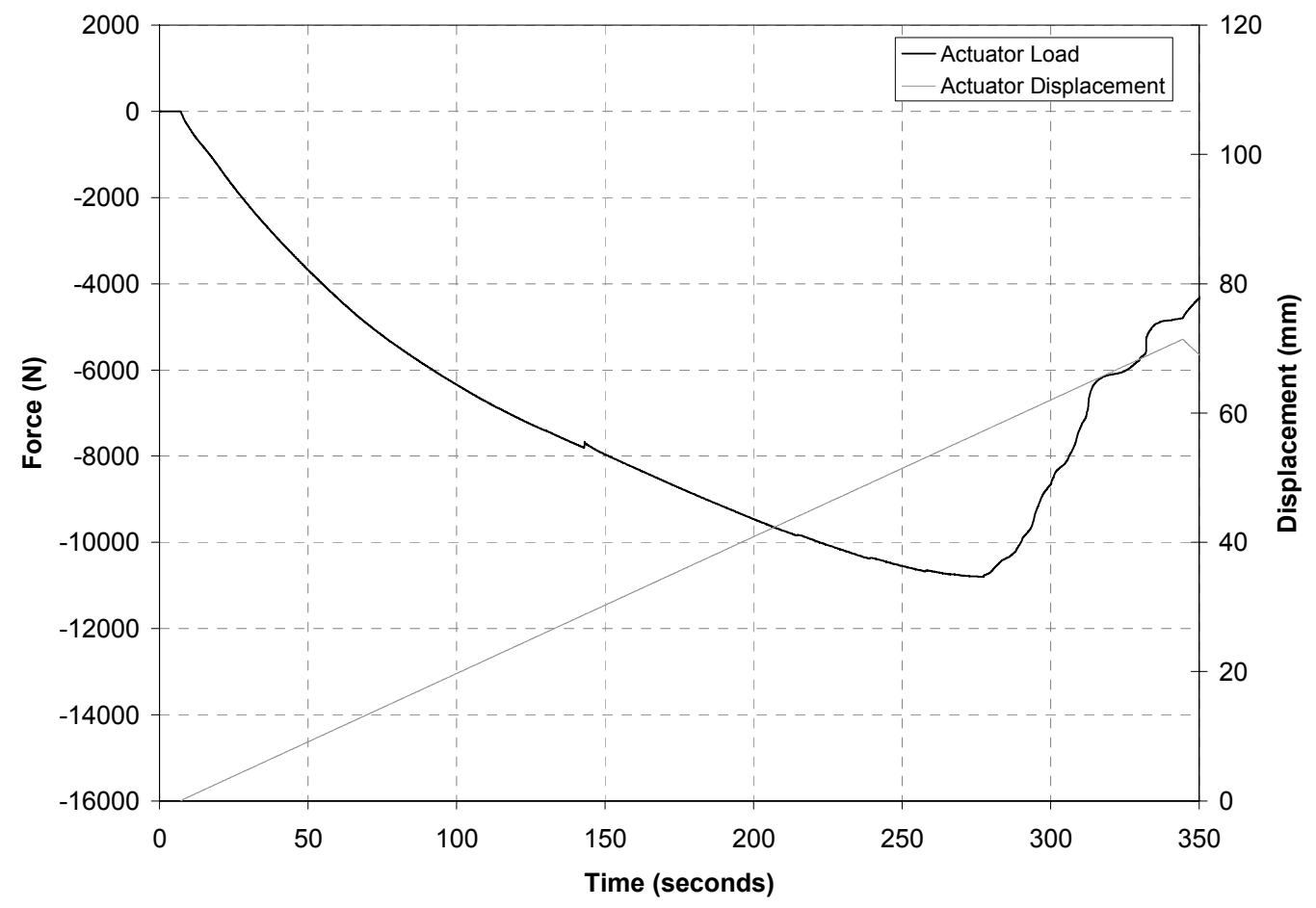

Figure 4.3. Lateral load applied to specimen with toe-nailed connections. 


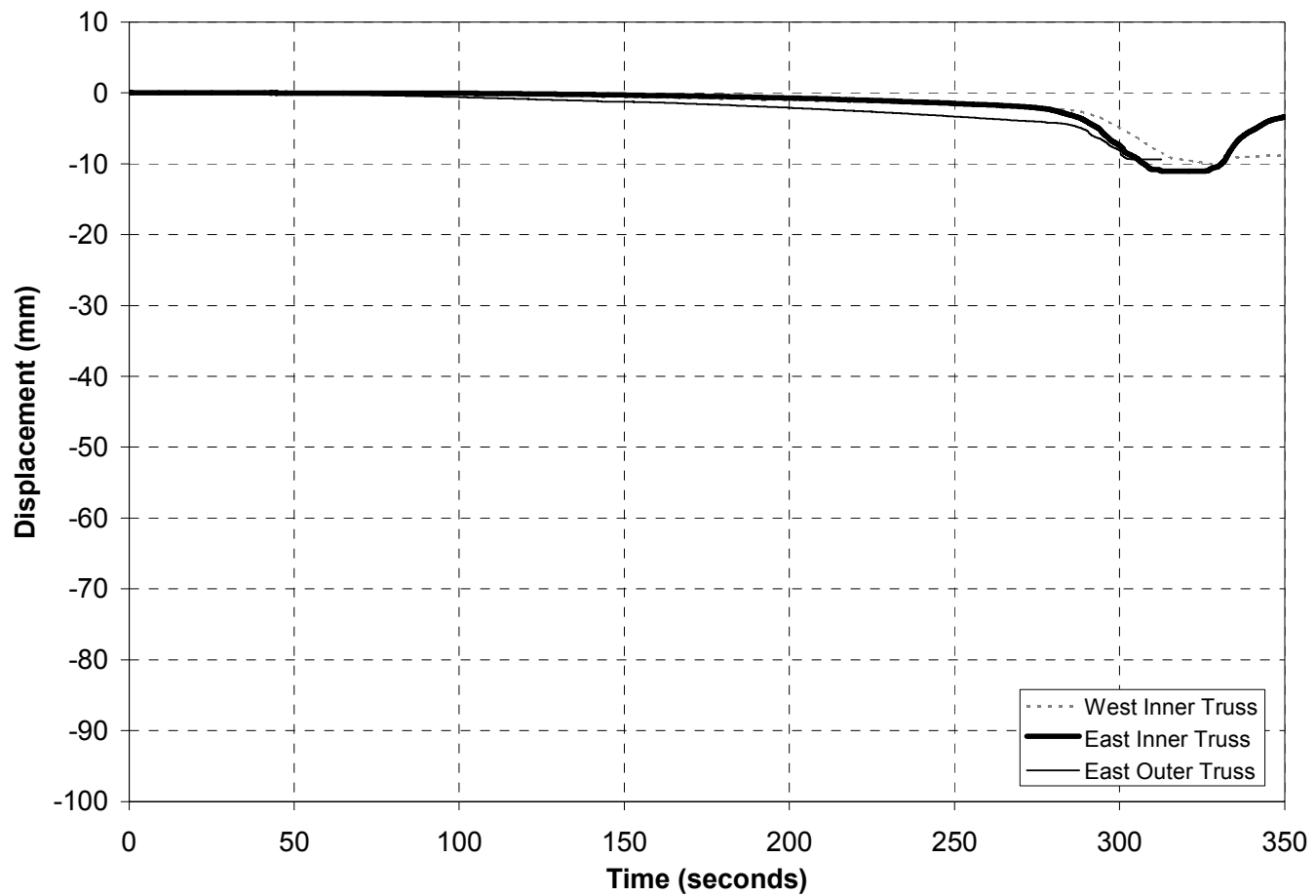

Figure 4.4. Lateral displacement responses for trusses with toe-nailed connections.

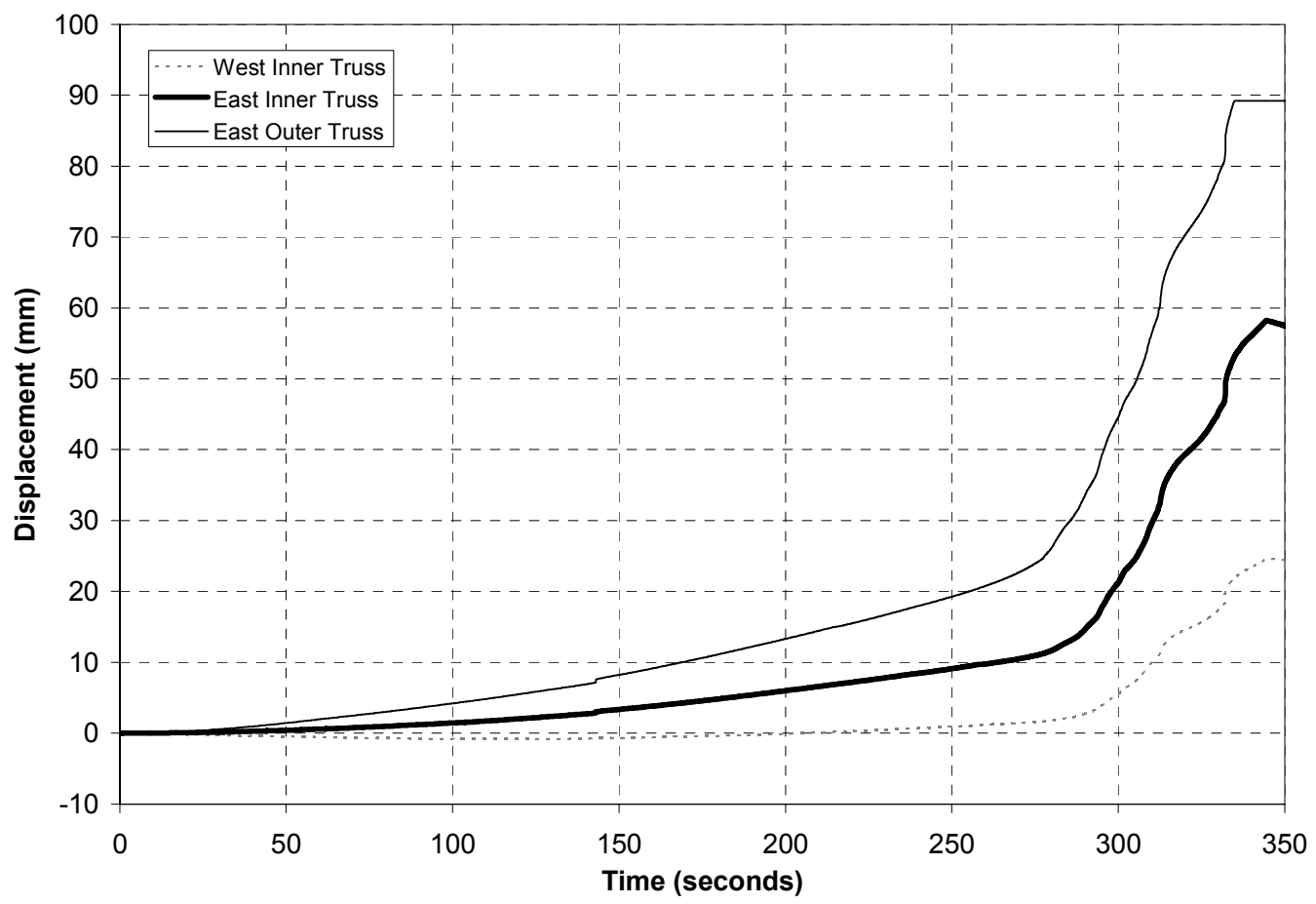

Figure 4.5. Uplift displacement responses for trusses with toe-nailed connections. 


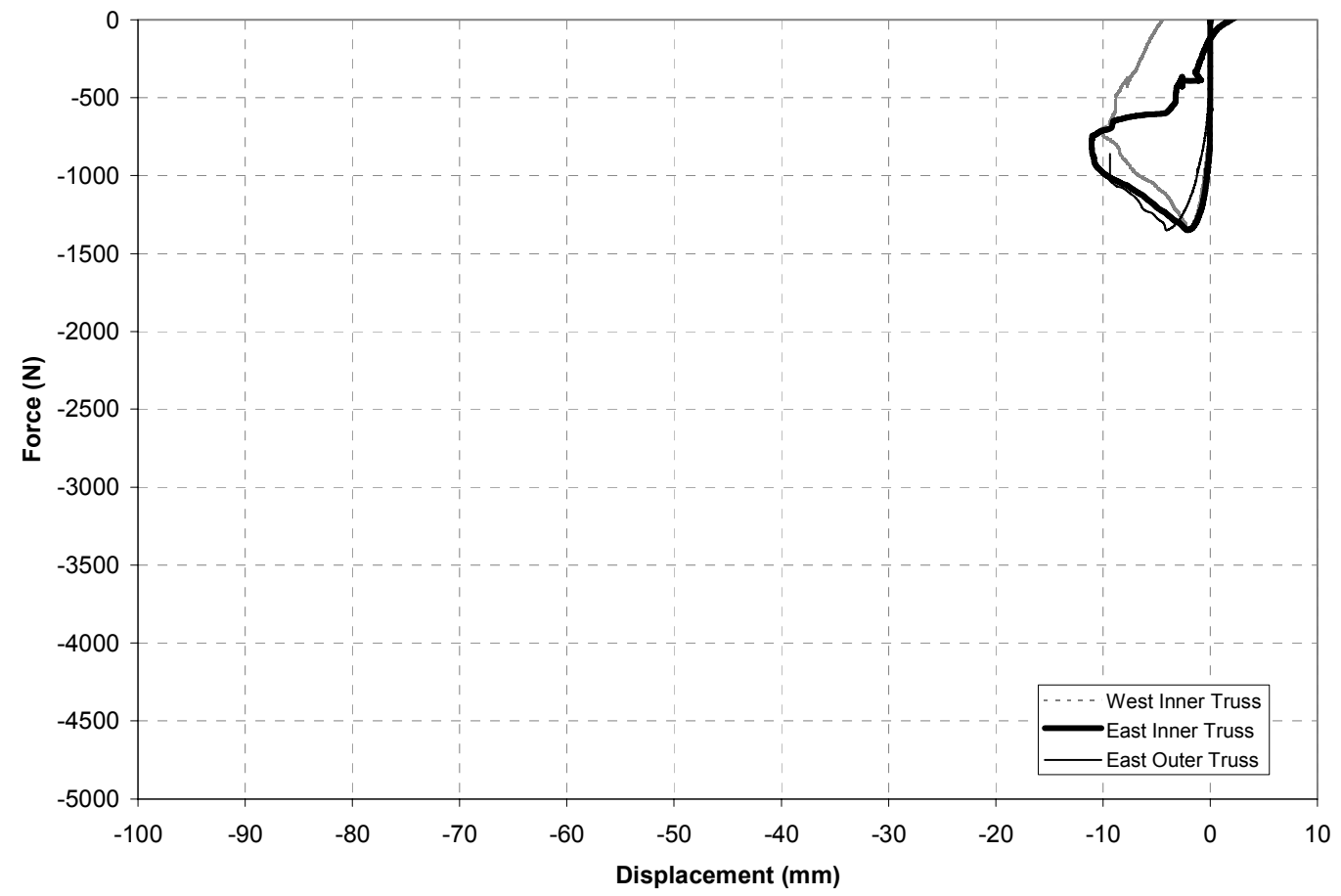

Figure 4.6. Lateral force-displacement responses for trusses with toe-nailed connections.

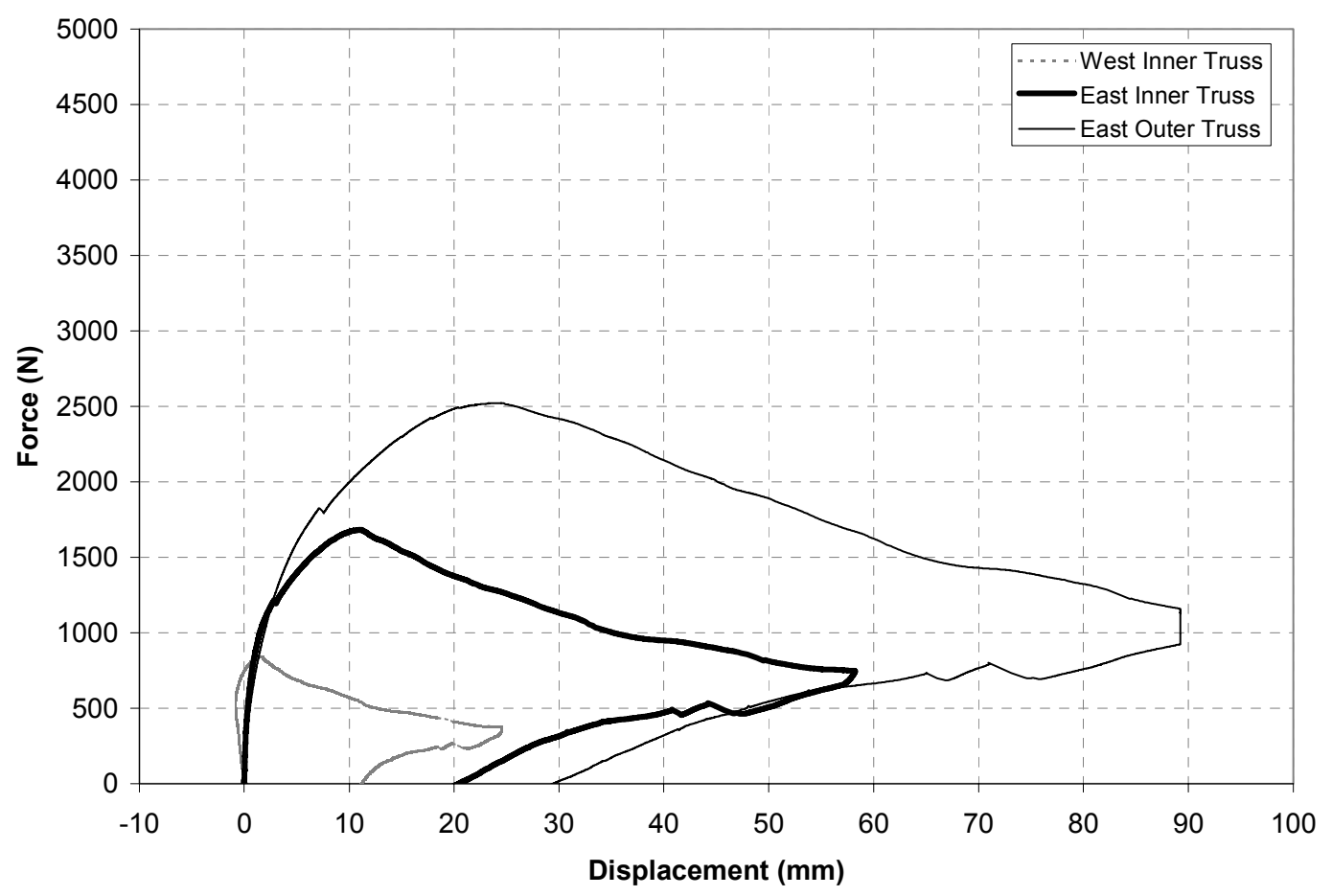

Figure 4.7. Uplift force-displacement responses for trusses with toe-nailed connections. 


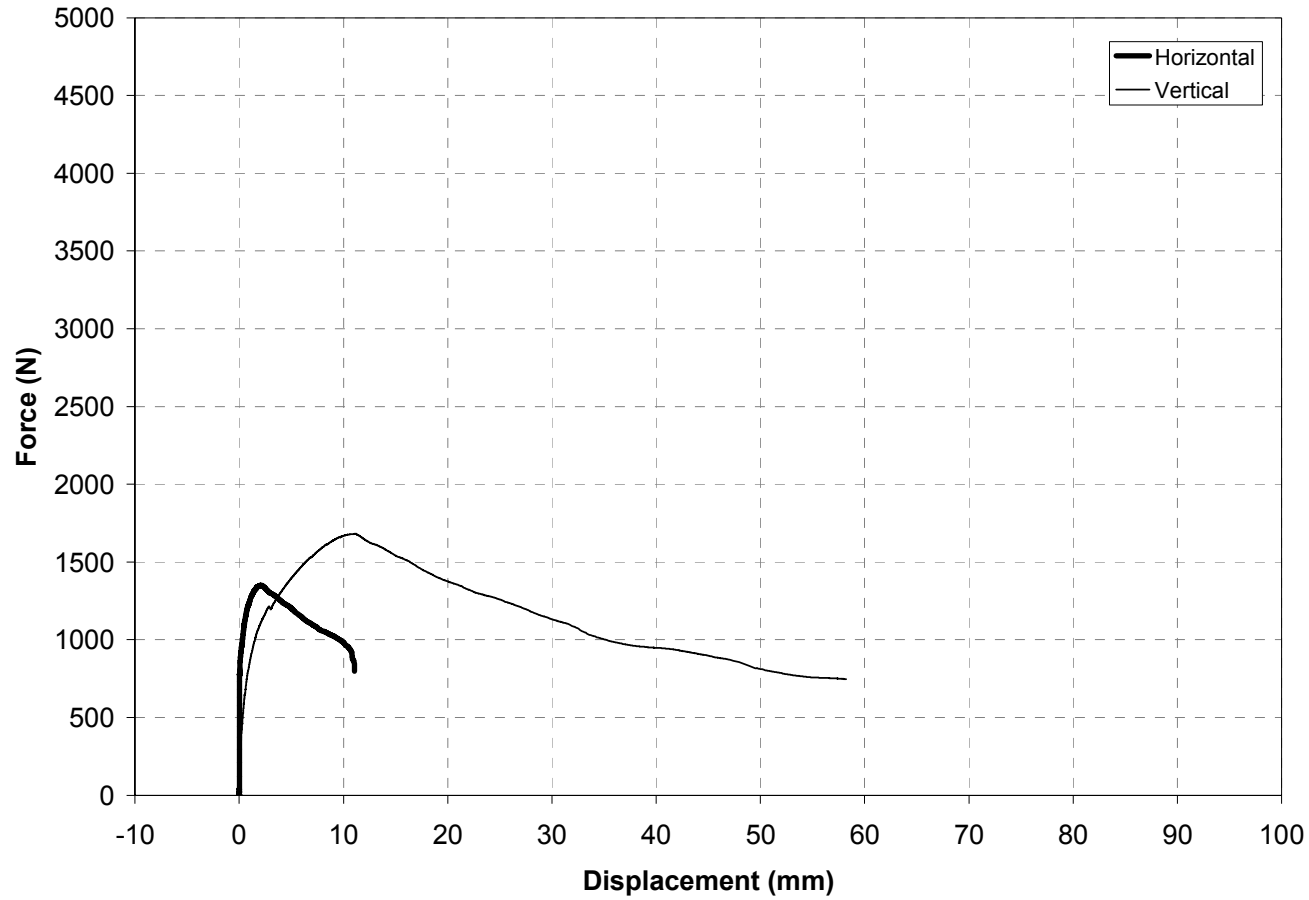

Figure 4.8. Comparison of lateral and vertical responses for inner truss with toe-nailed connections.

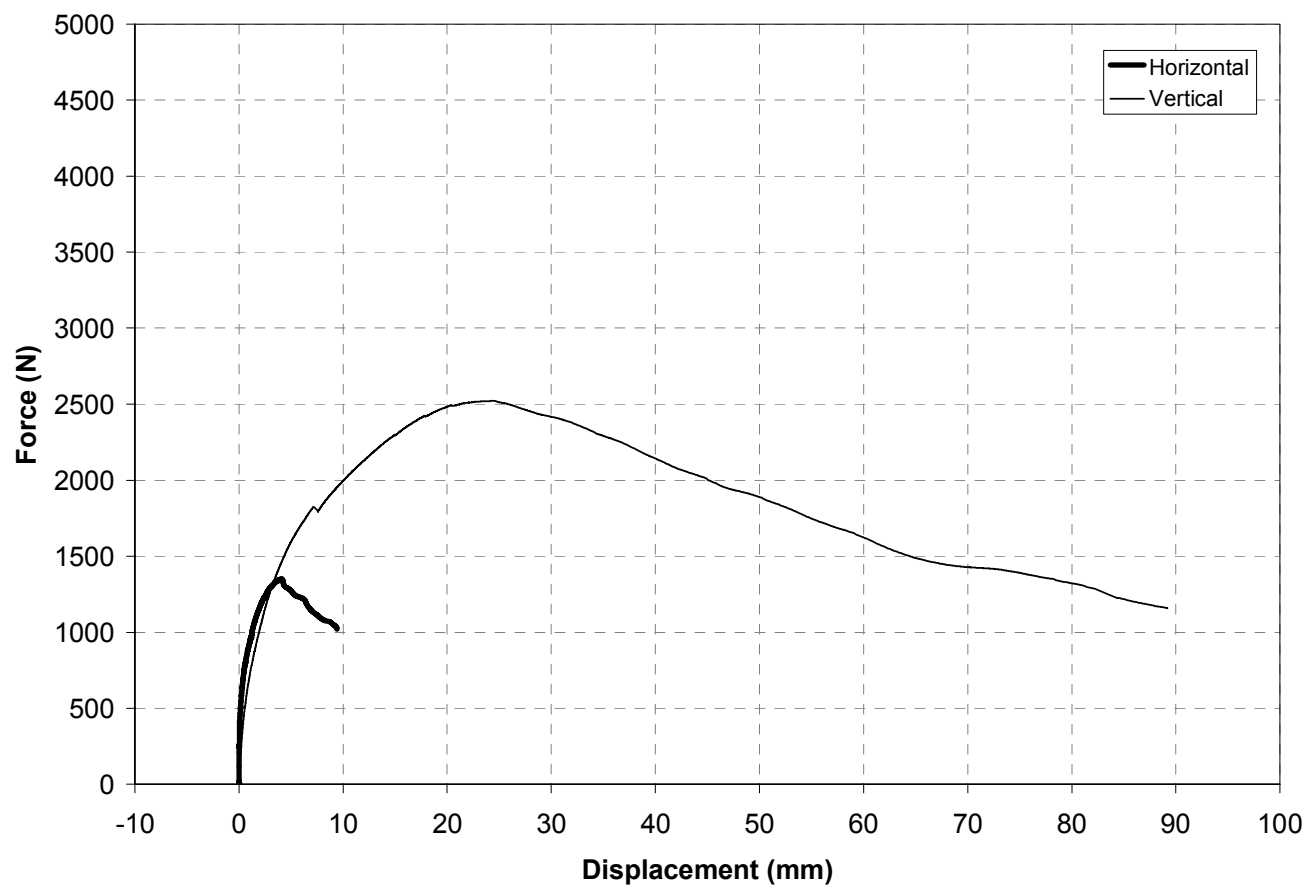

Figure 4.9. Comparison of lateral and vertical responses for outer truss with toe-nailed connections. 


\subsection{Comparison of Responses}

A direct comparison of the responses at the inner trusses with the two types of connections is shown in Figure 4.19, while the responses at the outer trusses are shown in Figure 4.20. The behavior of both of these types of connections is highly nonlinear, with most of the deformation occurring in the vertical direction. These figures clearly show that the hurricane clip connections have a significantly higher capacity for both uplift and shear. As in the case of the monotonic uplift loading, the residual strength of the hurricane clip connection tended to be similar to or greater than the capacity of the toe-nailed connection.

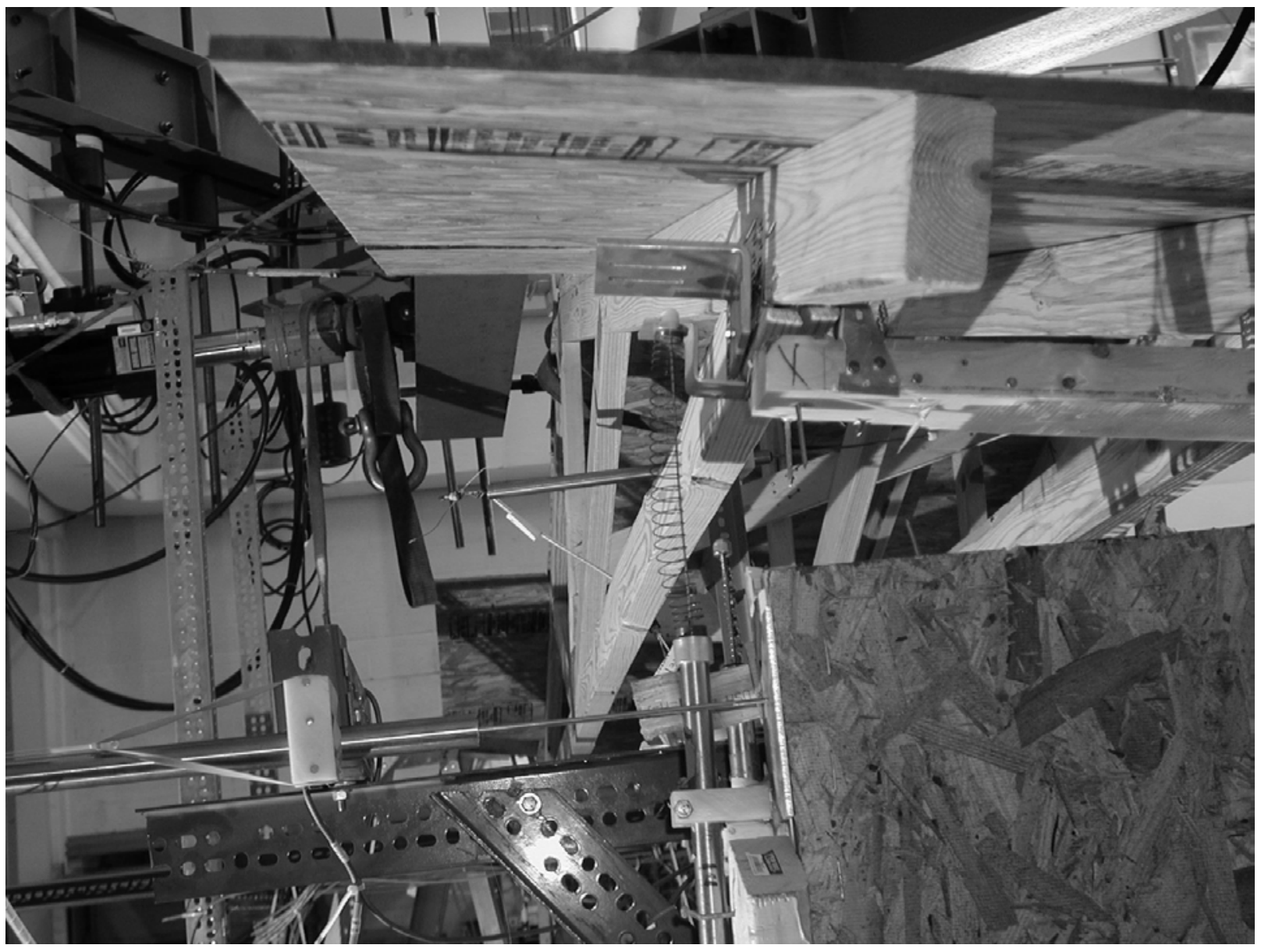

Figure 4.10. Failure of hurricane clip connection with lateral load. 


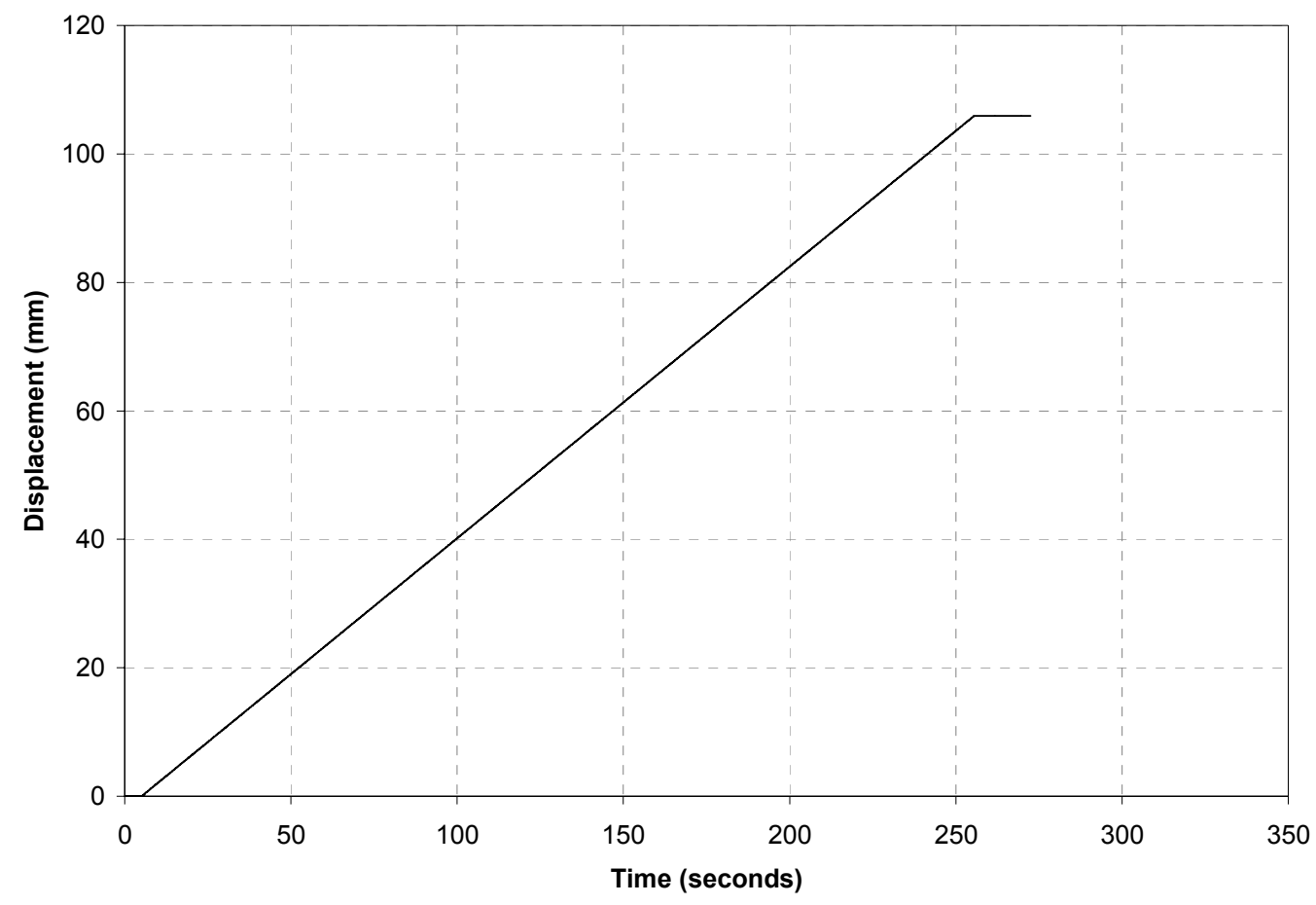

Figure 4.11. Lateral displacement applied to specimen with hurricane clips

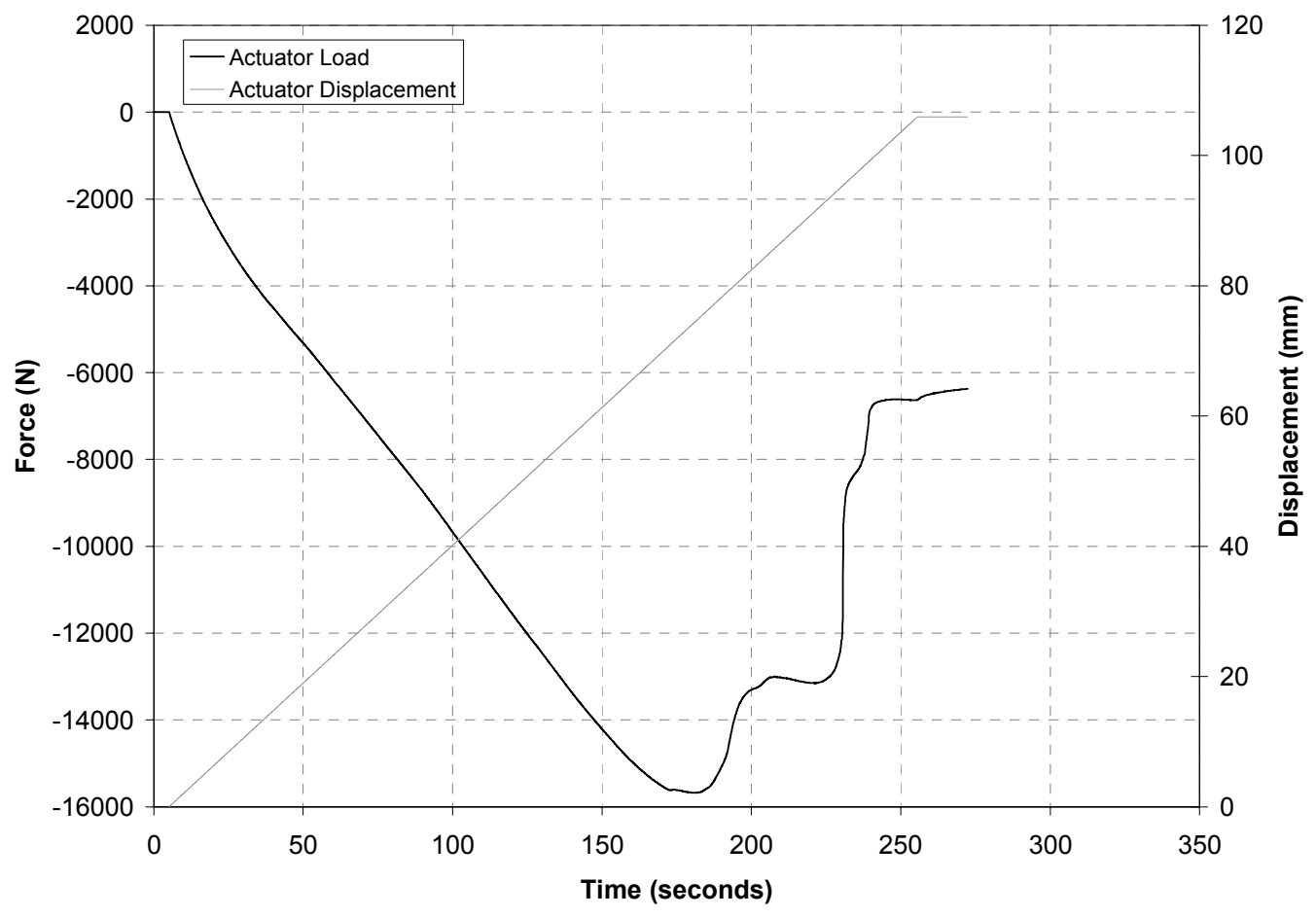

Figure 4.12. Lateral load applied to specimen with hurricane clips 


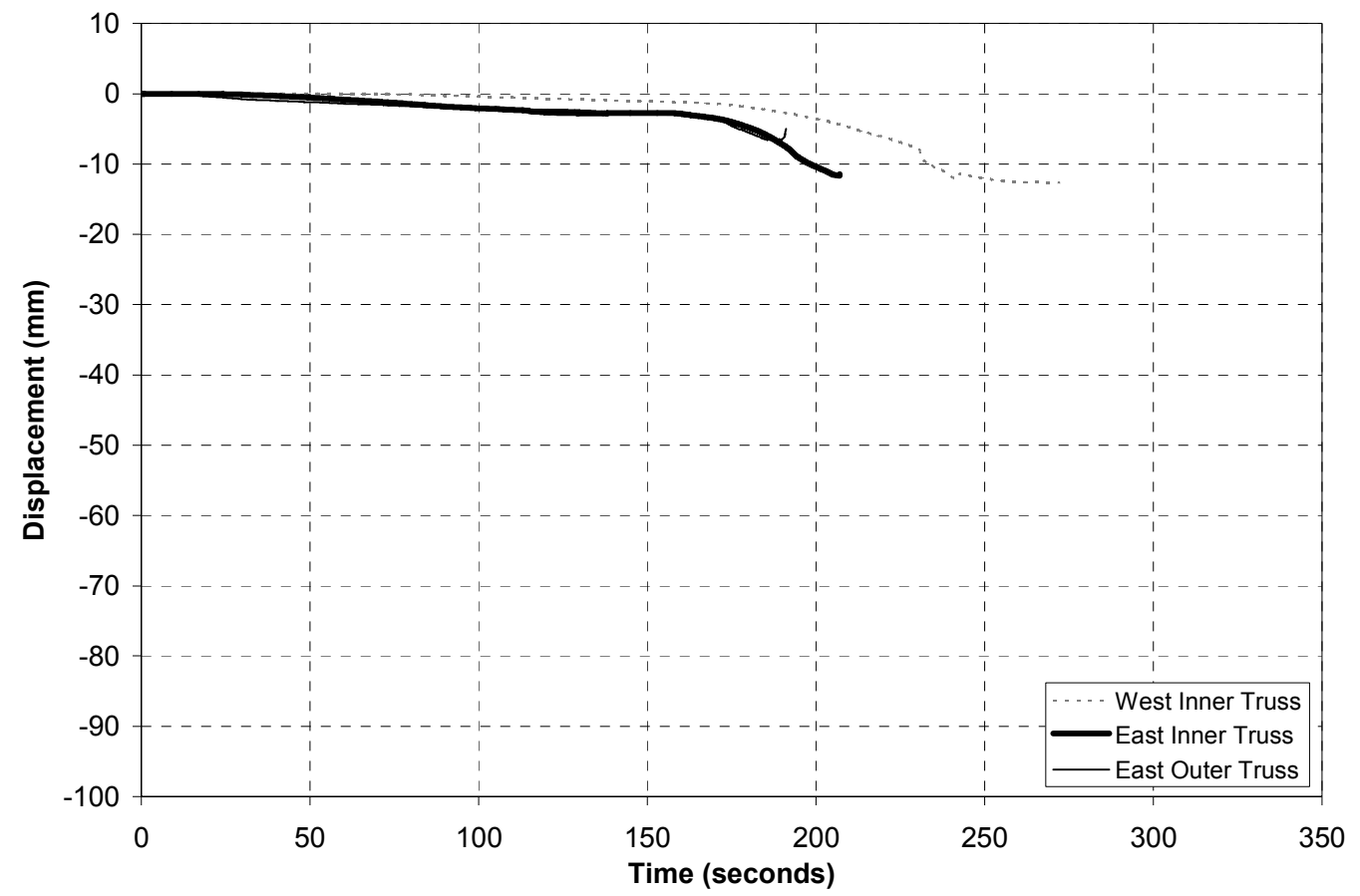

Figure 4.13. Lateral displacement responses for trusses with hurricane clips.

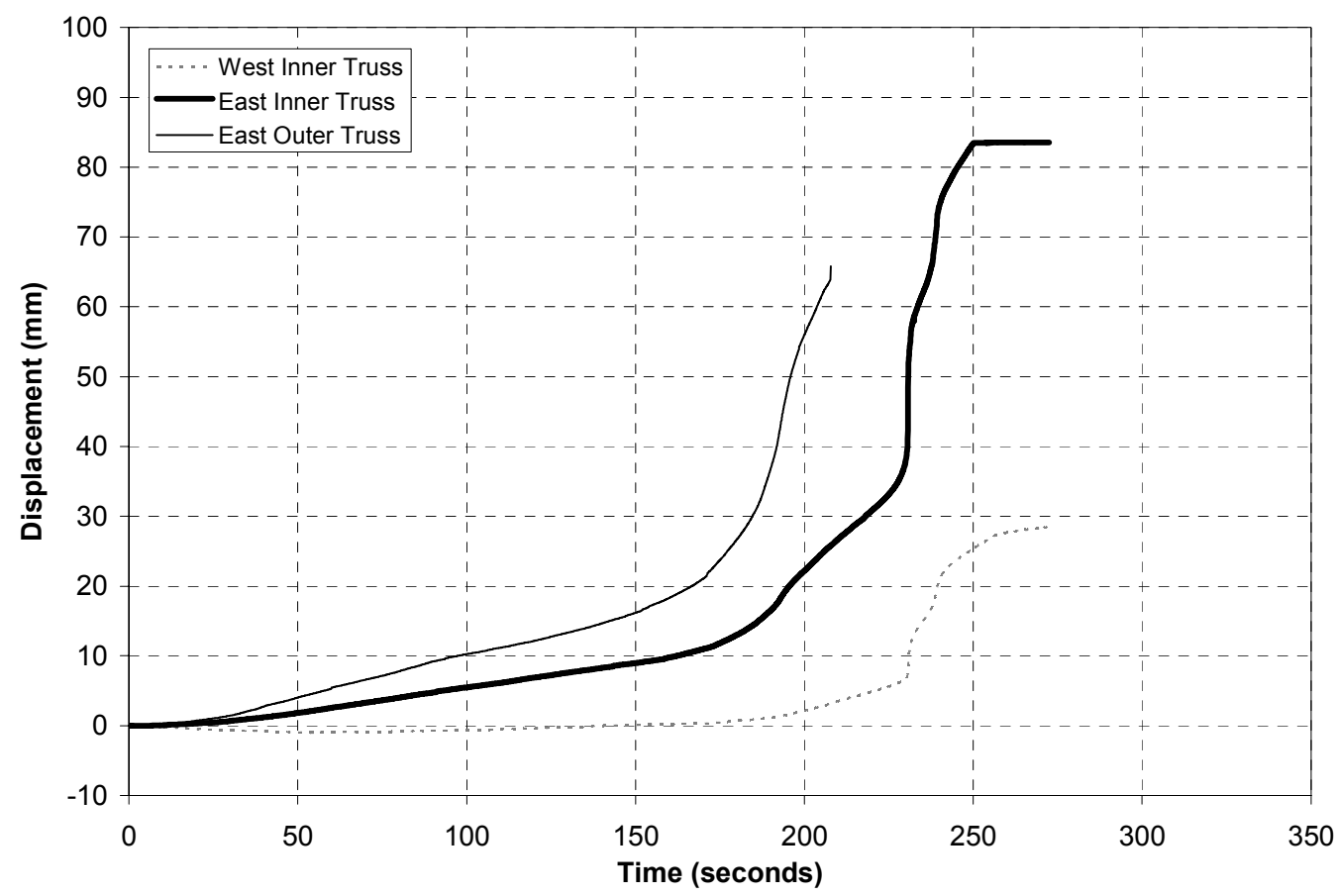

Figure 4.14. Uplift displacement responses for trusses with hurricane clips. 


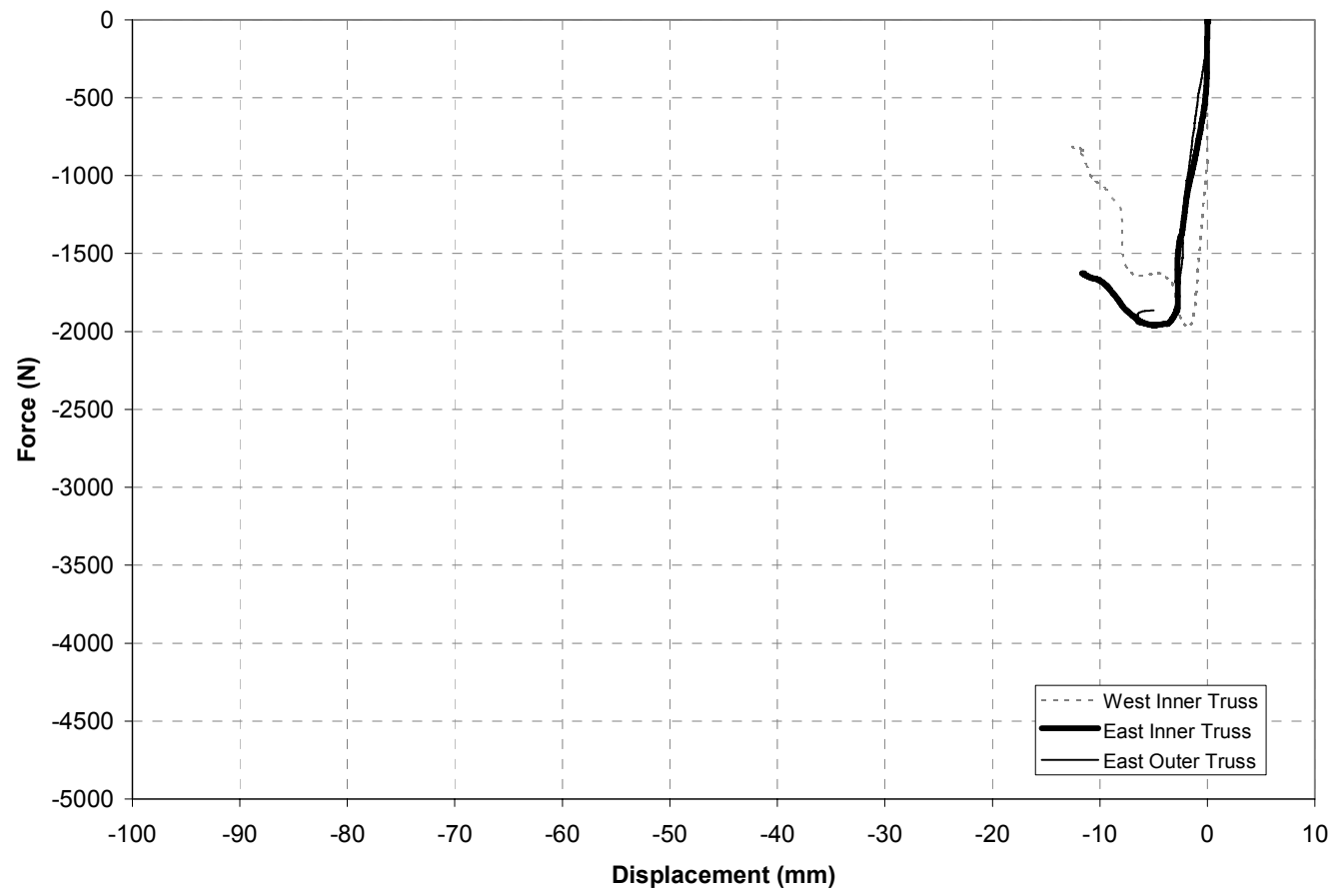

Figure 4.15. Lateral force-displacement responses for trusses with hurricane clips.

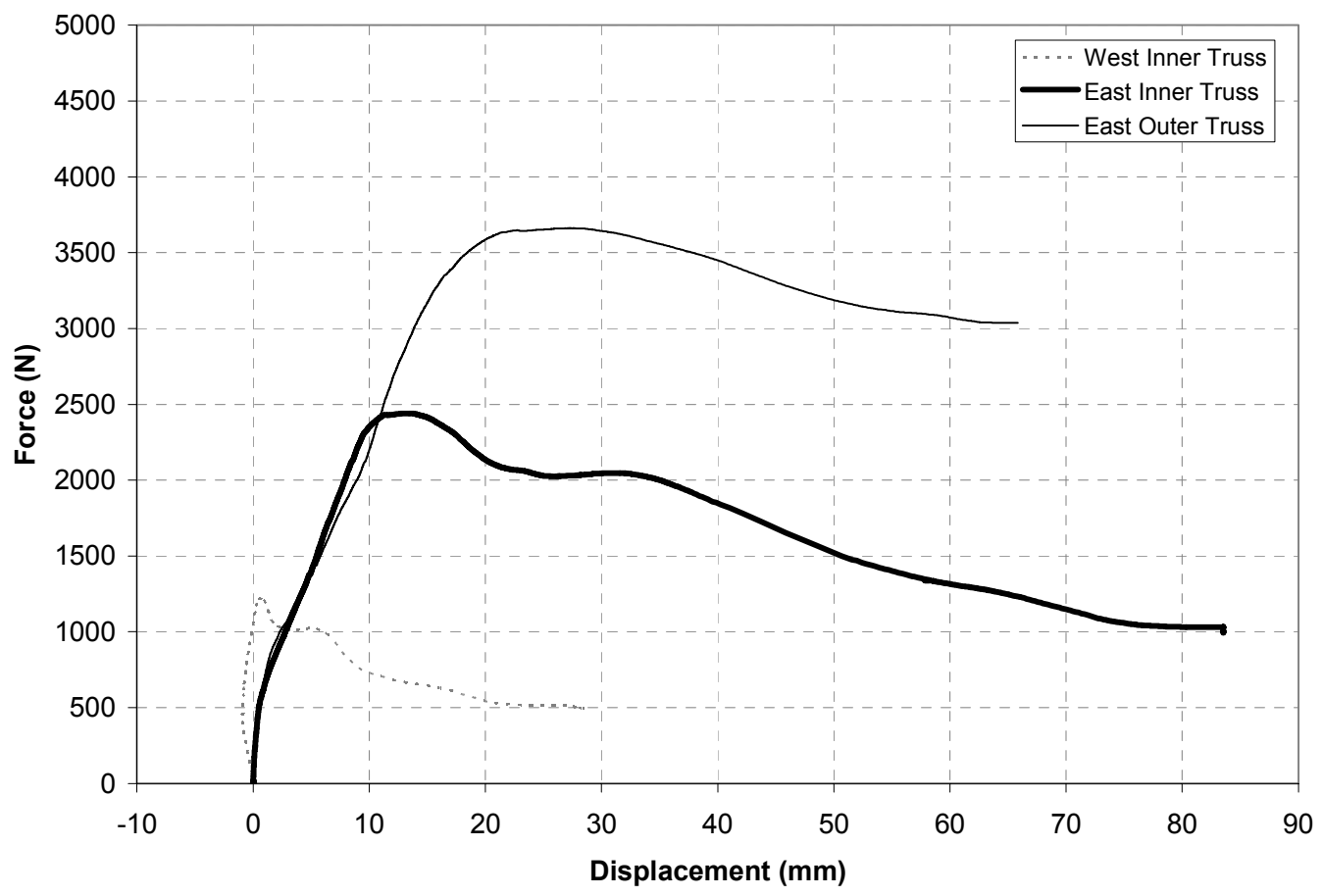

Figure 4.16. Uplift force-displacement responses for trusses with hurricane clips. 


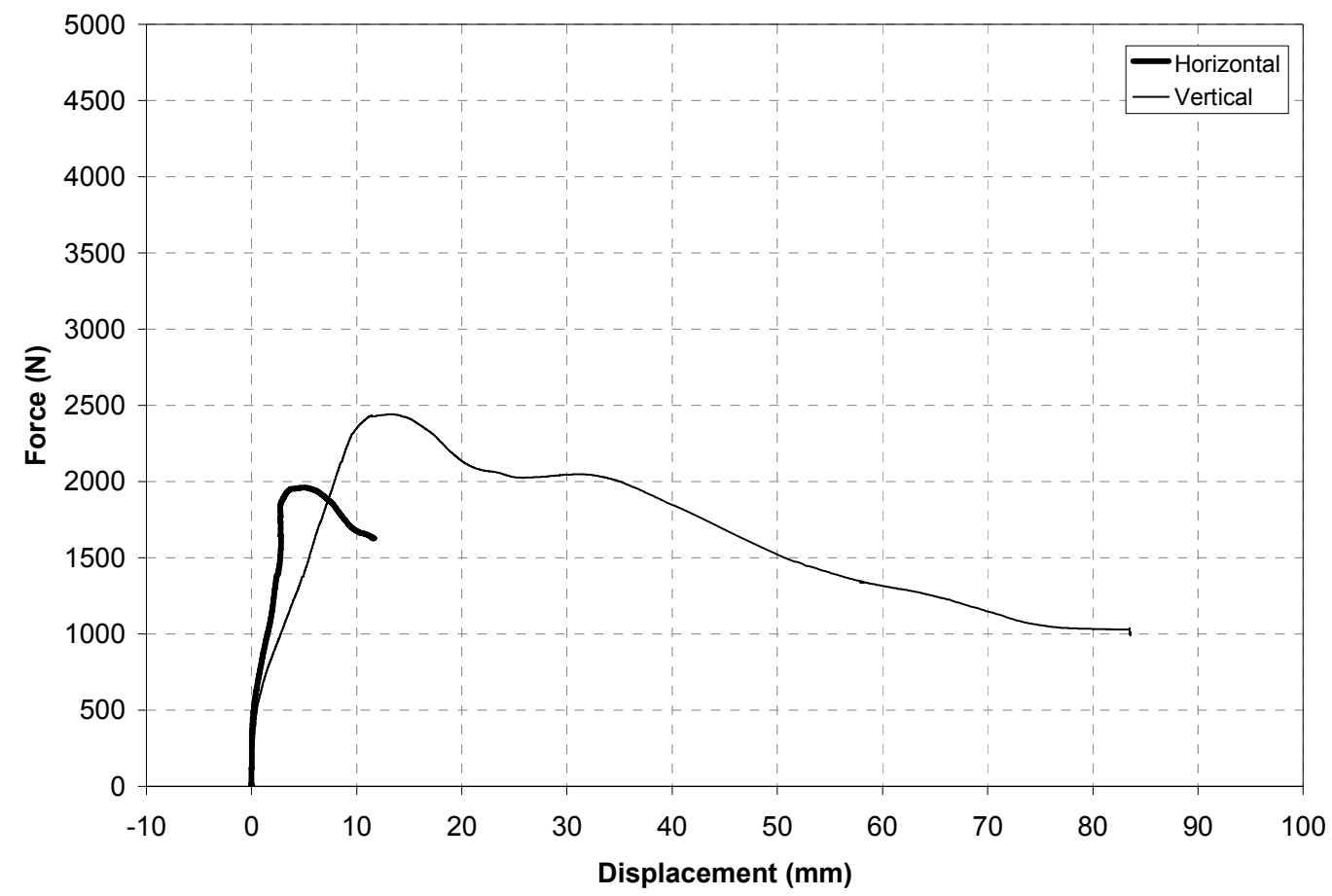

Figure 4.17. Lateral and vertical responses for inner truss with hurricane clips.

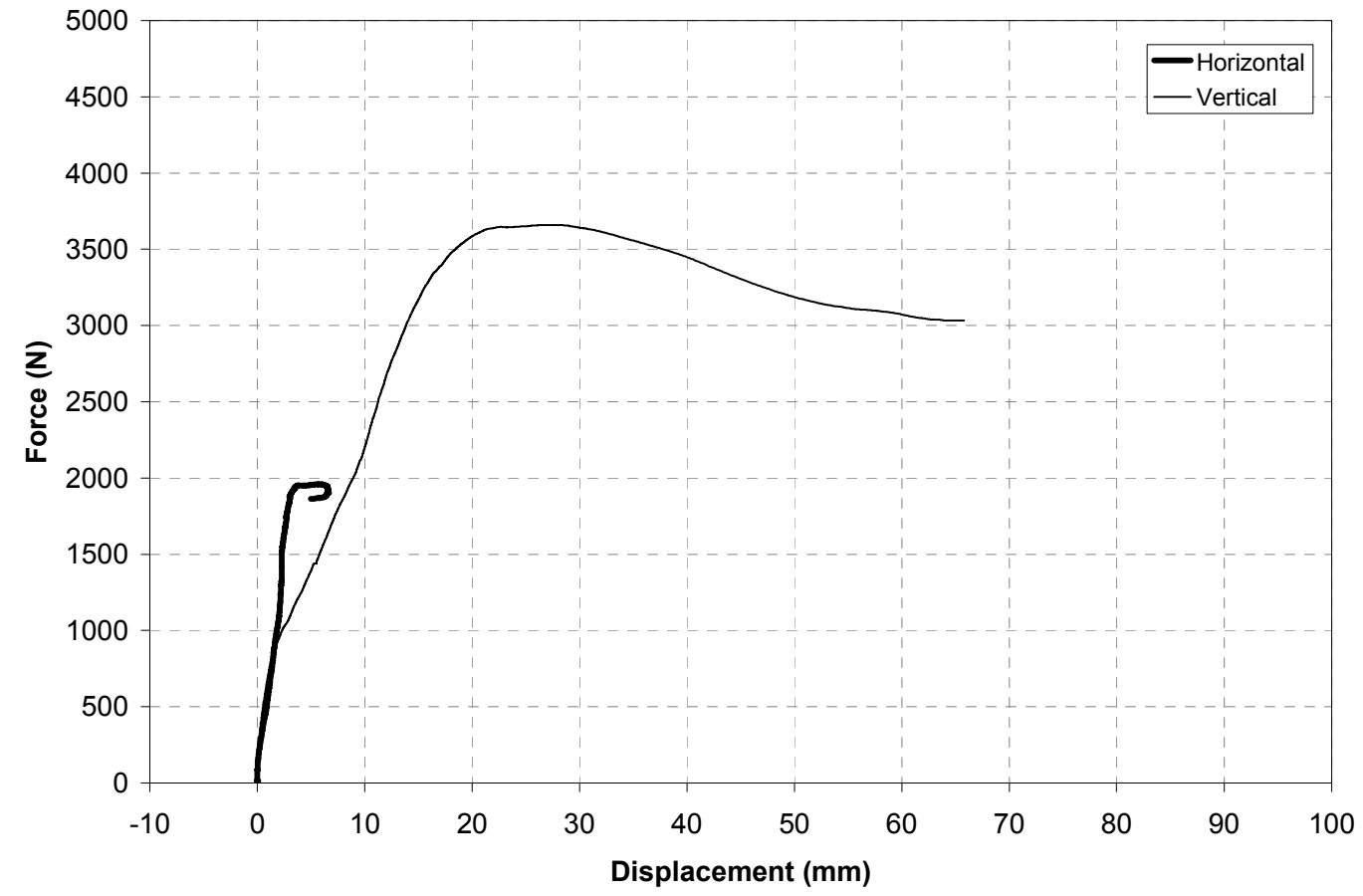

Figure 4.18. Lateral and vertical responses for outer truss with hurricane clips. 


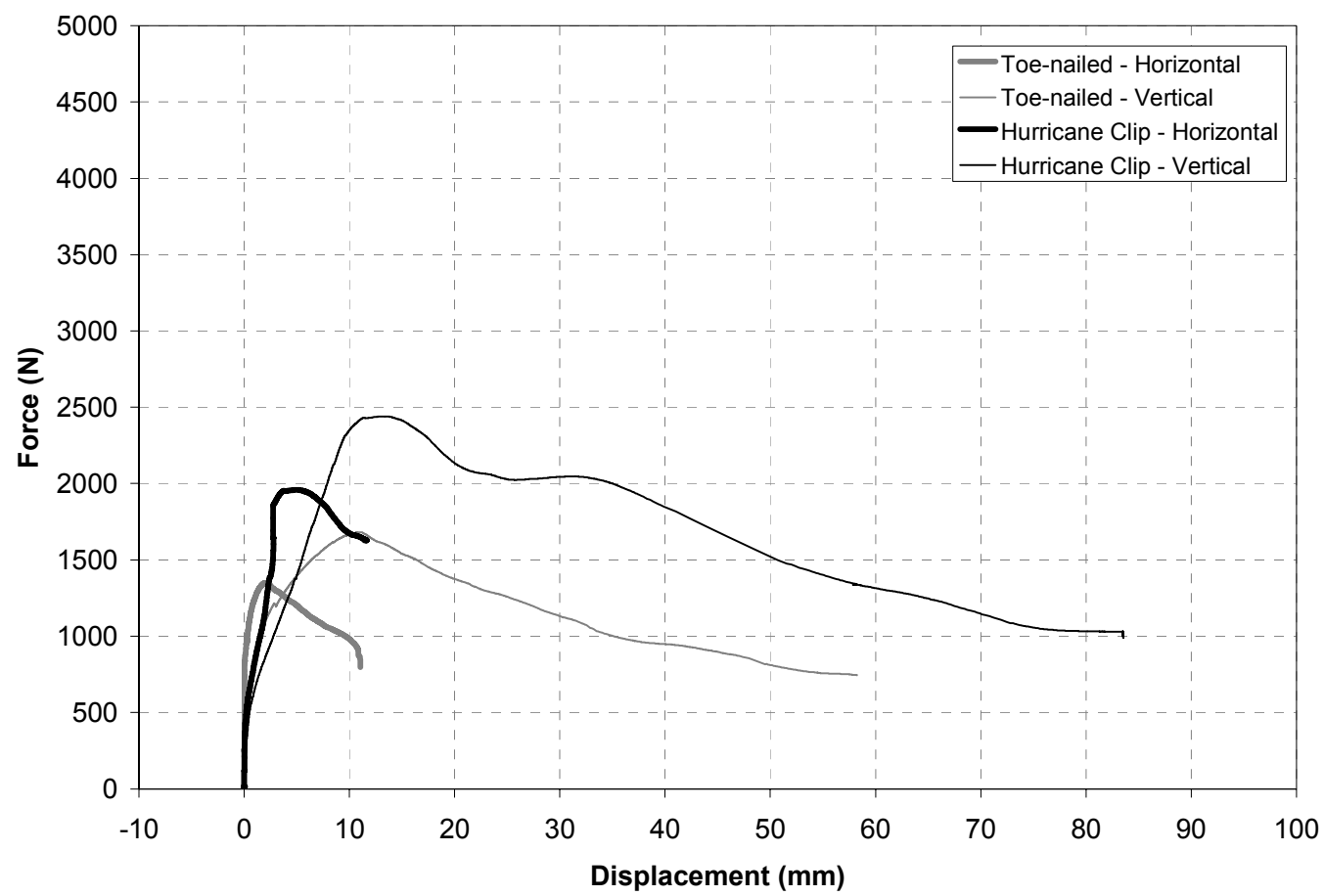

Figure 4.19. Comparison of responses of inner trusses.

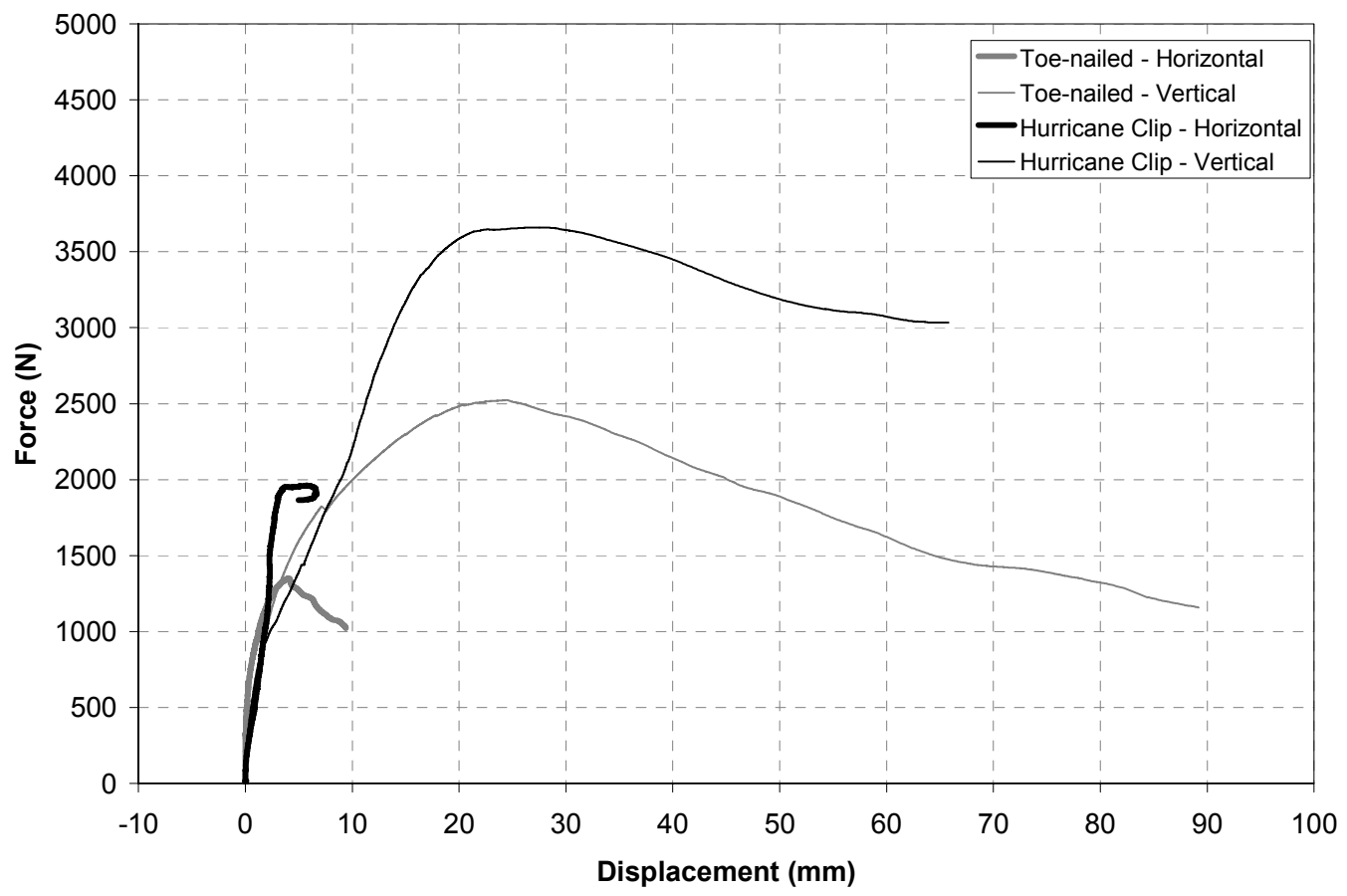

Figure 4.20. Comparison of responses of outer trusses. 


\section{Results of Cyclic Lateral load Tests}

Two specimens were tested with a cyclic lateral load to determine their response to an earthquake type loading. Again in one specimen the bottom chords of the roof trusses were connected to the walls with toe-nailed connections, while in the other specimen hurricane clips were used.

\subsection{Response with Toe-nailed Con- nections}

For the specimen with toe-nailed connections, the waveform described in section 2.4, was applied with a cycle period of $30 \mathrm{~s}$ and the unit amplitude of the generic waveform scaled to $32.24 \mathrm{~mm}$ (1.466 in). The resulting displacement curve is shown in Figure 5.2, and the resulting load is shown in Figure 5.3. Although the specimen's stiffness decreased during the test, the specimen resistance continued to increase until the final large cycle of motion, about $1220 \mathrm{~s}$ into the test. At this point, the connections at tension end of the specimen pulled free of the top plate. This failure can be seen in Figure 5.1. As in the case of the previous tests with the toe-nailed connections, the failure was due to the nails withdrawing from the top plate. This failure resulted in some wood splitting in the top plate of the wall, but little damage to the wood of the trusses.

The lateral deformations in the toe-nailed connections of four connections for three of the trusses are shown in Figure 5.4. Note that the failure occurred on the north side of the specimen, so three of the four curves represent the non-failing response. From this figure it can be noted that the outer truss connection on the south side, which did not completely fail, began to deform significantly after about $600 \mathrm{~s}$. The inner truss connection on the north side had relatively moderate shear deformations until the last cycle before it failed.
The corresponding uplift deformations in the connections are shown in Figure 5.5. From these results it is clear that the connections were more flexible in tension, and that both the outer truss connection on the south side and the inner truss connection on the north side began to deform more than the other connections after about $600 \mathrm{~s}$.

The corresponding force-displacement responses are shown in Figures 5.6 and 5.7. The responses of all four connections exhibit significant hysteresis, indicating that these connections would dissipate a significant amount of seismic energy before failure. For all connections except the east outer truss connection, the envelopes of the lateral and uplift responses during this test were similar to the responses observed during the monotonic lateral load test. However, the east connection on the outer truss exhibited more lateral deformation and less lateral stiffness than the other connections, while carrying more vertical load than was typical in prior tests.

\subsection{Response with Hurricane Clips}

For the specimen with hurricane clips, the waveform described in section 2.4, was applied with a cycle period of $30 \mathrm{~s}$ and the unit amplitude of the generic waveform scaled to $50.19 \mathrm{~mm}$ (1.976 in), as can be observed in Figure 5.8. The load that resulted is shown in Figure 5.9. The specimen resisted the applied load with some degradation in stiffness, but increasing resistance, until the last large deformation cycle, which occurred approximately $1220 \mathrm{~s}$ into the test. At this point the specimen's north wall began to fail at the sill plate, with the studs and cladding pulling free of the sill. The hurricane clip connections had not yet failed when the test was stopped. 
The lateral deformations in the connections of three of the trusses are shown in Figure 5.10, and the uplift deformations in these connections are shown in Figure 5.11. While none of the connections failed, the responses shown in Figure 5.10 clearly indicate that the connection in the east inner truss may have begun to fail at about $950 \mathrm{~s}$ into the test. Based on the responses shown in both figures, it is clear that, as in the monotonic lateral load test, the hurricane clip connections were quite stiff in shear, but relatively flexible in tension.

The corresponding force displacement responses are shown in Figures 5.12 and 5.13. As in the case of the toe-nailed connections, the responses of all four connections shown in these figures exhibit significant hystere- sis. The east inner truss connection, which may have begun to fail early in the test, had the largest hysteresis. All of the connections responses had envelopes that were similar to the responses observed during the monotonic lateral load test. Since none of the connections failed entirely, the ultimate load capacity for the connections with this type of loading was not determined. However, it is clear for this load case the hurricane clips were stronger than the wall itself.

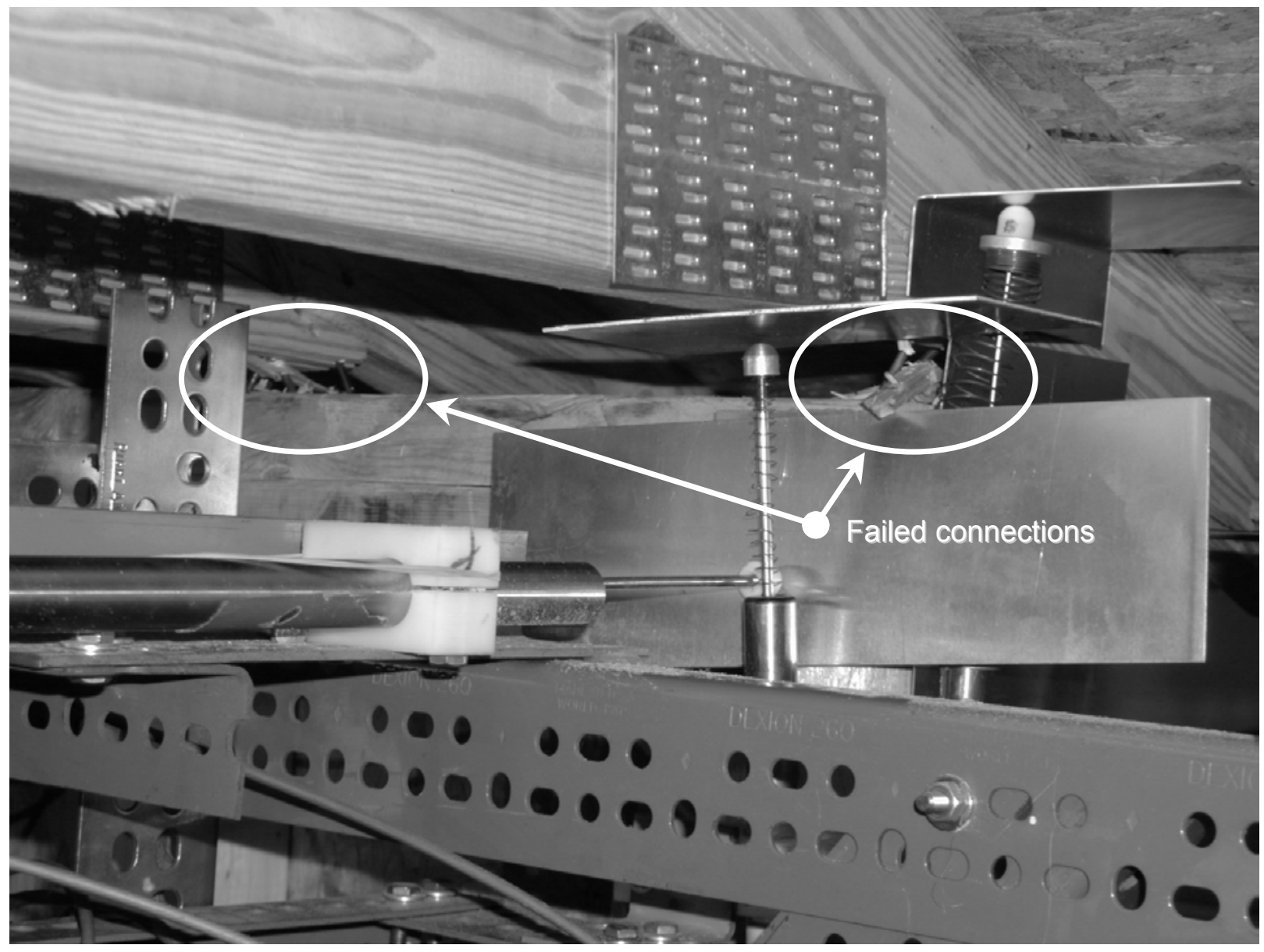

Figure 5.1. Failure of toe-nailed connection with cyclic load. 


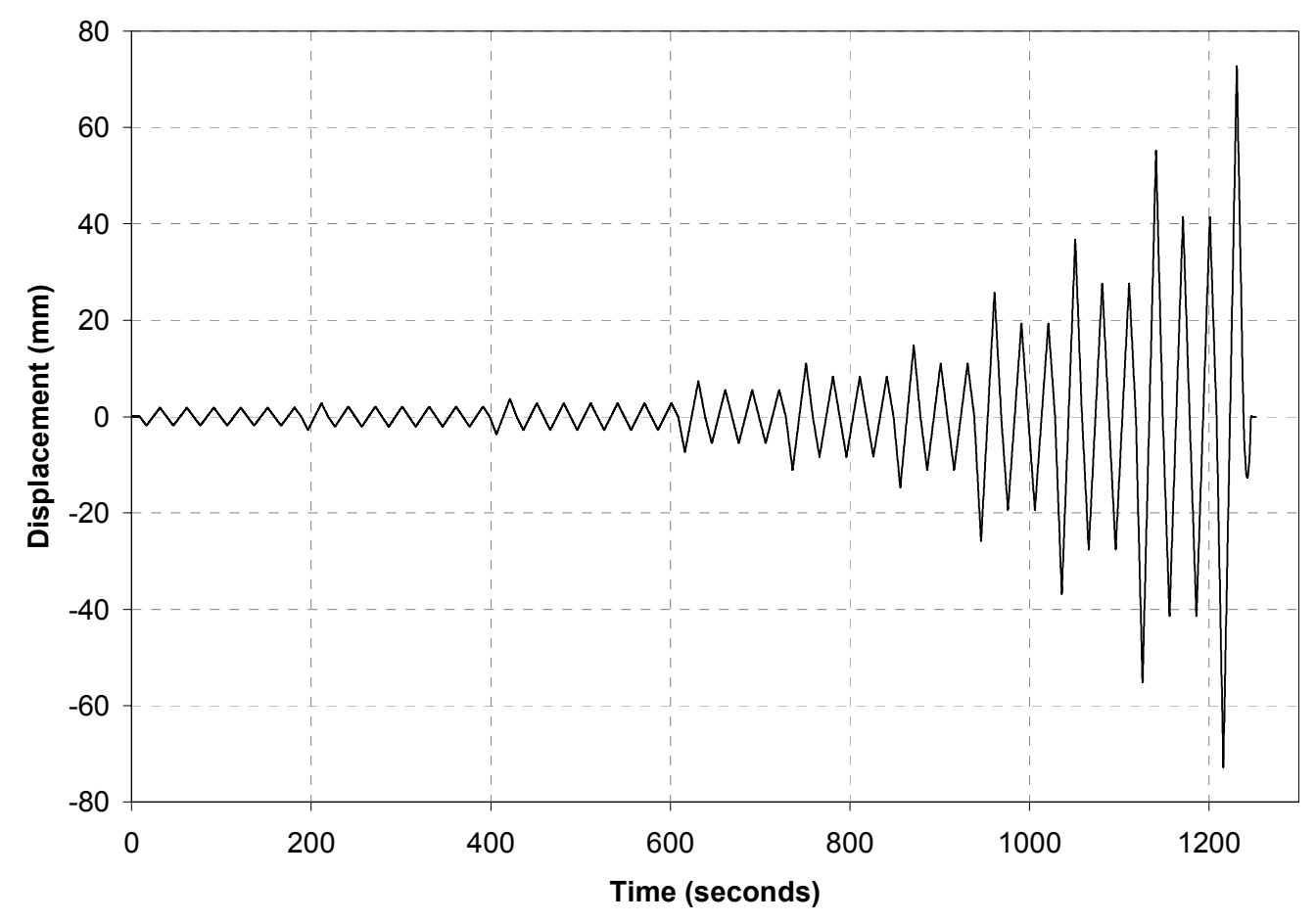

Figure 5.2. Lateral displacement applied to specimen with toe-nailed connections.

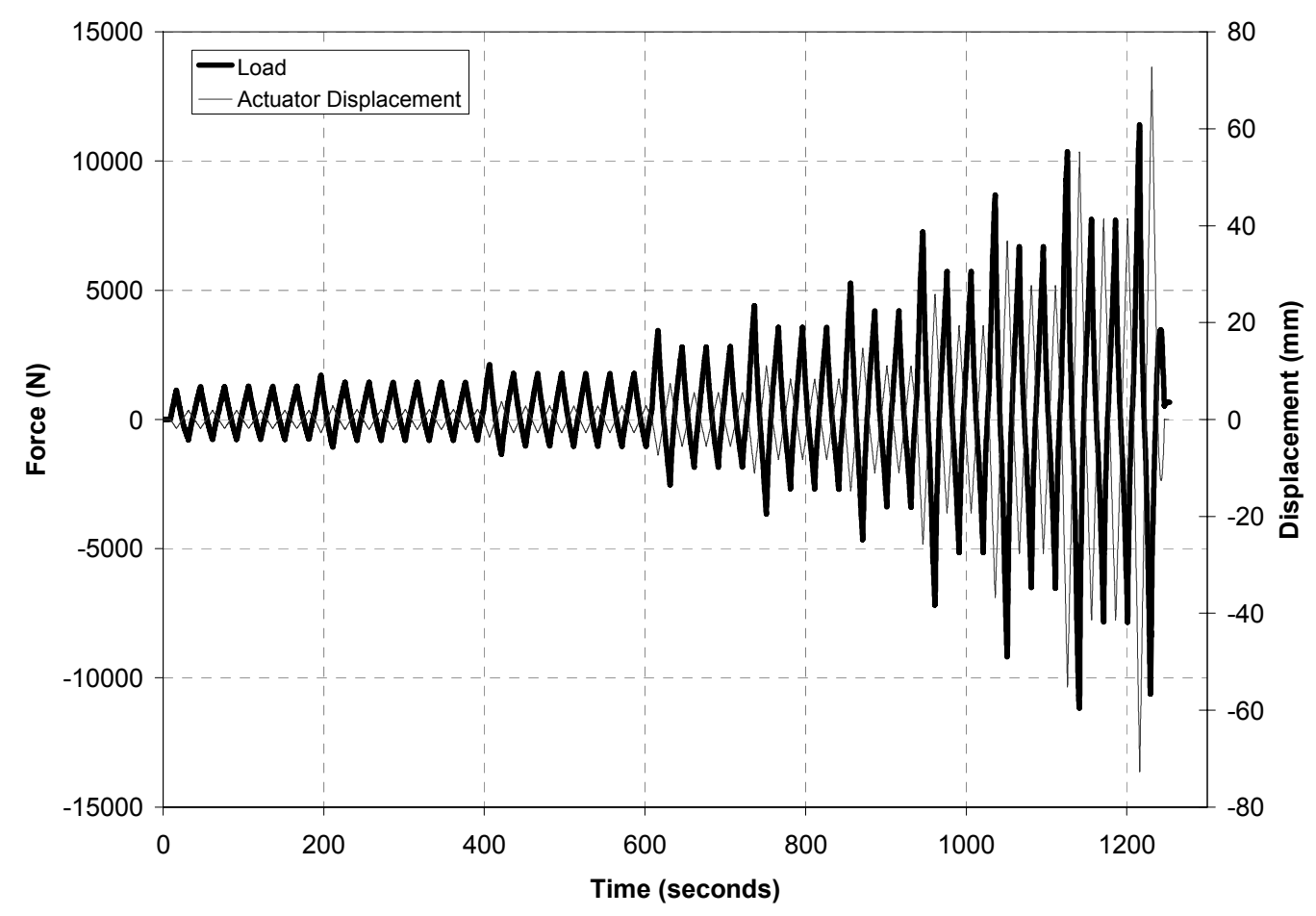

Figure 5.3. Lateral load applied to specimen with toe-nailed connections. 


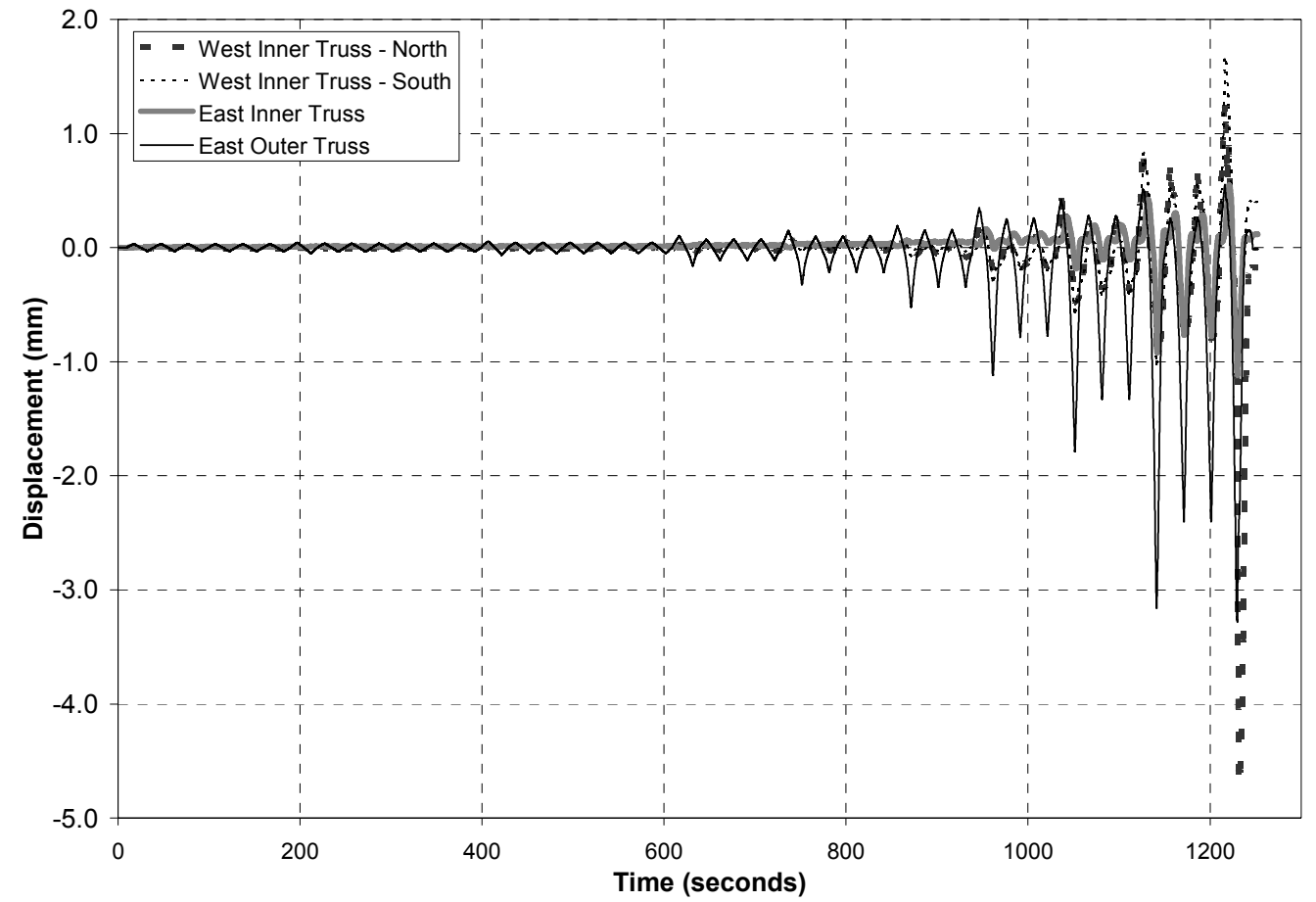

Figure 5.4. Lateral displacement responses for trusses with toe-nailed connections.

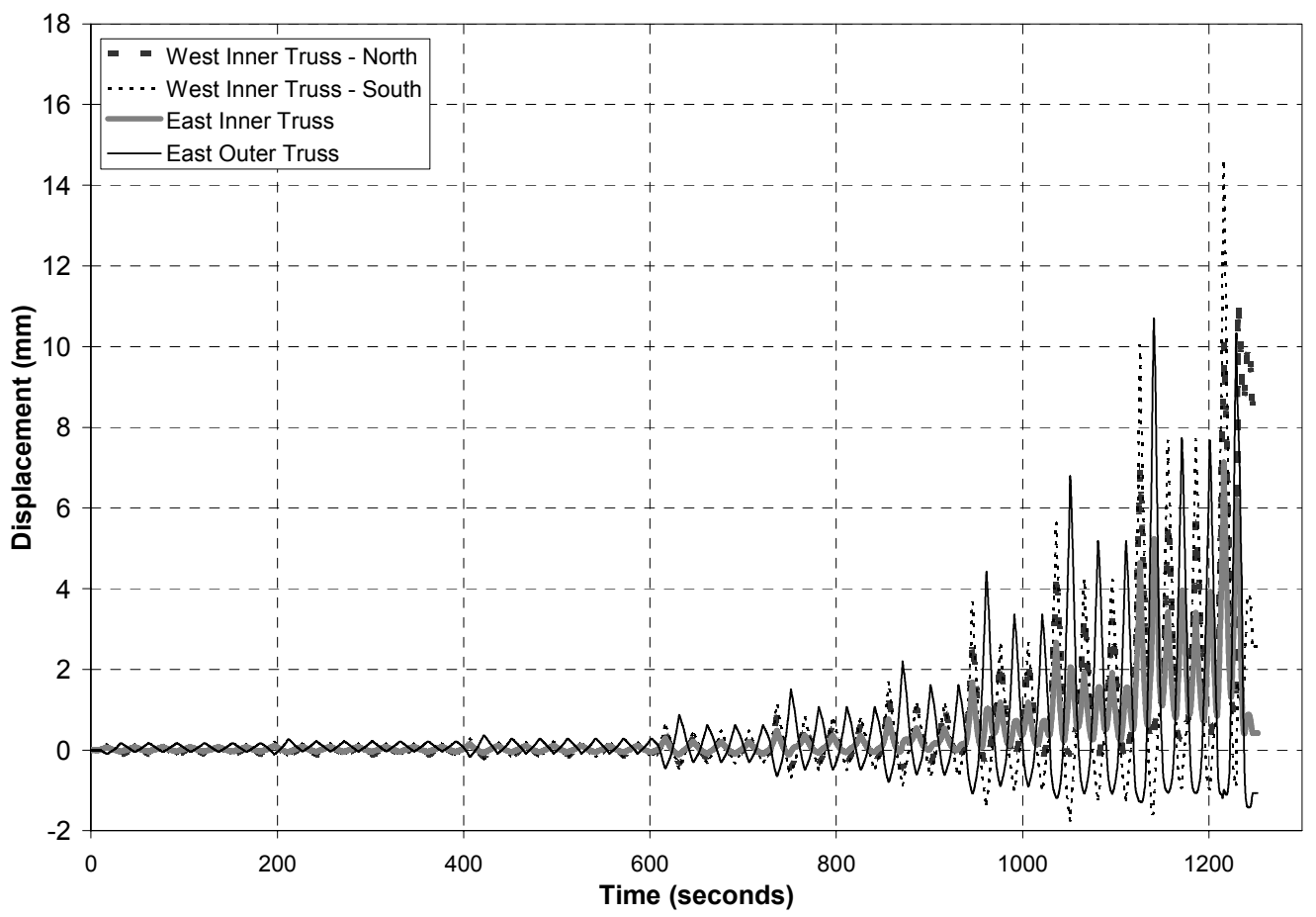

Figure 5.5. Uplift displacement responses for trusses with toe-nailed connections. 


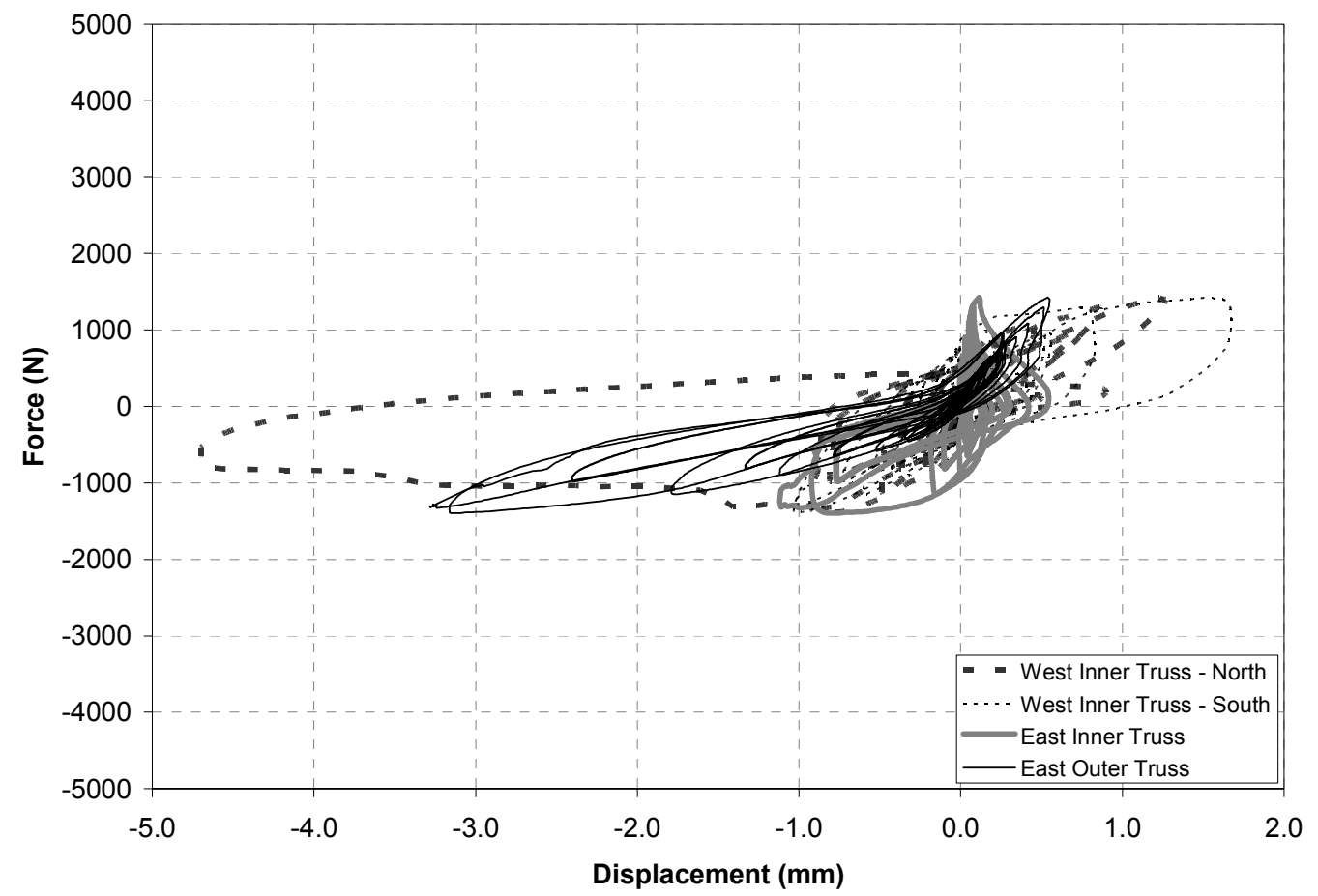

Figure 5.6. Lateral force-displacement responses for trusses with toe-nailed connections.

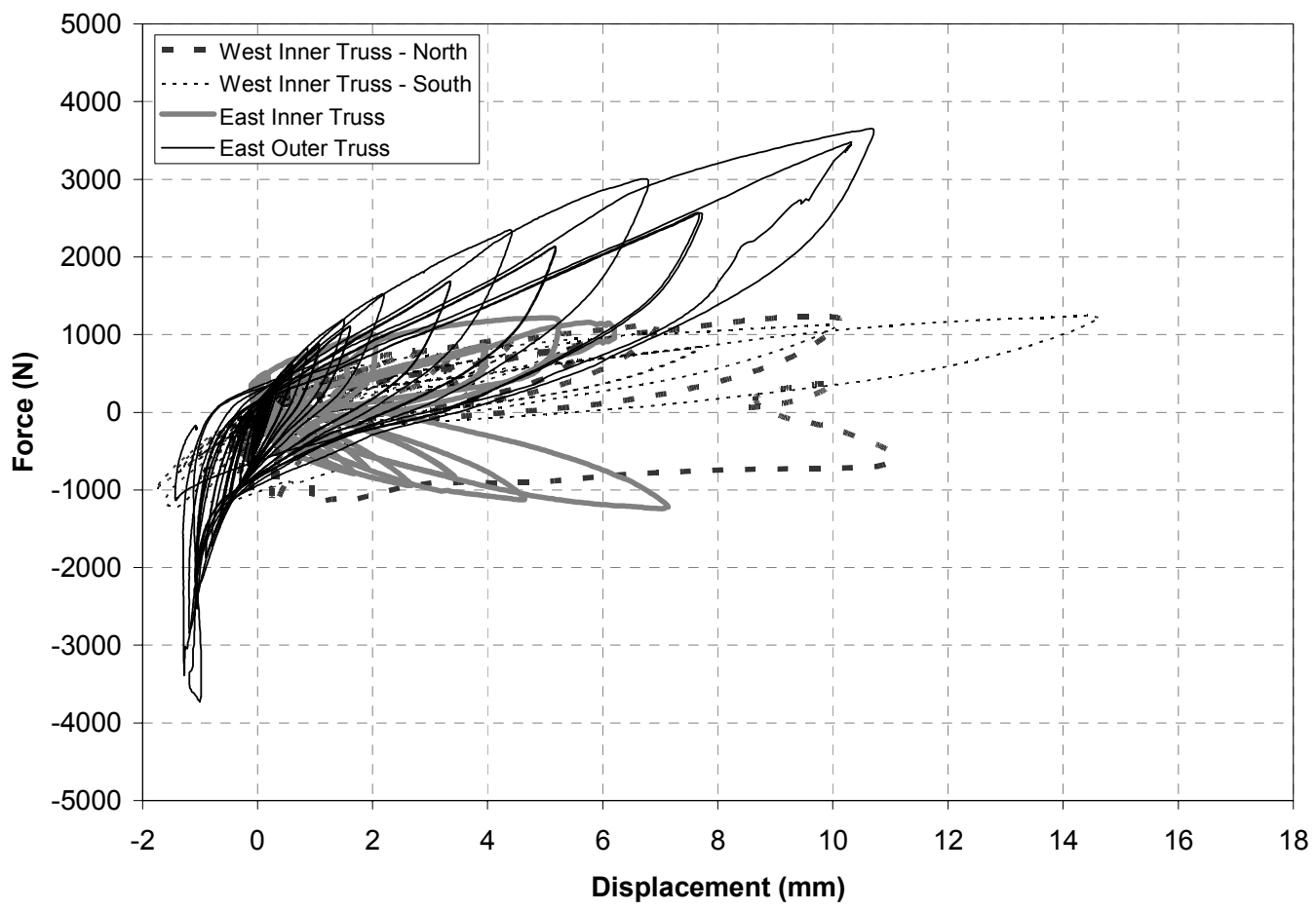

Figure 5.7. Uplift force-displacement responses for trusses with toe-nailed connections. 


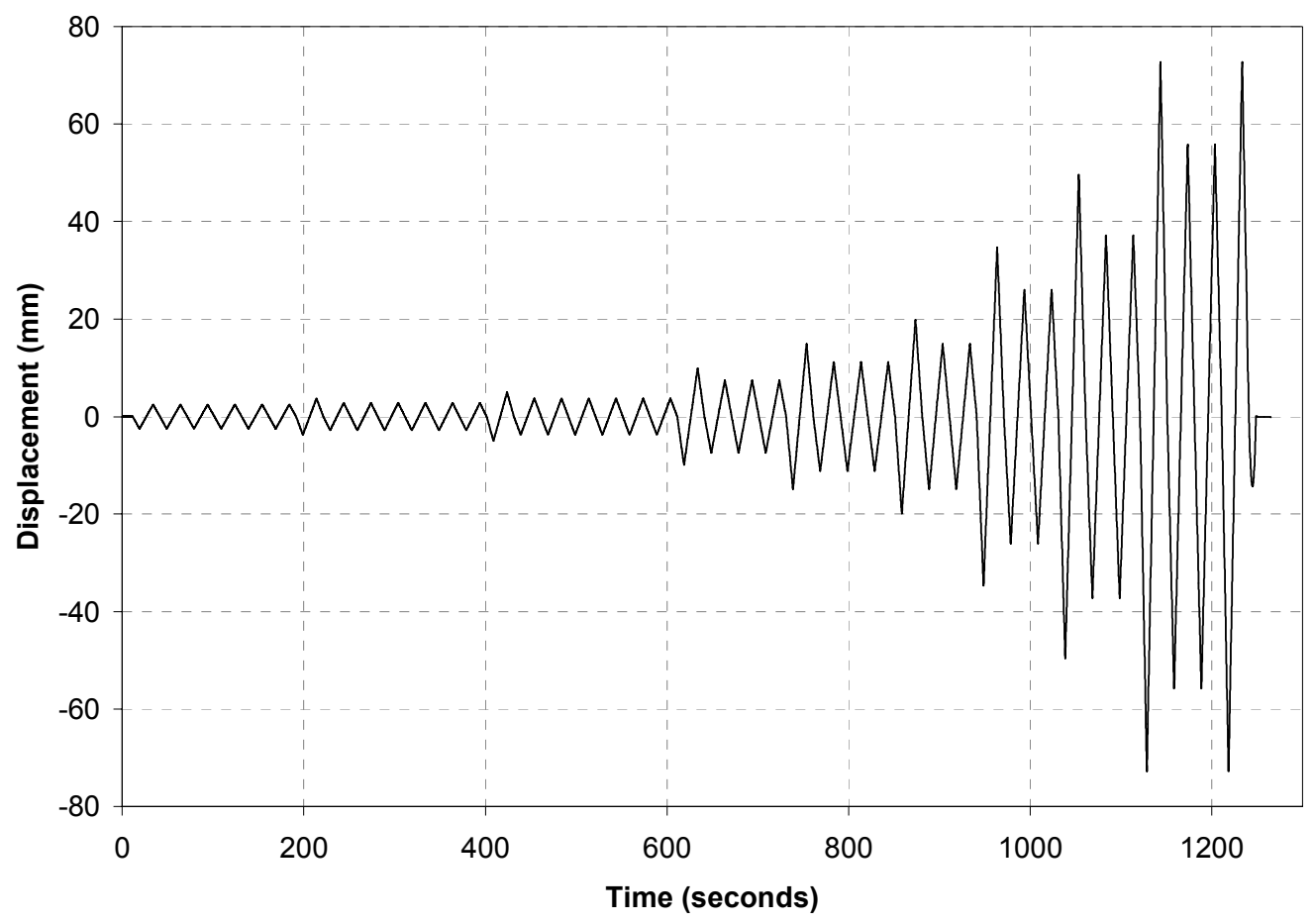

Figure 5.8. Lateral displacement applied to specimen with hurricane clips.

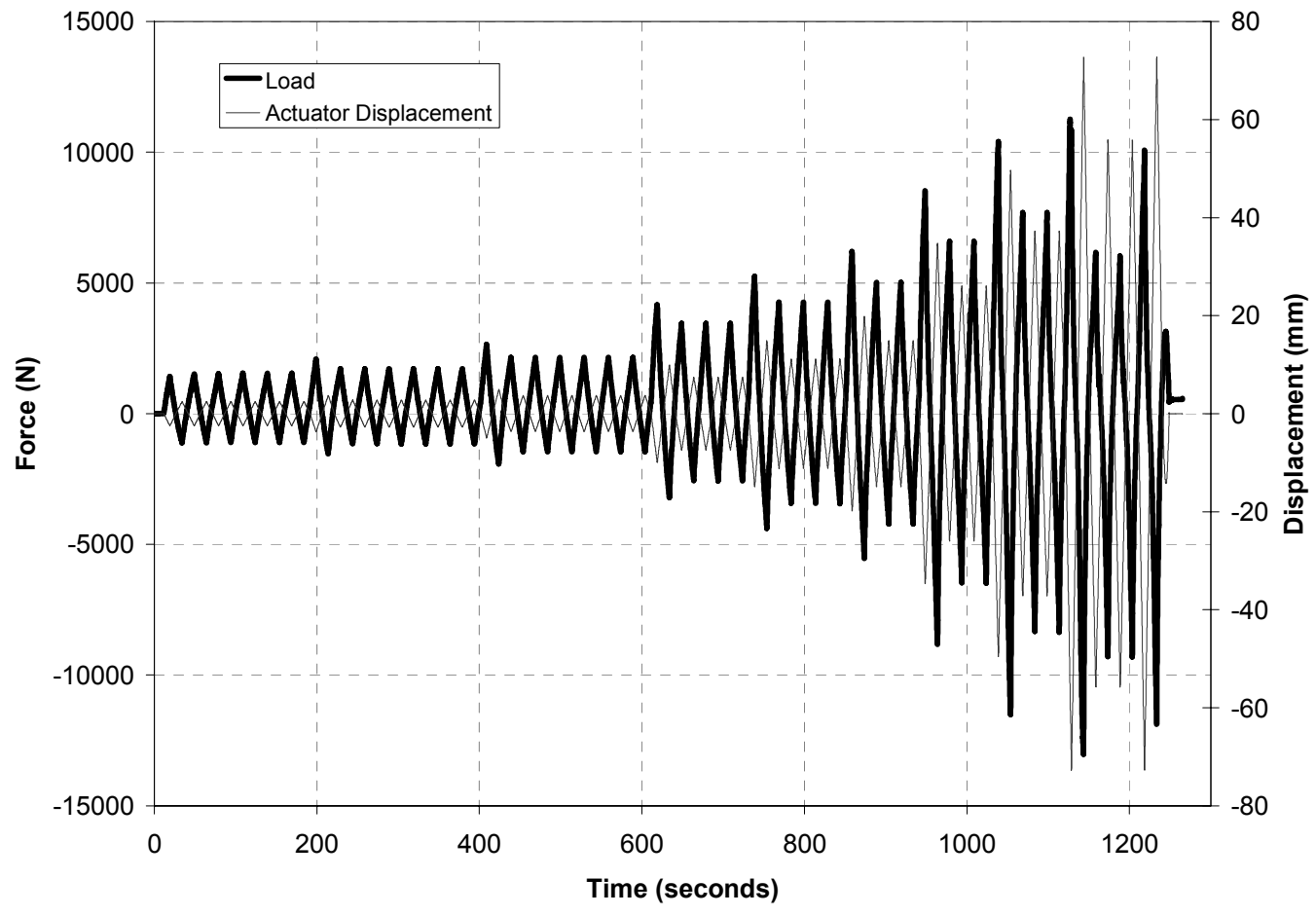

Figure 5.9. Lateral load applied to specimen with hurricane clips. 


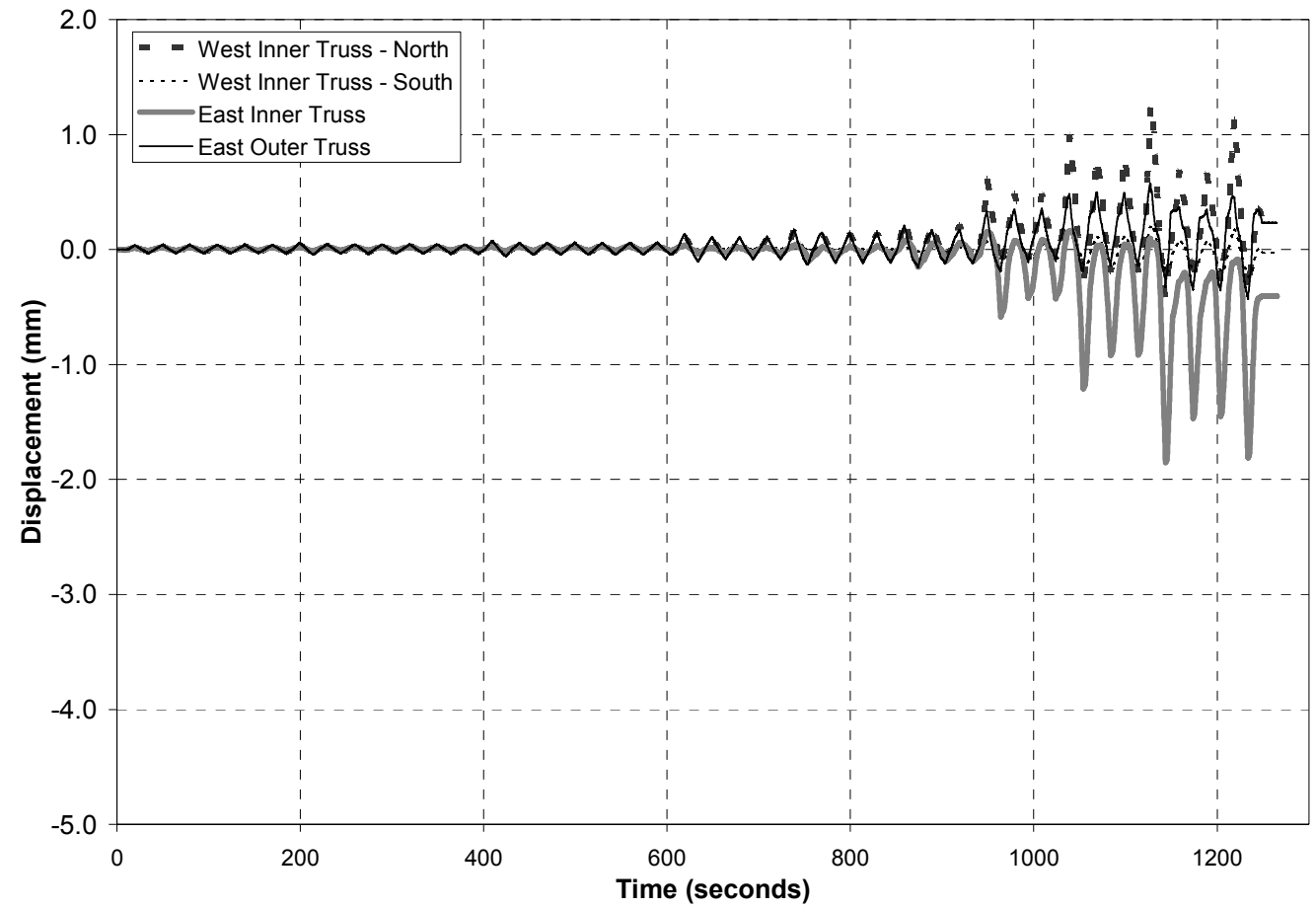

Figure 5.10. Lateral displacement responses for trusses with hurricane clips.

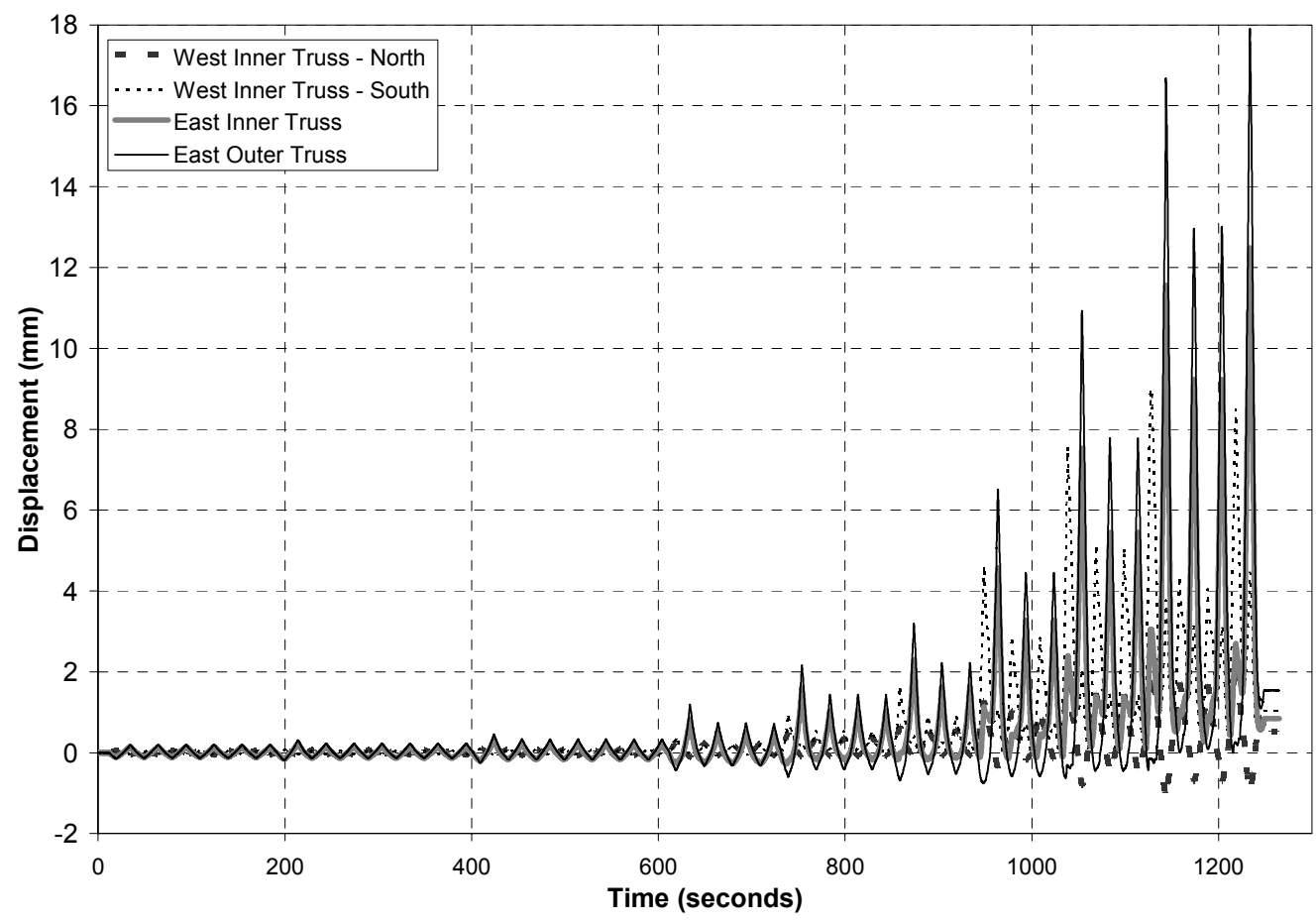

Figure 5.11. Uplift displacement responses for trusses with hurricane clips. 


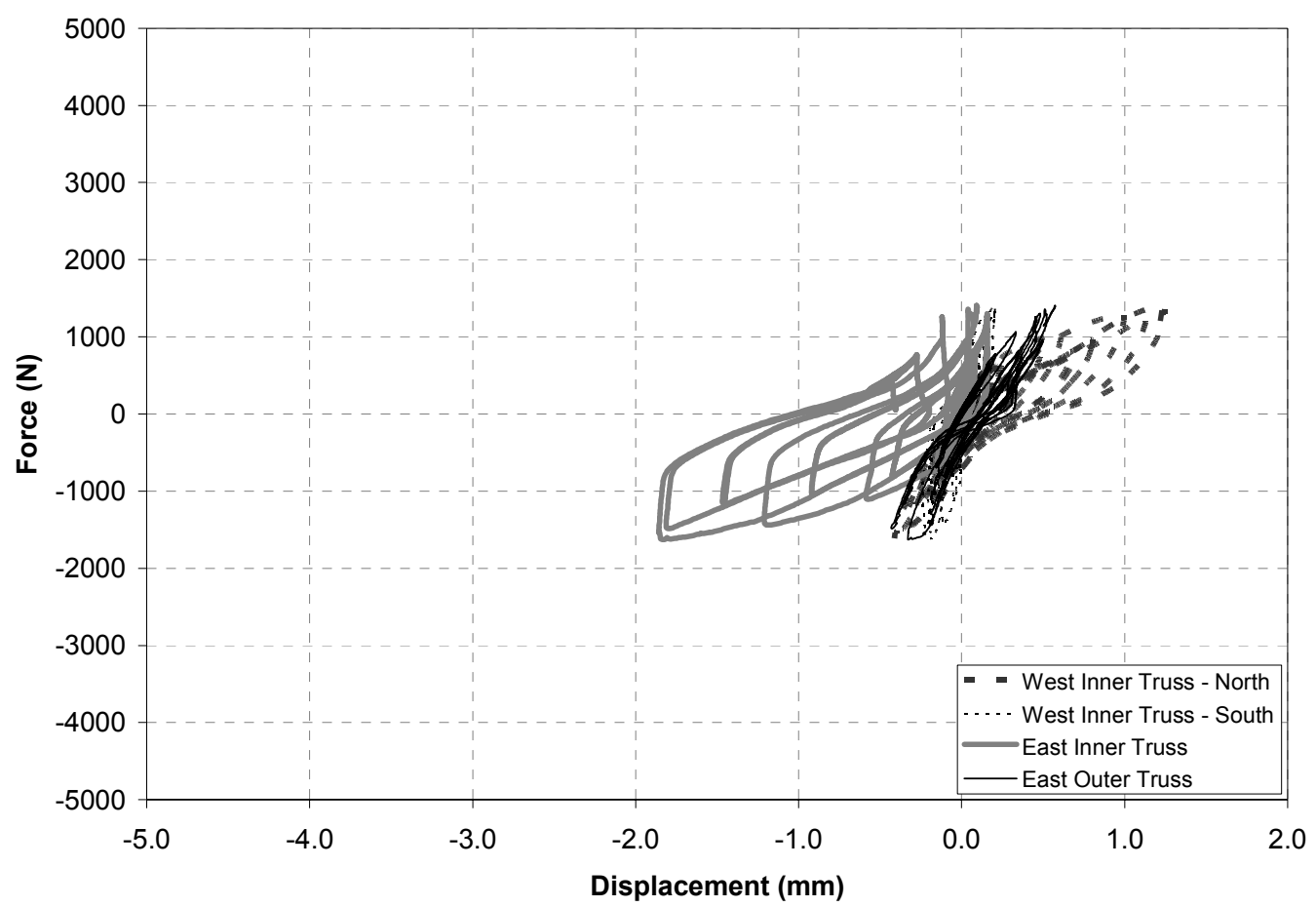

Figure 5.12. Lateral force-displacement responses for trusses with hurricane clips.

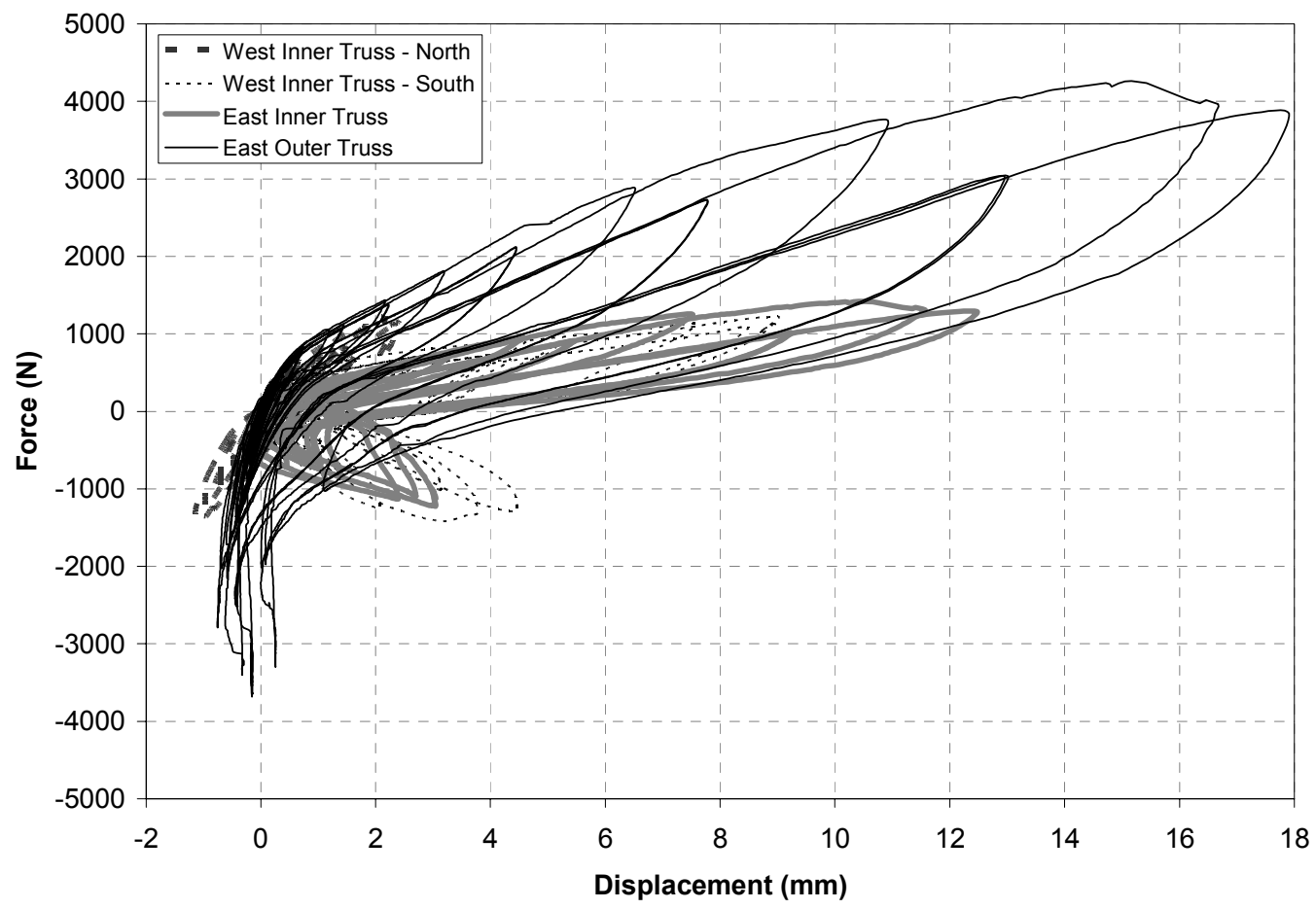

Figure 5.13. Uplift force-displacement responses for trusses with hurricane clips. 


\subsection{Comparison of Responses}

A direct comparison of the results is difficult, because the hurricane clip connection did not completely fail. As was the case with the monotonic lateral load, the behavior of both of these types of connections is highly nonlinear, which lead to significant hysteresis in the response. This hysteresis will help to provide significant energy dissipation during seismic events. The results show that the hurricane clip connections have a higher capacity to withstand such loading, but how much greater the capacity is could not be determined. 
This page intentionally left blank. 


\section{Results OF COMBINEd UPLIFT AND LATERAL LOAD TESTS}

The final two specimens were tested with a combined uplift and lateral load to simulate the wind effects on the structure, including a lateral load component due to pressure on the outside walls. As describe in section 2.4, a constant uplift deformation was applied to the roof at a rate of $6.35 \mathrm{~mm} / \mathrm{min}$ ( $0.25 \mathrm{in} / \mathrm{min})$. At the same time the applied vertical load was measured, and a lateral displacement applied to produce a lateral load equal to $29.5 \%$ of the vertical load. Limitations in the speed of the control computer and the highly nonlinear nature of the specimens limited the accuracy of the lateral loads as the displacements became large, but generally the peak lateral loads were about $25 \%$ of the peak vertical loads. The same loading sequence was used for both specimens.

\subsection{Response with Toe-nailed Con- nections}

The two deformations applied to the specimen with toe-nailed connections are shown in Figure 6.2. The resulting loads are shown in Figure 6.3. As in the previous tests, the specimen's stiffness decreased throughout the test, but the resistance continued to increase until connections began to fail about $250 \mathrm{~s}$ into the test. At this point the nails in the connection that was being placed in tension by the overturning moment from the lateral portion of the load pulled free from the top plate of the wall, as shown in Figure 6.1. This failure resulted in some wood splitting in the top plate of the wall, but little other damage to the material.

The lateral deformations in the toe-nailed connections of three of the trusses are shown in Figure 6.4 and the uplift deformations in the same connections are shown in Figure 6.5. The corresponding force displacement responses are shown in Figures
6.6 and 6.7. The responses of all three connections were quite similar in both shear and tension, although the outer connection, which failed first, was carrying slightly more tension, due to the overturning moments caused by the lateral load.

The lateral and vertical components of the response of the east inner truss are shown in Figure 6.8, while Figure 6.9 shows the same response for the east outer truss. These curves clearly show that during this test there was little difference in the initial lateral and vertical stiffnesses of the connection. The curves also illustrate how much more deformation occurred in the vertical direction than the lateral. The peak vertical loads carried by these connections were greater than the loads carried by similar connections subjected to uplift loading alone.

\subsection{Response with Hurricane Clips}

The two deformations applied to the specimen with hurricane clips are shown in Figure 6.11, and the applied loads are shown in Figure 6.12. As was the case in the monotonic lateral load test, the specimen resisted the applied load with a near constant stiffness, until the first connection began to fail at about $180 \mathrm{~s}$ into the test. The failure occurred at the connection on the outer truss that was in tension from both the uplift and the overturning moment due to the lateral load. The failure consisted of the top plate of the wall splitting, which allowed the hurricane clip to pull free, as can be seen in Figure 6.10. The connection of the inner truss next to the one that failed first, failed by the nails withdrawing from the intact top plate.

The lateral deformations in the connections of three of the trusses are shown in Figure 
6.13, and the uplift deformations in these connections are shown in Figure 6.14. The corresponding force displacement responses are shown in Figures 6.15 and 6.16. Again, the responses of the two inner connections were quite similar, but the outer connection, which failed first, exhibited much less stiffness in both shear and uplift, and failed at a relatively low load. In fact, the capacity of this connection was only slightly greater than the toe-nailed connections and much less than other hurricane clip connections. The reduced capacity may have been due to an inherent weakness in the wood of the top plate, or a split in the wood caused by a poorly driven nail.
Figure 6.17 shows the lateral and vertical components of the response of the east inner truss. These curves clearly show that the initial lateral and vertical stiffnesses of the connection were nearly equal, and how much more deformation occurred in the vertical direction than the lateral. Figure 6.18 shows the same response for the east outer truss. In this case, both of the connection stiffnesses are much less than those of the inner truss. As mentioned above, the outer truss connection failed at a relatively small load, and the deformations at failure were much greater than for the other connections.

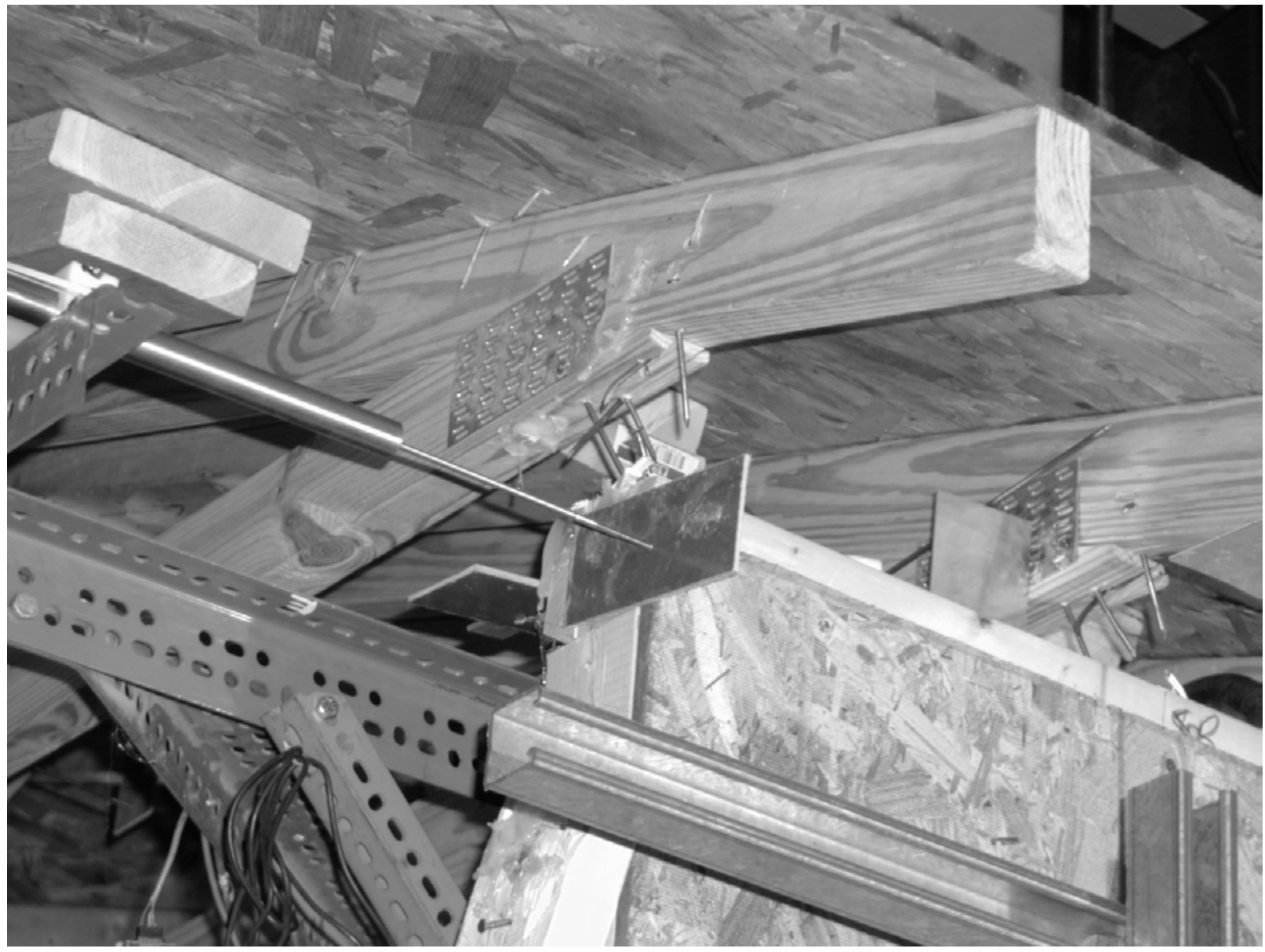

Figure 6.1. Failure of toe-nailed connection with combined load. 


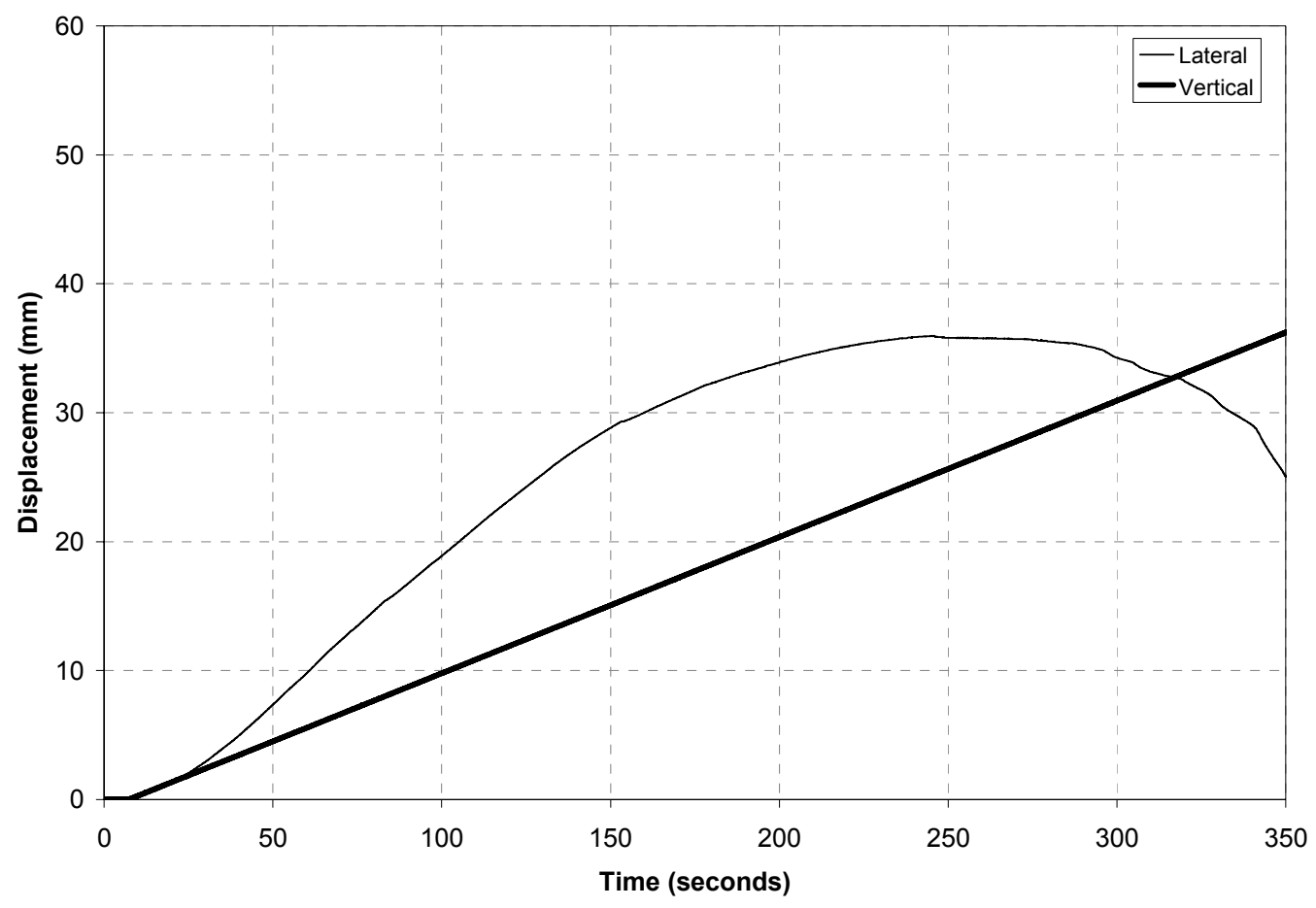

Figure 6.2. Displacements applied to specimen with toe-nailed connections.

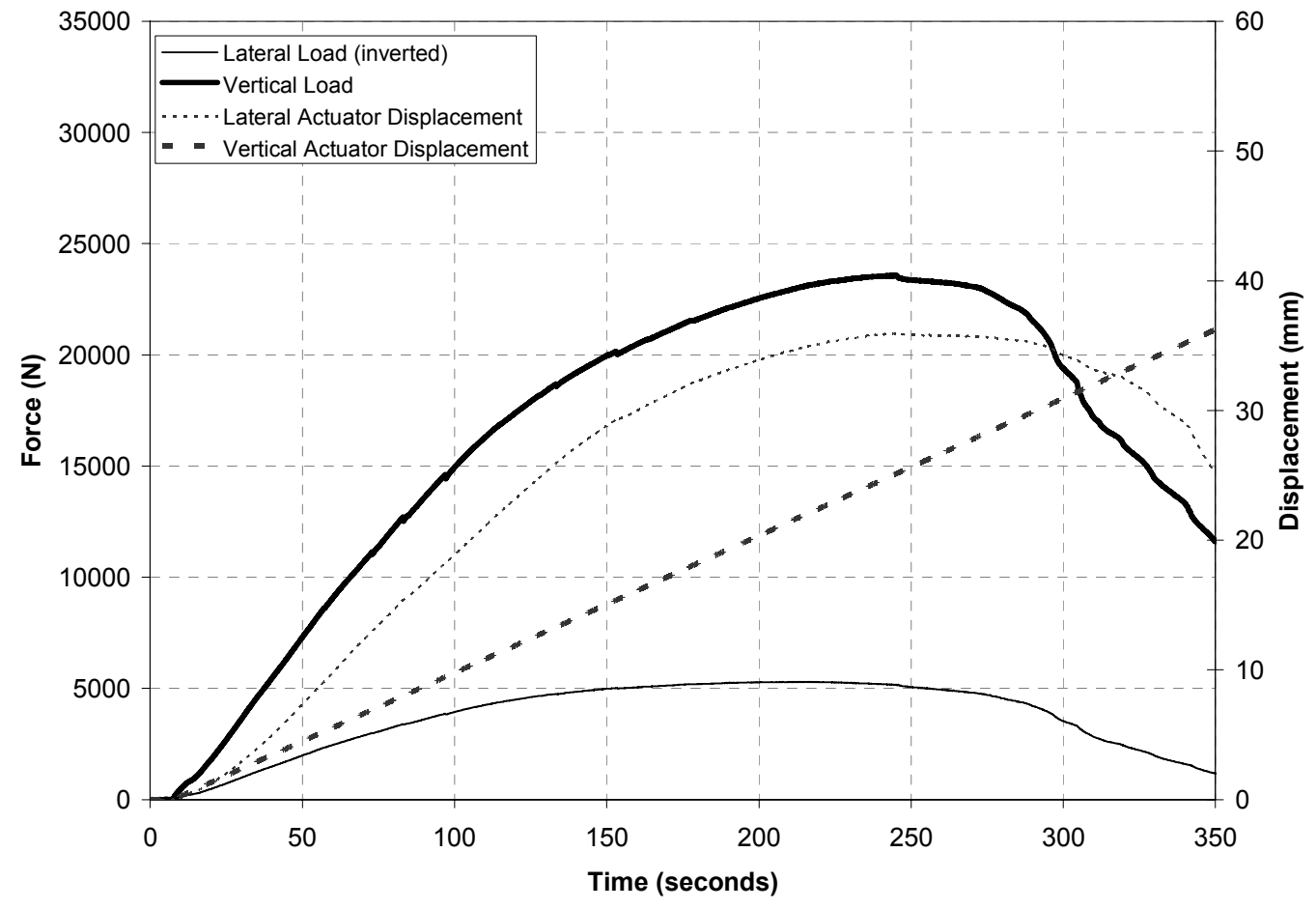

Figure 6.3. Loads applied to specimen with toe-nailed connections. 


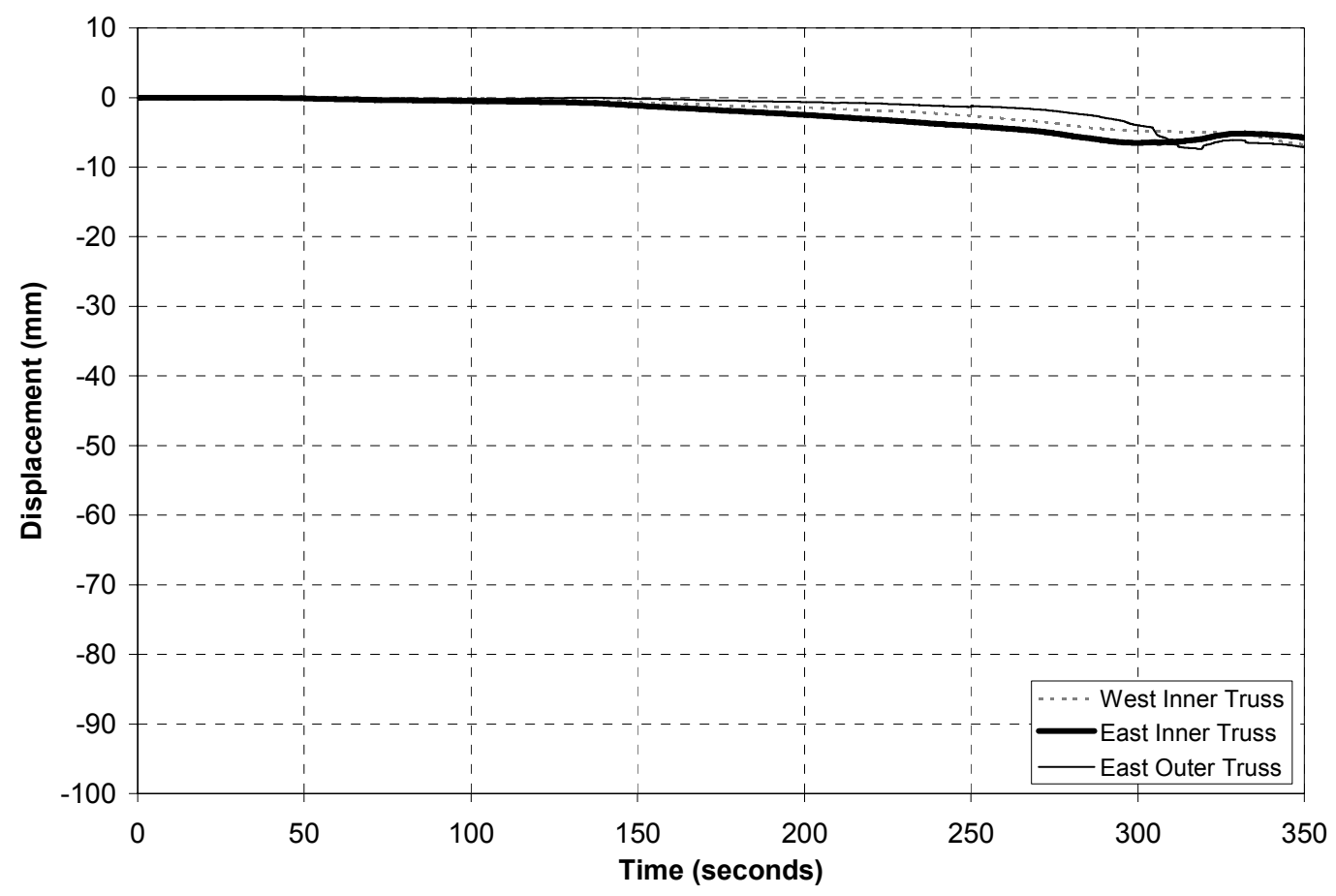

Figure 6.4. Lateral displacement responses for trusses with toe-nailed connections.

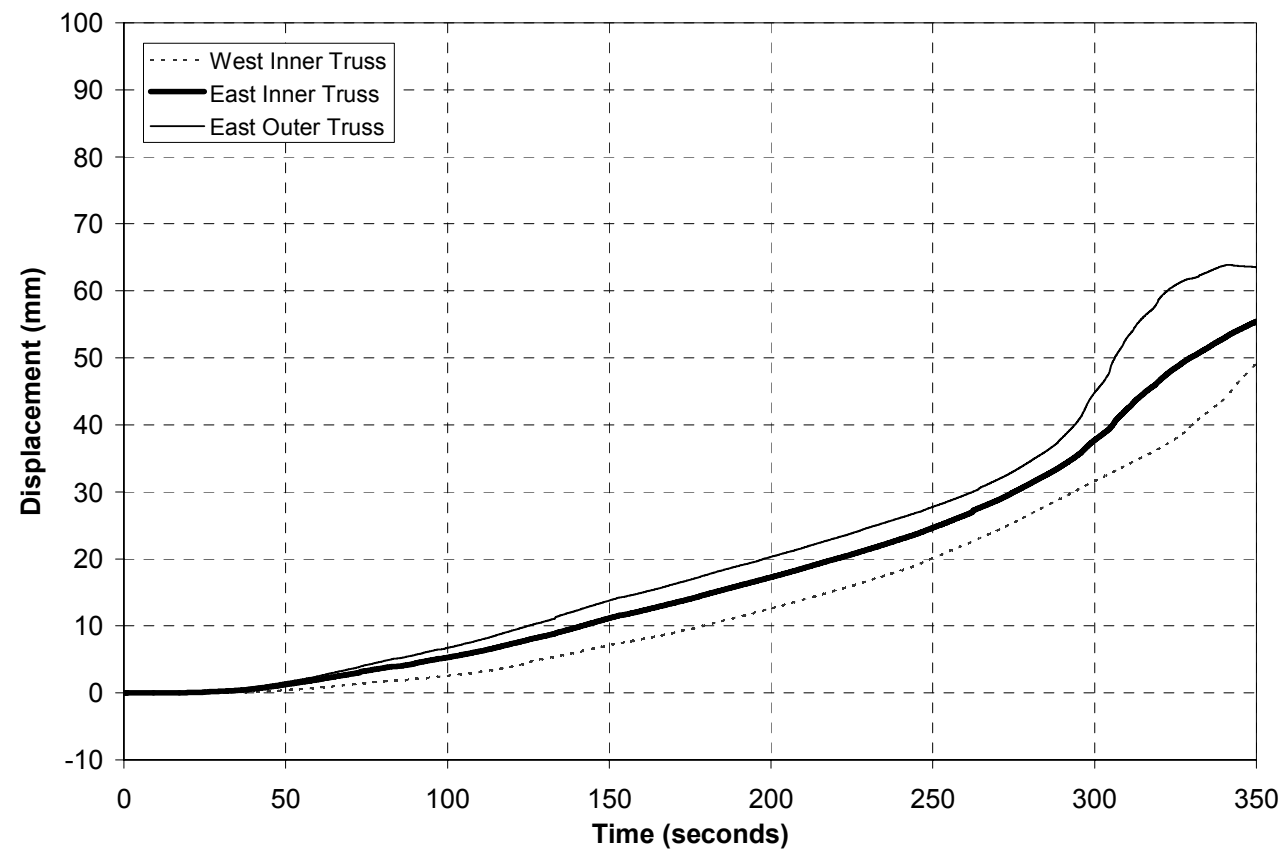

Figure 6.5. Uplift displacement responses for trusses with toe-nailed connections. 


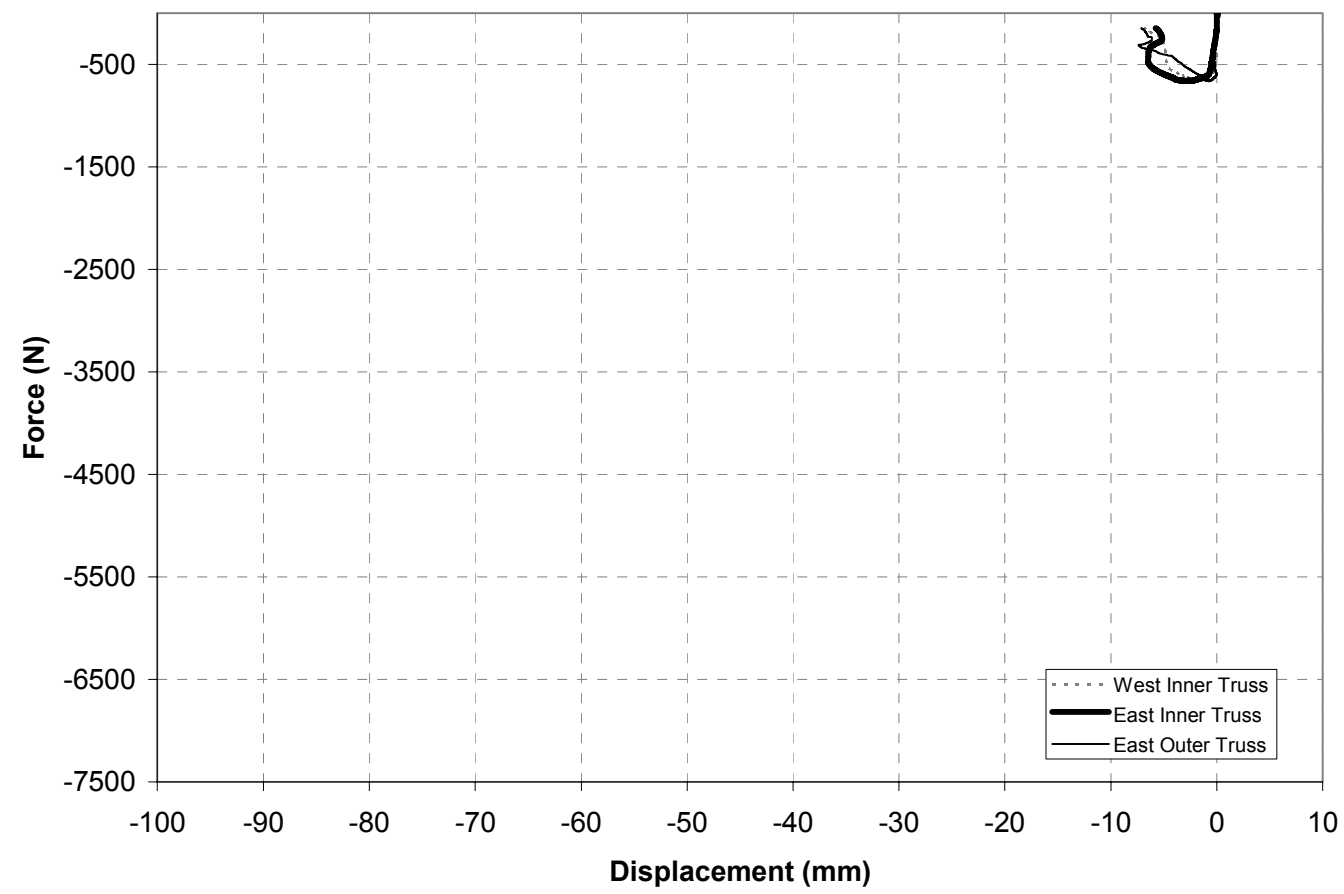

Figure 6.6. Lateral force-displacement responses for trusses with toe-nailed connections.

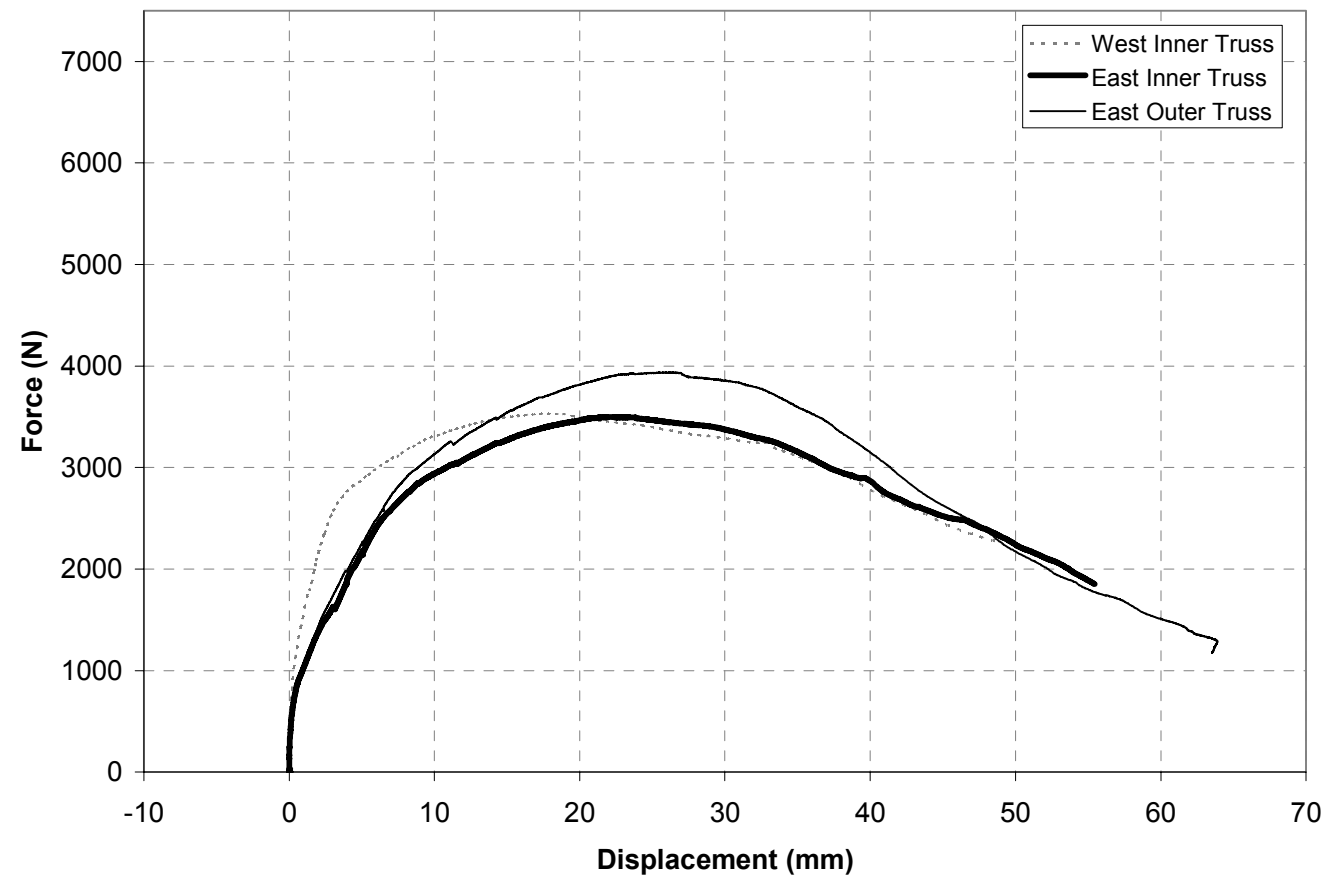

Figure 6.7. Uplift force-displacement responses for trusses with toe-nailed connections. 


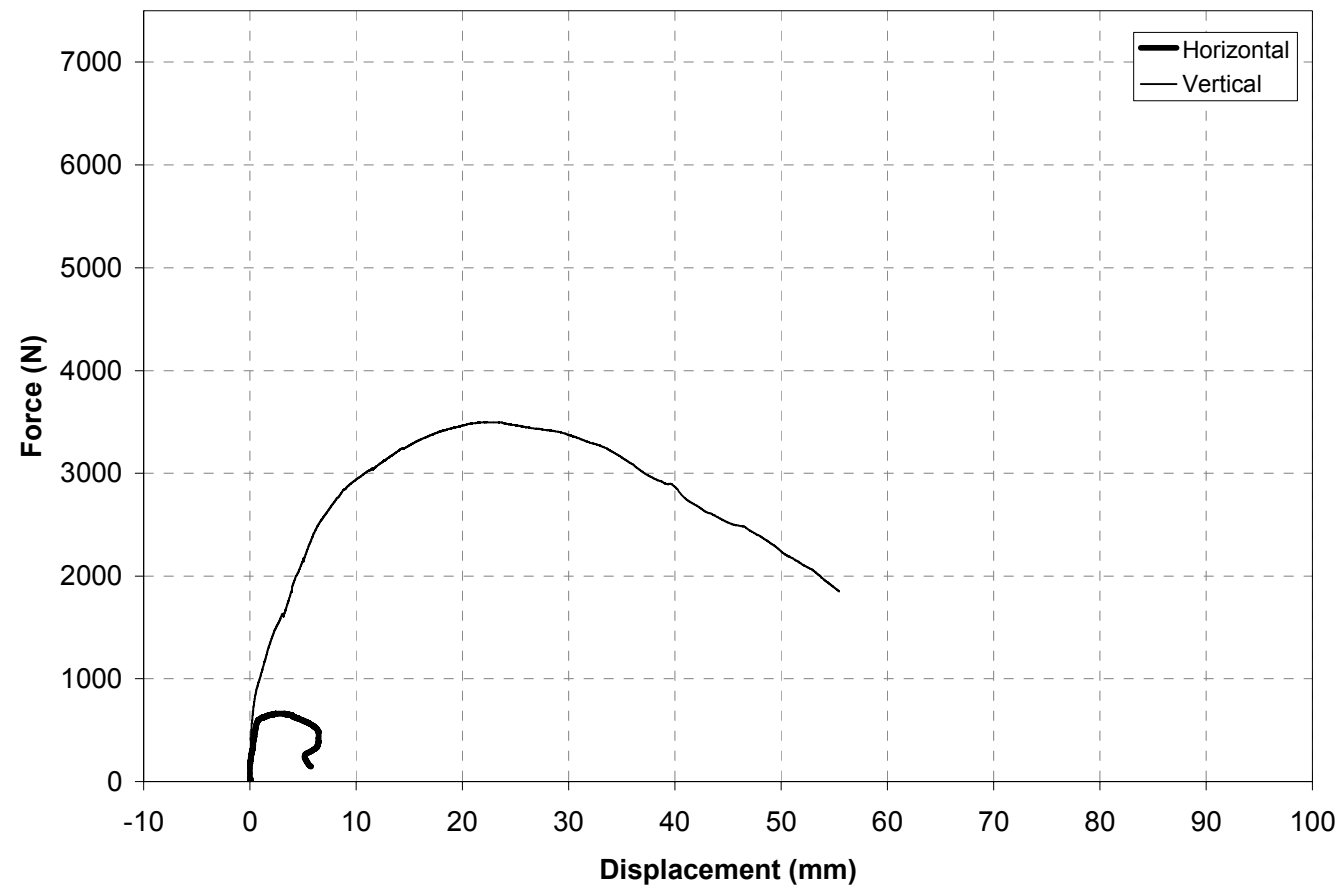

Figure 6.8. Lateral and vertical responses for inner truss with toe-nailed connections.

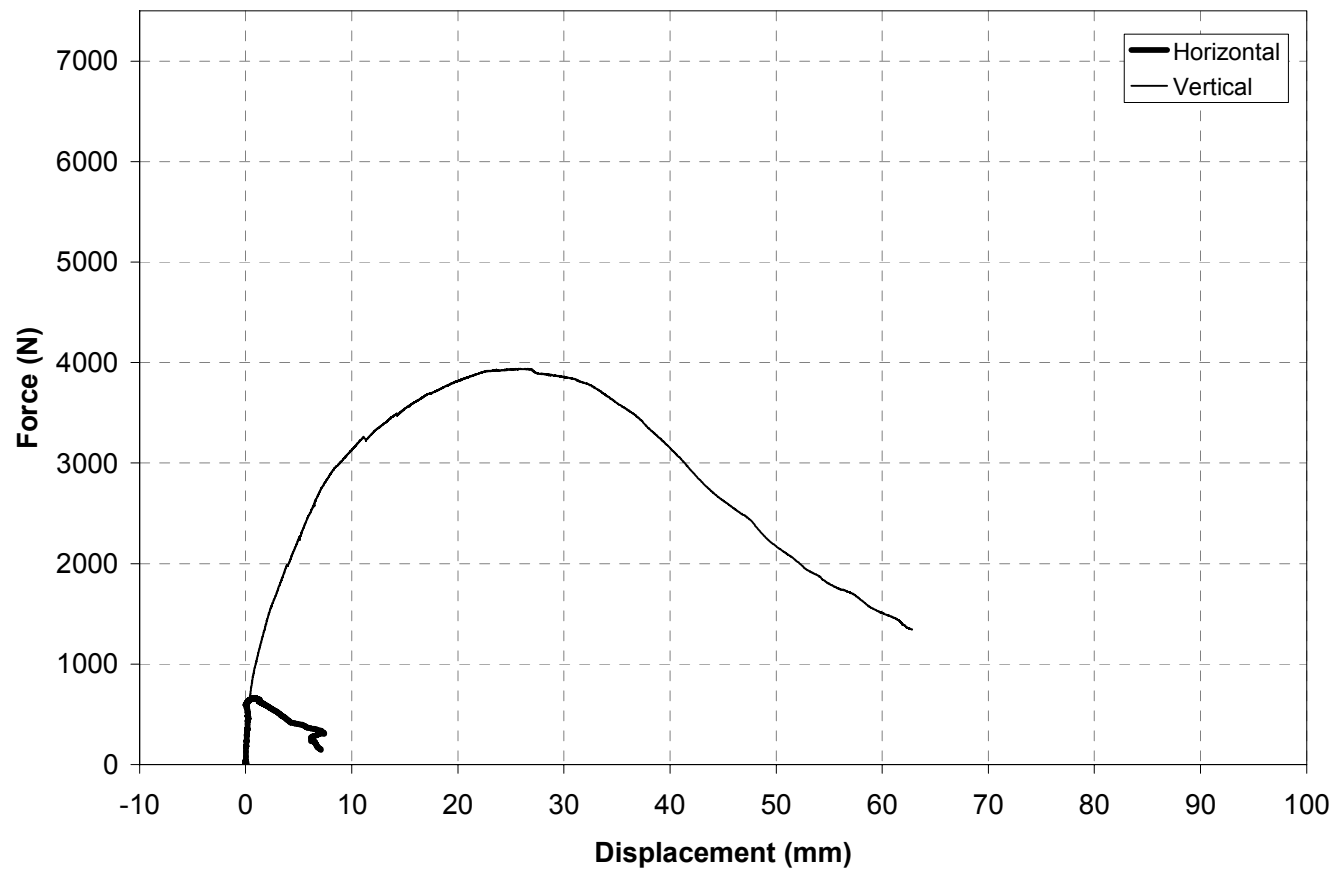

Figure 6.9. Lateral and vertical responses for outer truss with toe-nailed connections. 


\subsection{Comparison of Responses}

A direct comparison of the responses at the east inner trusses with the two types of connections is shown in Figure 6.19, while the responses for the outer trusses are shown in Figure 6.20. The behavior of the inner trusses matches the behavior seen in other loading cases, with the hurricane clips providing a much greater capacity than the toe-nailed connections. However, as discussed above, and clearly visible in Figure 6.20, the outer truss hurricane clip connection that failed when the top plate of the wall split provided only a slightly greater capacity than the toe-nailed connection. These curves highlight the great variability that can occur in the response of wood frame construction, due to both the variabil- ity in the materials and in the quality of workmanship. Note, however, that the overall strength of the specimen was not greatly compromised by the weak outer connection. The combined strength of the other three hurricane clips on that wall of the specimen allowed the specimen to resist almost $45 \%$ more load than the specimen with toe-nailed connections.

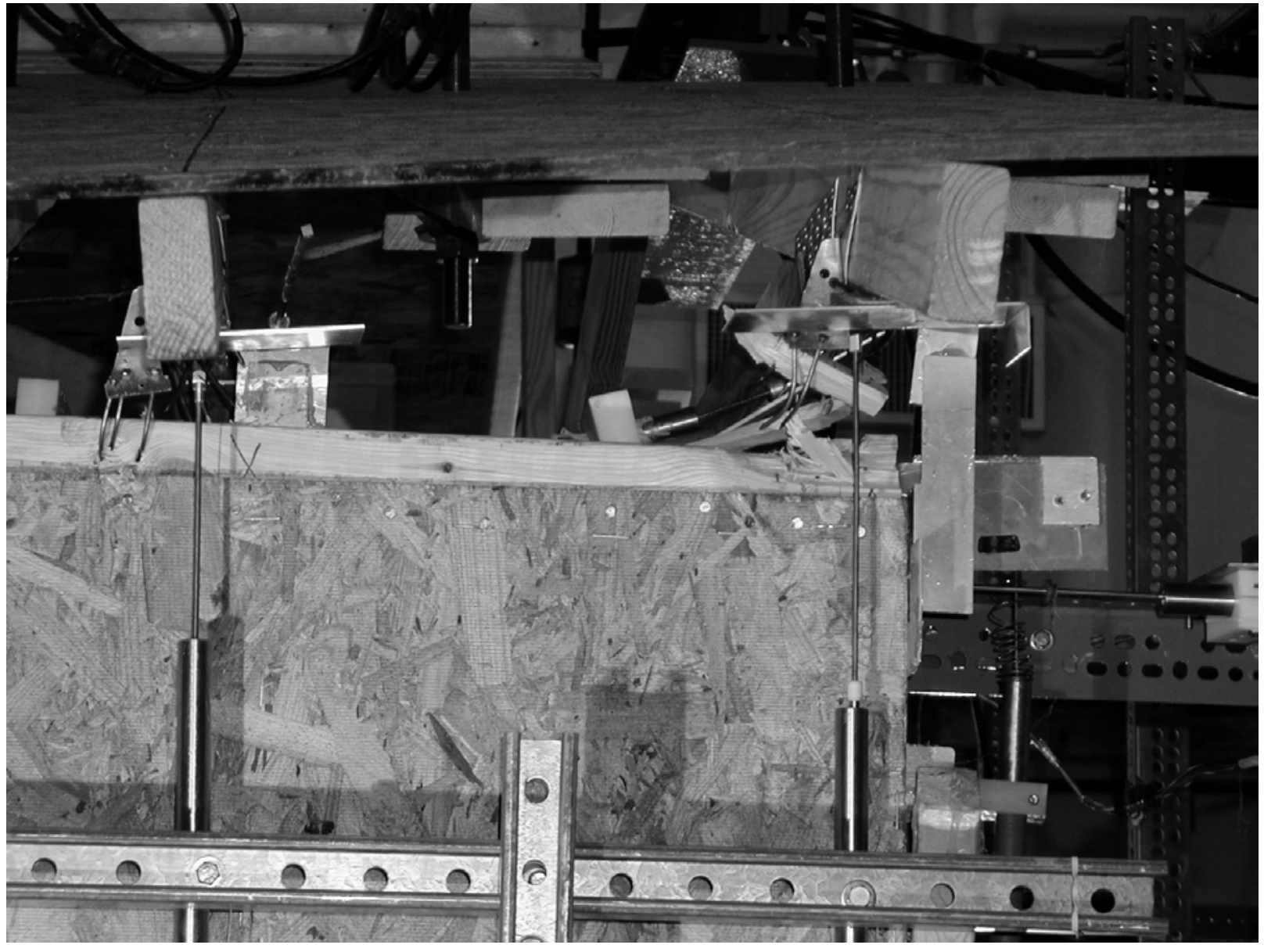

Figure 6.10. Failure of hurricane clip connection with combined load. 


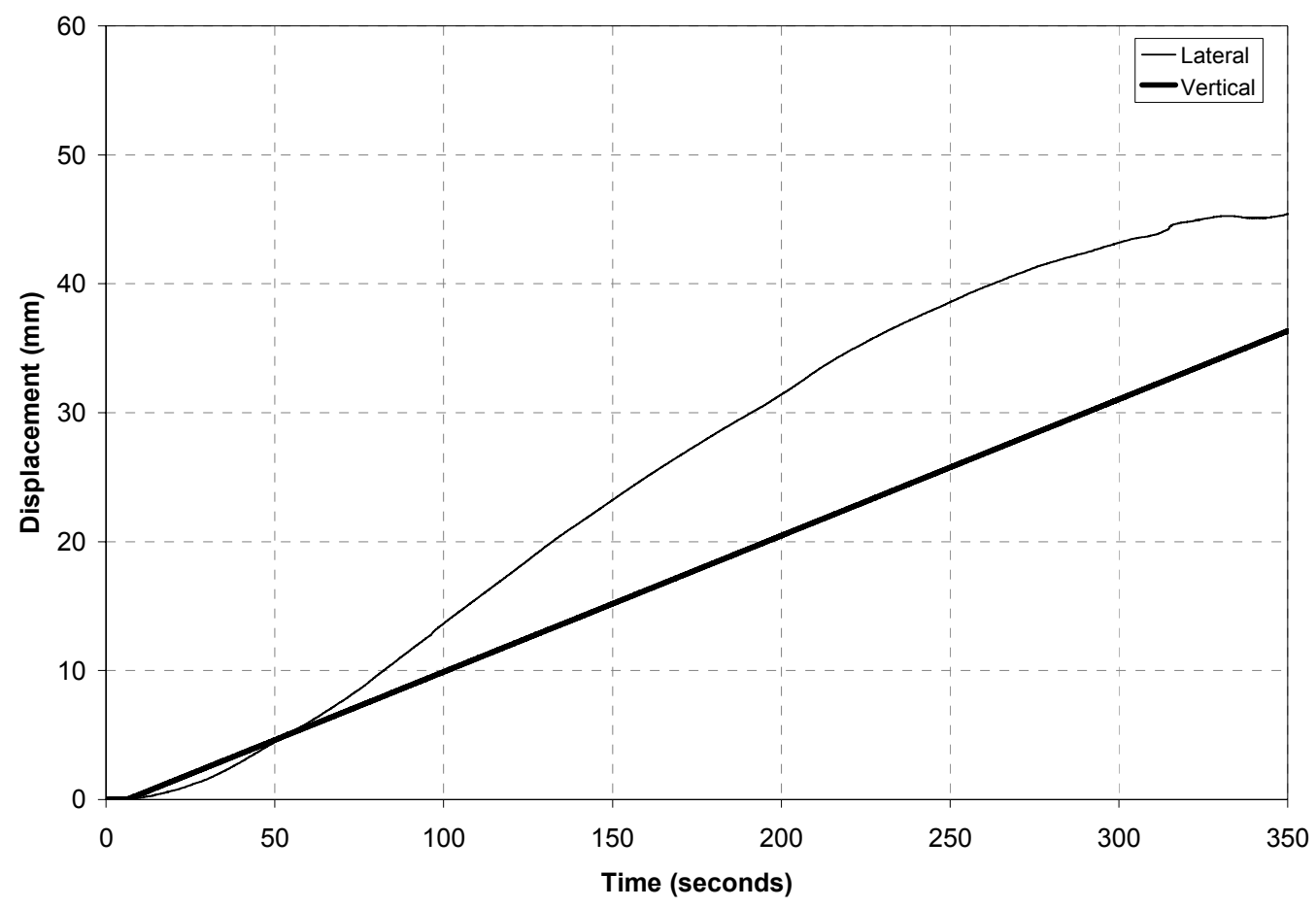

Figure 6.11. Displacements applied to specimen with hurricane clips.

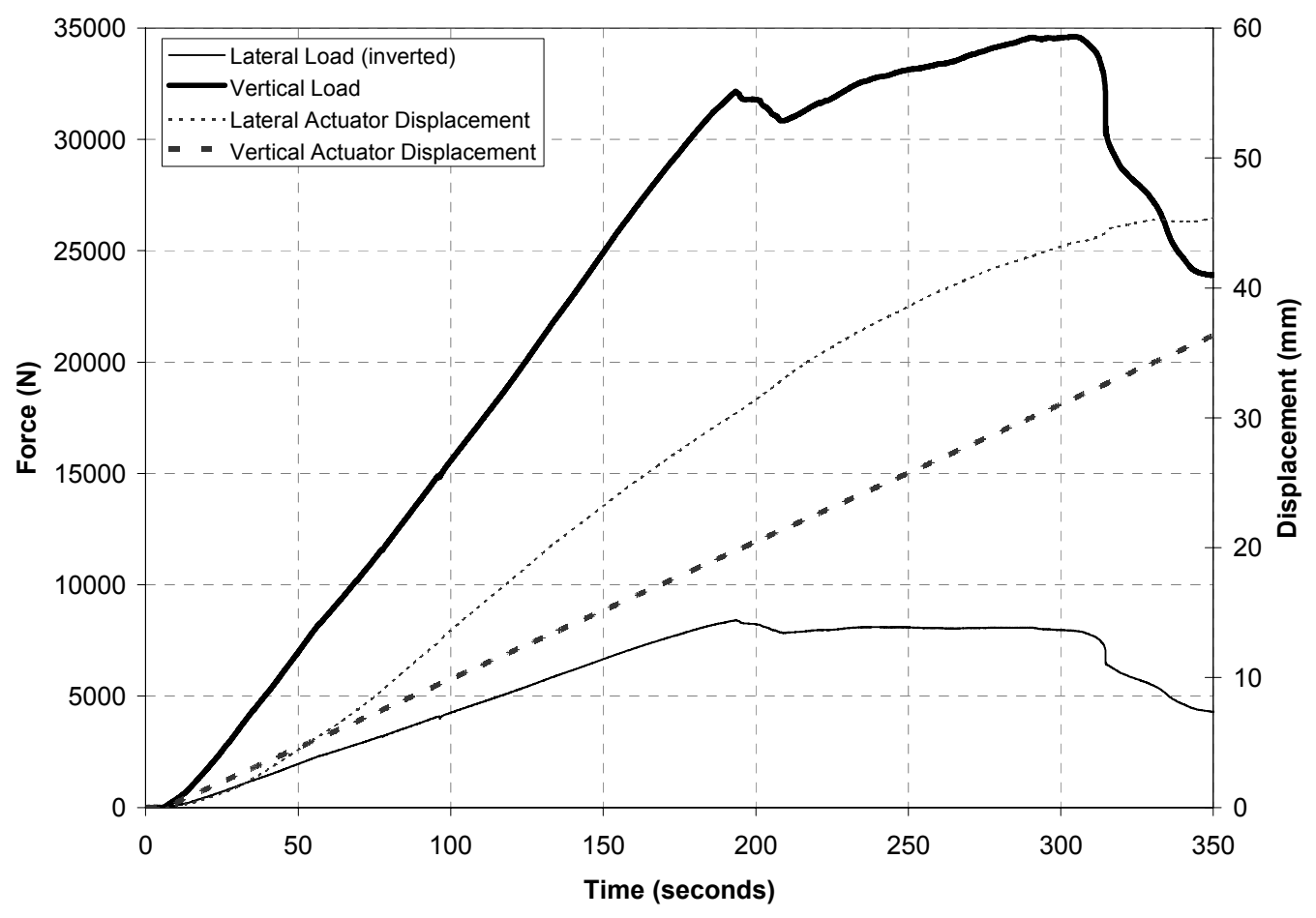

Figure 6.12. Loads applied to specimen with hurricane clips. 


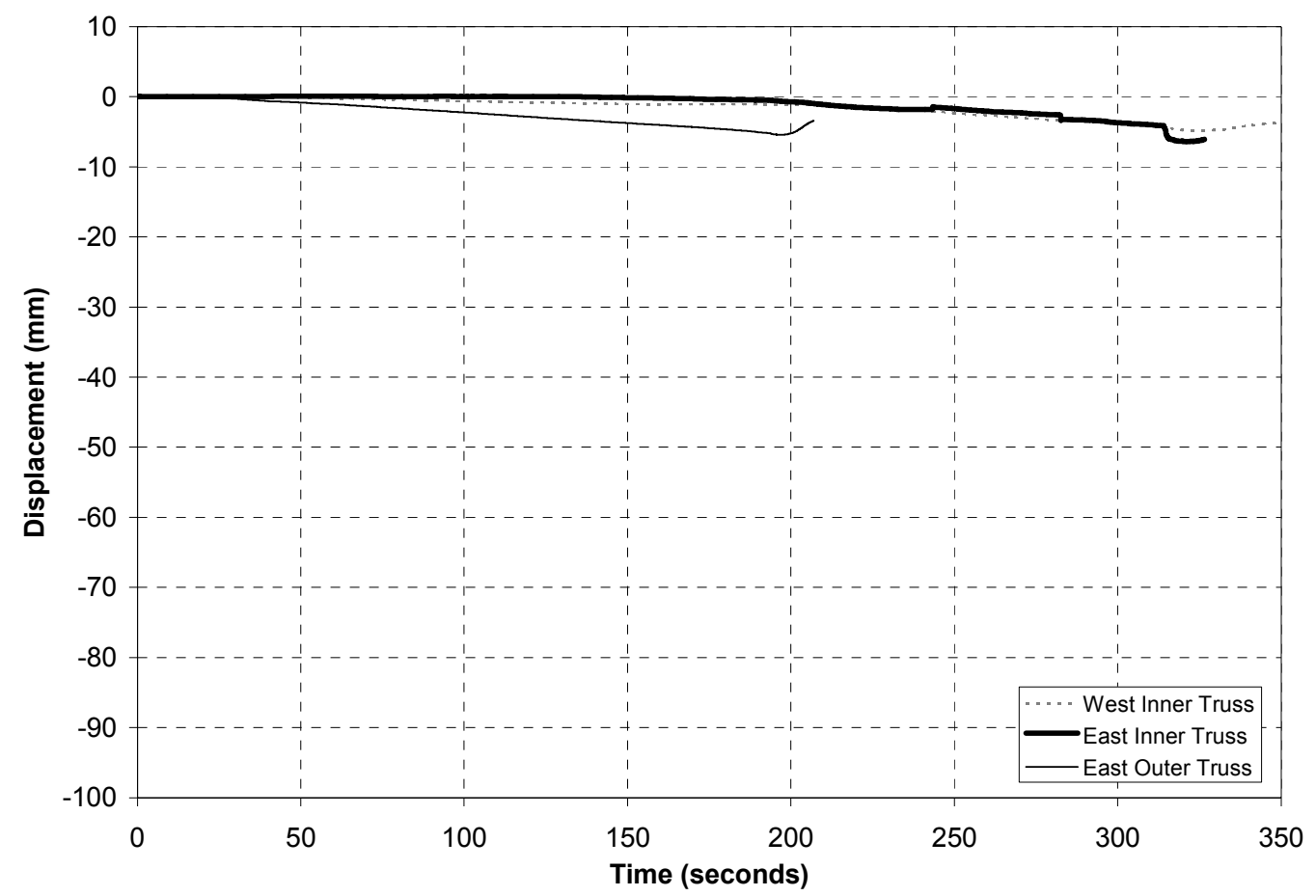

Figure 6.13. Lateral displacement responses for trusses with hurricane clips.

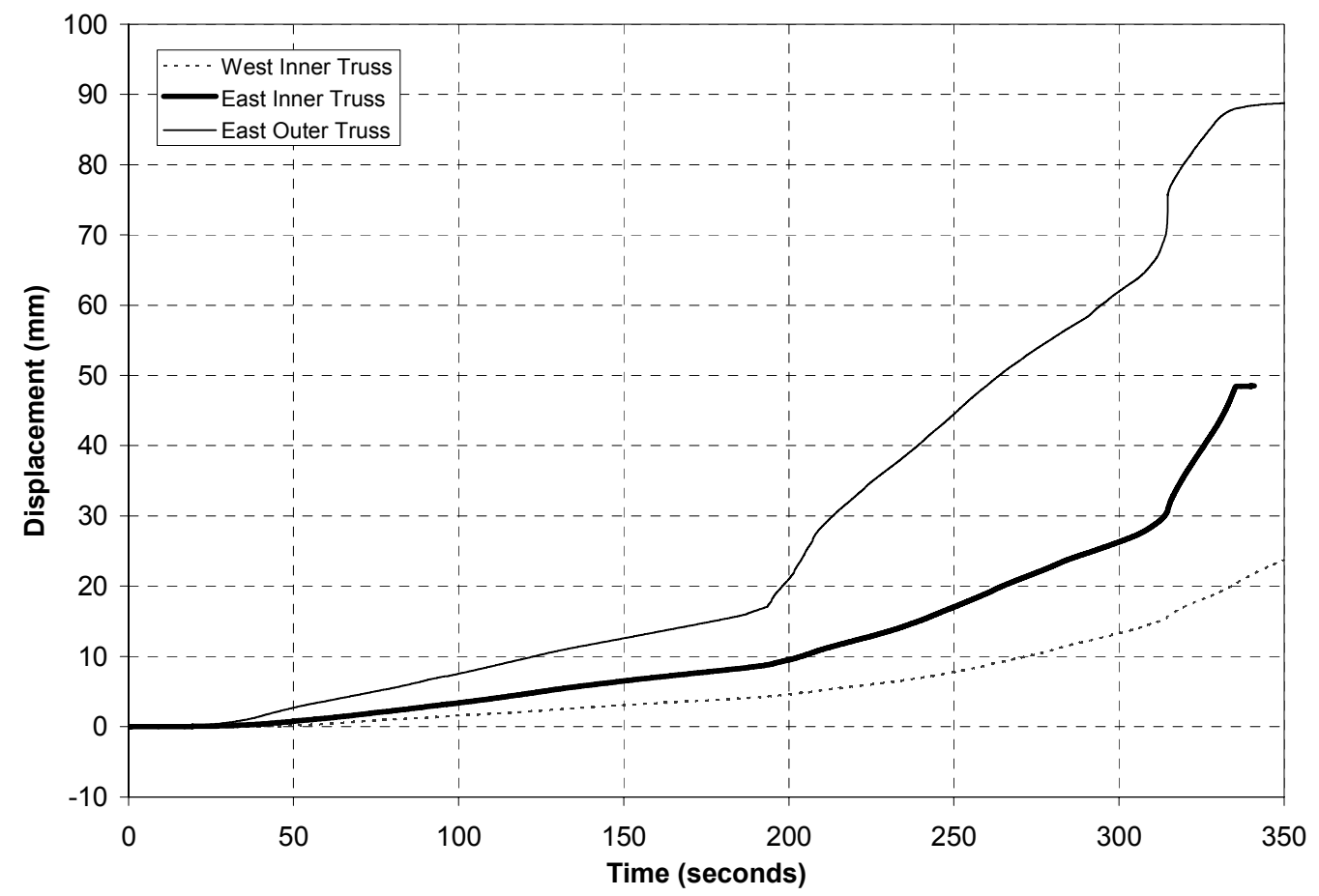

Figure 6.14. Uplift displacement responses for trusses with hurricane clips. 


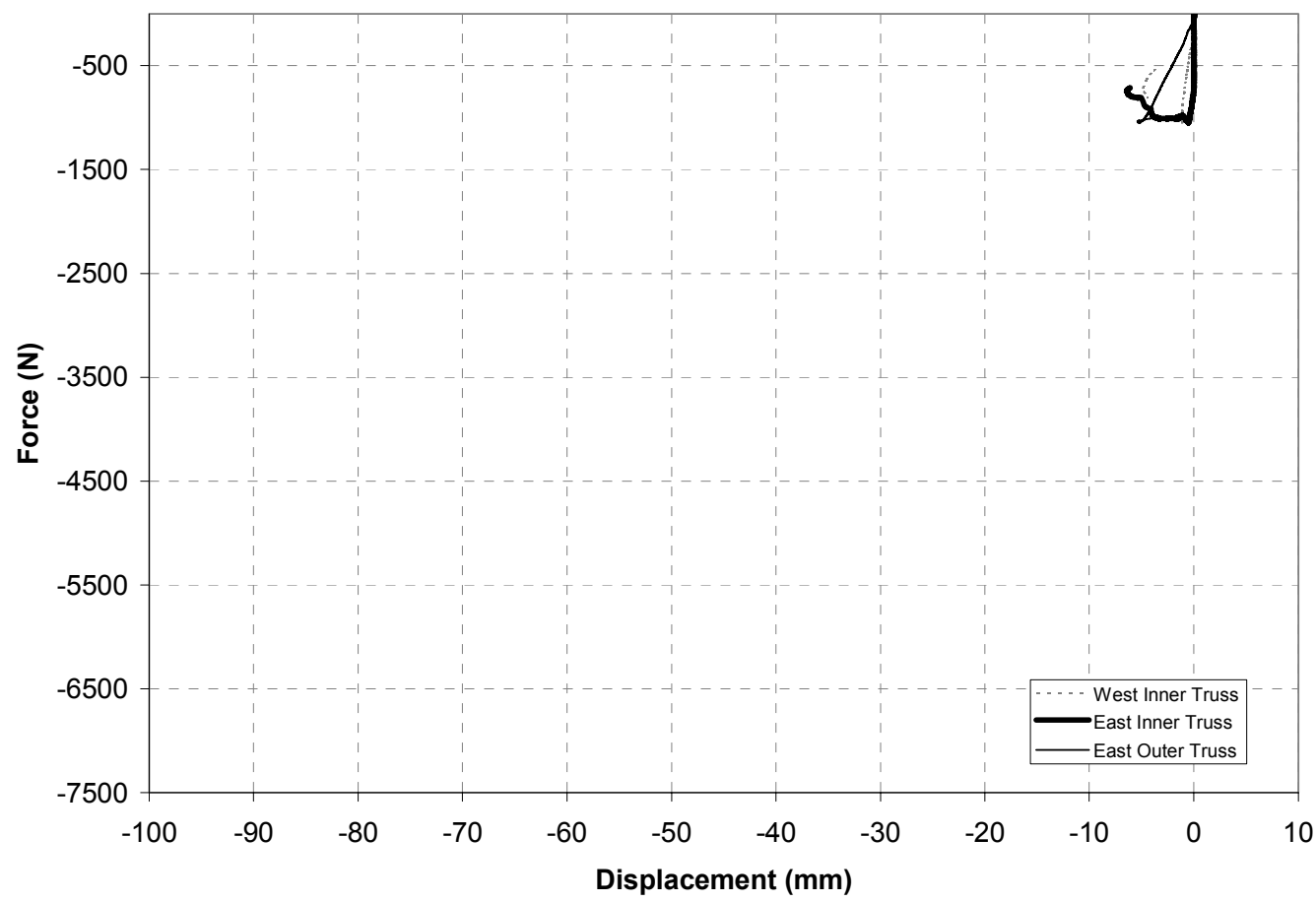

Figure 6.15. Lateral force-displacement responses for trusses with hurricane clips.

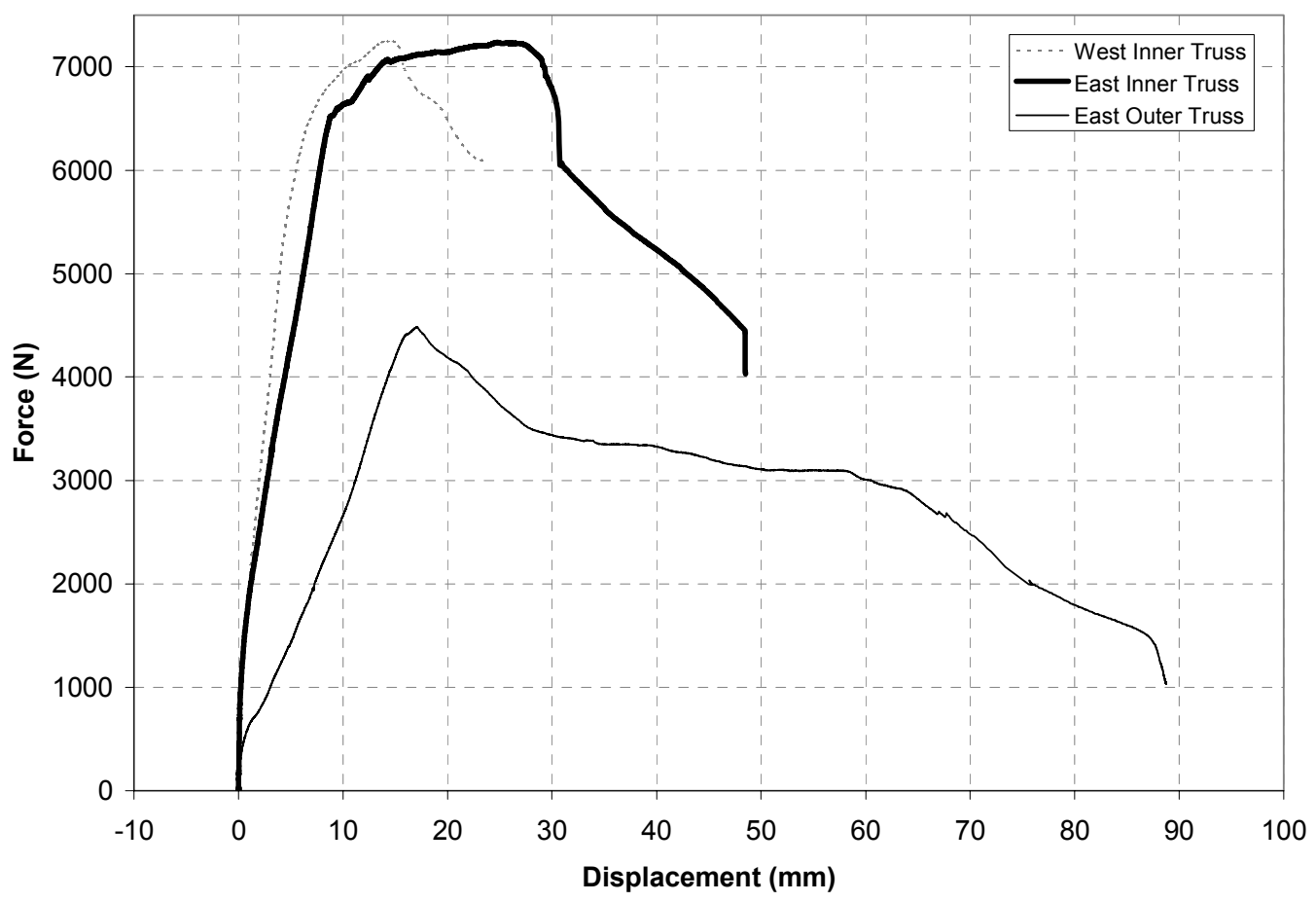

Figure 6.16. Uplift force-displacement responses for trusses with hurricane clips. 


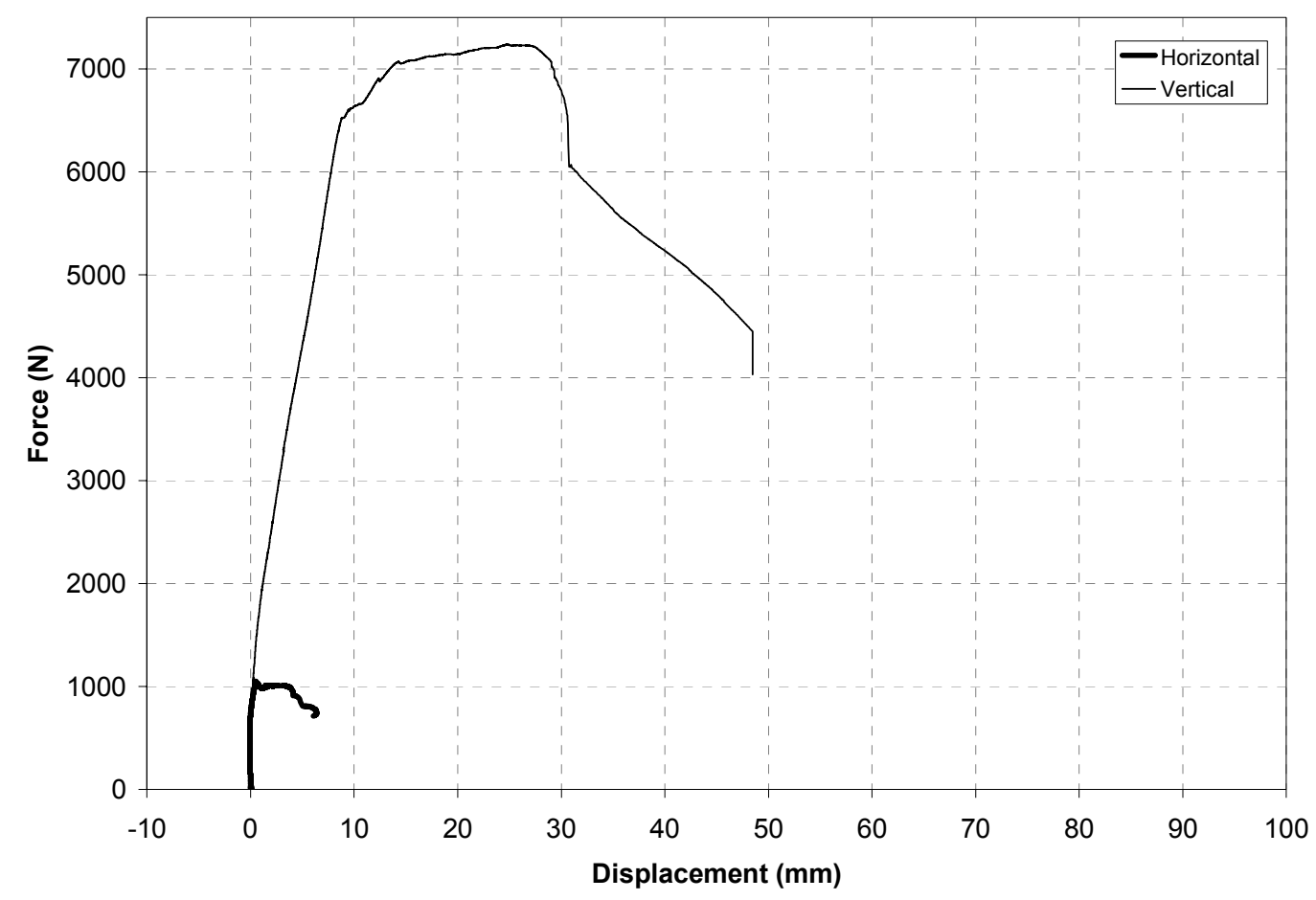

Figure 6.17. Lateral and vertical responses for inner truss with hurricane clips.

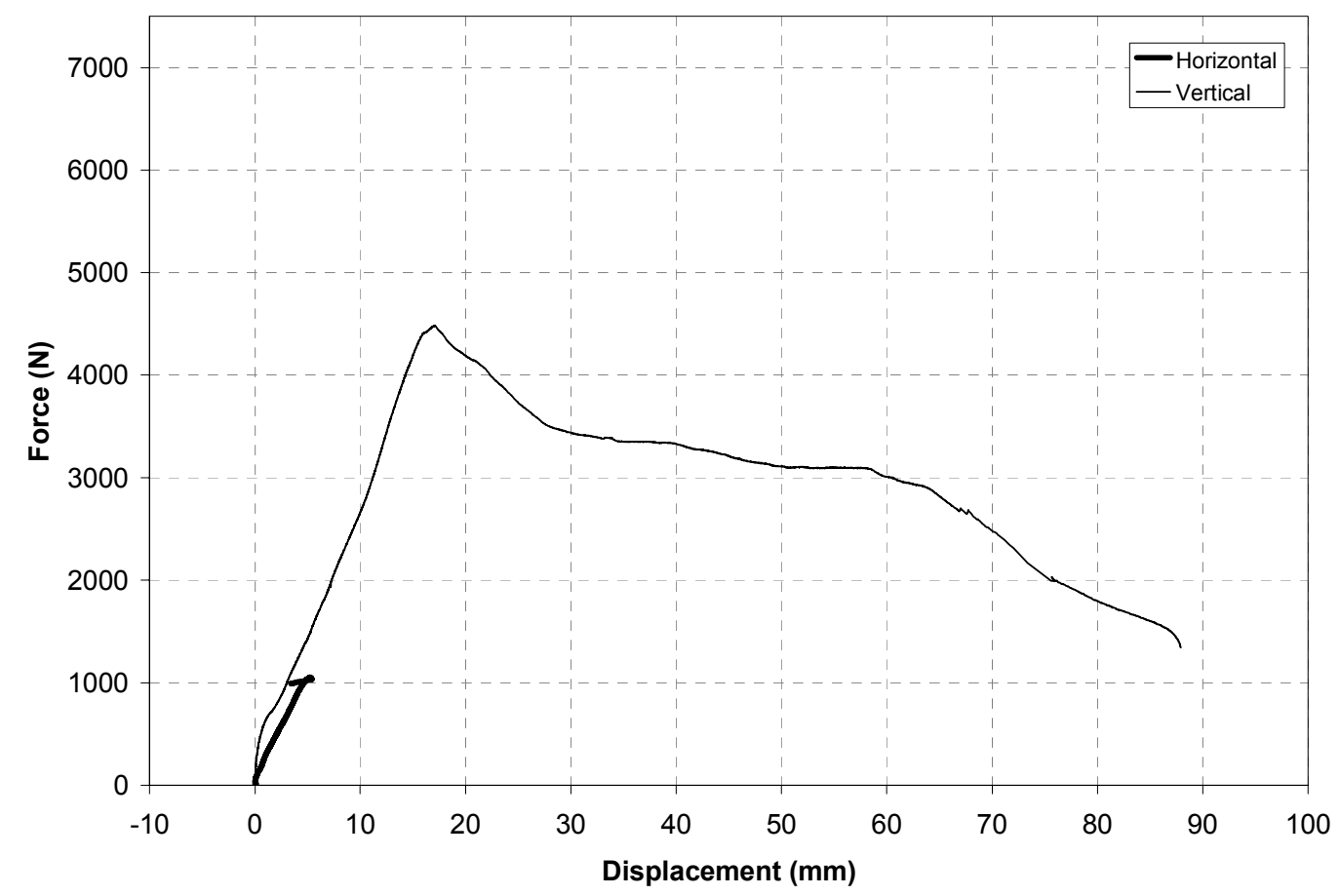

Figure 6.18. Lateral and vertical responses for outer truss with hurricane clips. 


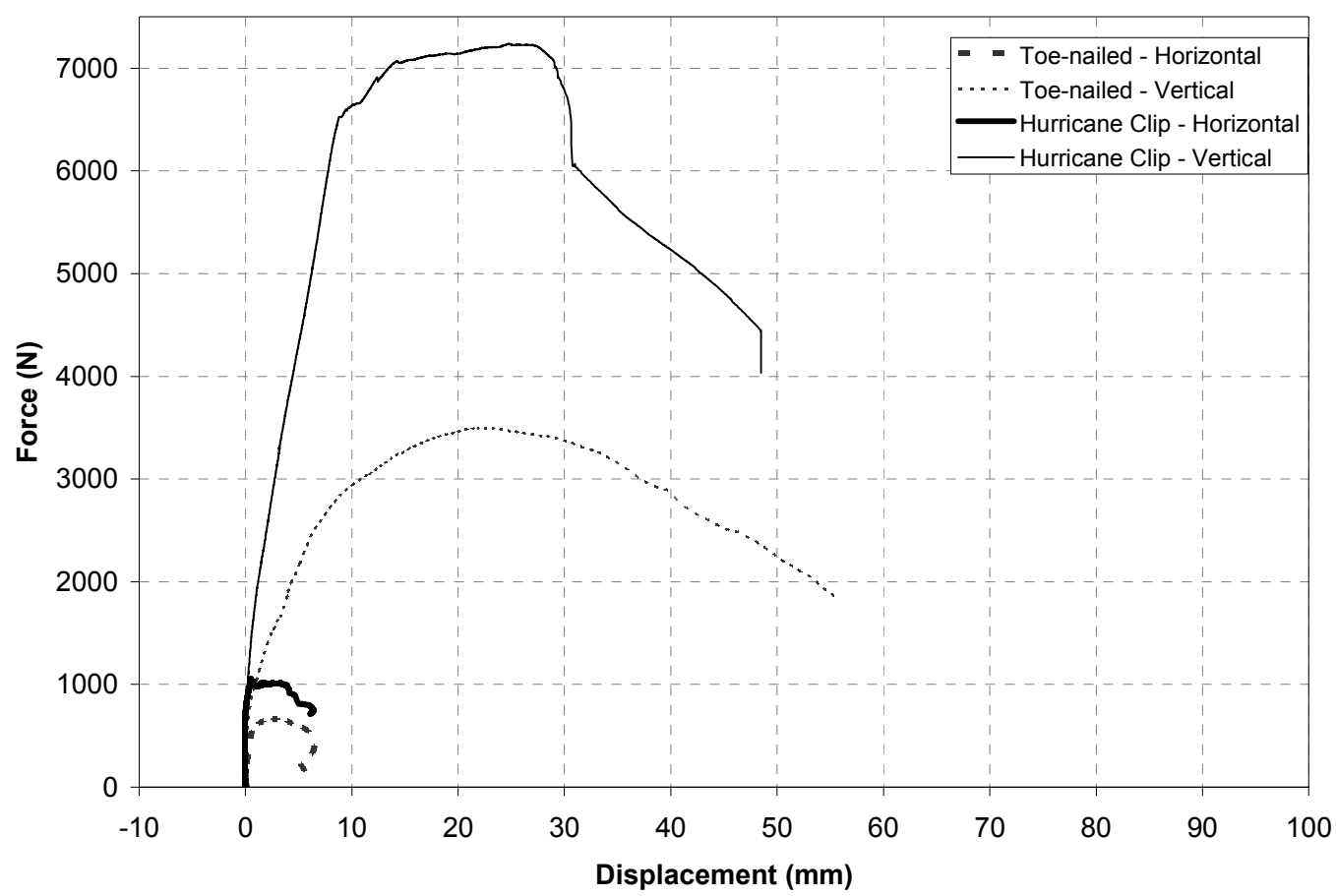

Figure 6.19. Comparison of responses of inner trusses.

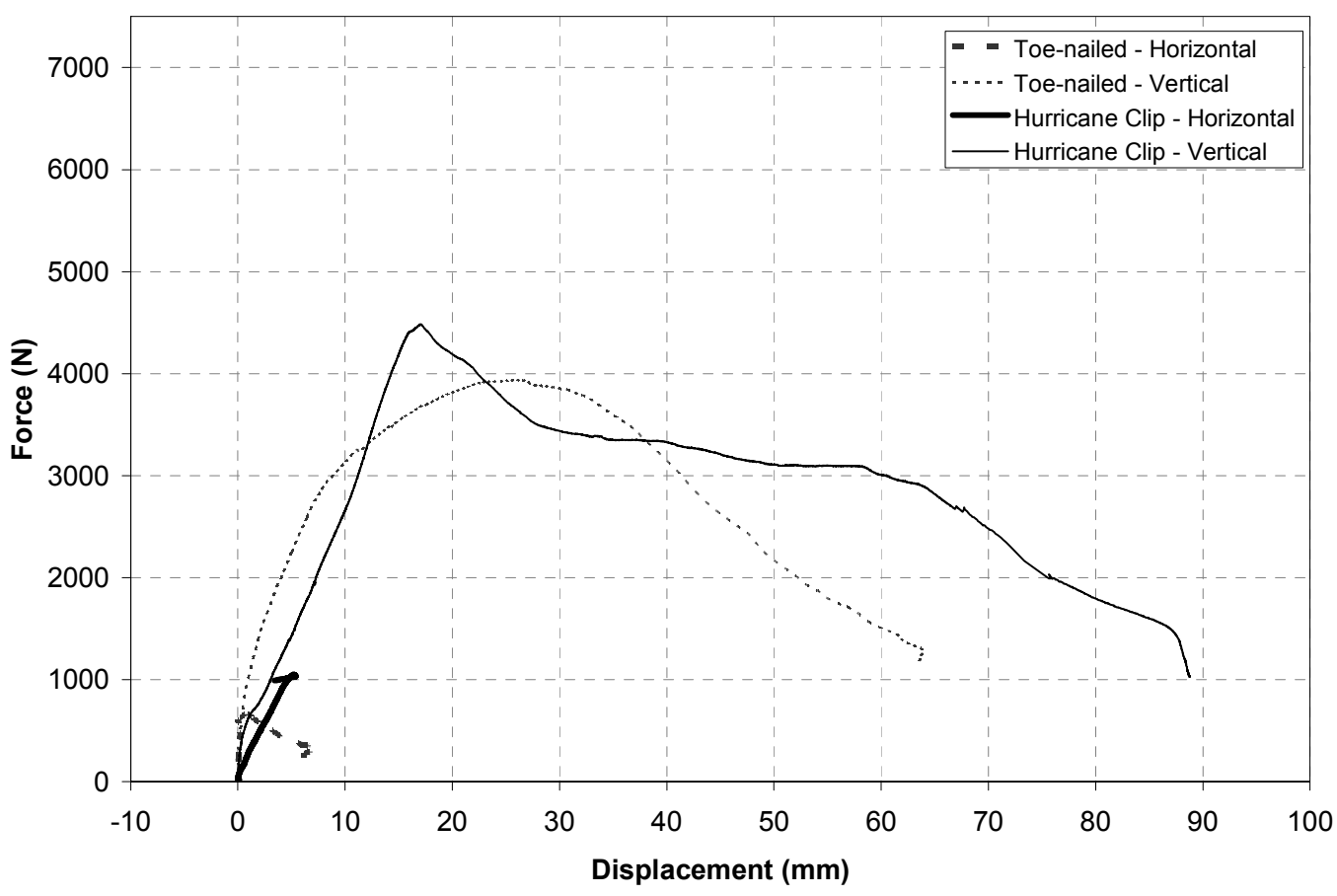

Figure 6.20. Comparison of responses of outer trusses. 


\section{Conclusions}

Recent disasters in the United States have resulted in few casualties, but they have caused substantial damage and significant economic loss to residential housing. An investigation of the state-of-the-art in experimental and analytical research on wood-frame housing found that while significant progress has been made in analytical modeling and testing of shear walls and diaphragms, only limited progress has been made on the testing and modeling of complete houses and inter-component connections.

The research reported herein attempts to help improve the performance of woodframe housing by filling one of the gaps in the understanding of the structural behavior of wood frame buildings subjected to extreme loads. This work consisted of experimentally testing two types of roof to wall connections to determine their performance and to provide the data, which are now lacking but are necessary for the future development of analytical models of the connections and for complete 3-D numerical models of entire houses. Such models will lead to improved design tools for wood-frame construction, and to stronger and more structurally efficient residential buildings.

The two types of connections tested included toe-nailed connections and hurricane clips. The simple toe-nailed connections represent the most common type of roof to wall connection in areas that are not routinely subjected to hurricanes. The hurricane clips represent the lightest and simplest version of a wide range of clips and straps that can be used to increase the strength of roof to wall connections.

The specimens with these connections were subjected to four types of loading: mono- tonic uplift, monotonic lateral load or pushover, combined uplift and lateral load, and cyclic lateral loading. The first two load types provide general failure response curves, while the third and fourth load types provide specific data on how these connections will respond when loaded to failure by strong winds and seismic loads, respectively.

The results of the monotonic uplift load test showed that the behavior of both types of connections tested is nonlinear under this form of load. The results also showed that once either of these connections reaches their ultimate load they lose a significant portion of their resistance. However, the hurricane clip connection had a significantly higher uplift capacity, and in most cases a larger failure deformation than the toenailed connections. The results showed that the residual strength of the hurricane clip connection tended to be greater than the capacity of the toe-nailed connection.

The tests with monotonic lateral loading showed that the behavior of both of these types of connections tended to be stiffer in shear than in tension (or uplift). Because the loads on the individual connections were a combination of shear and uplift, with the uplift caused by overturning moments in the specimen, the performance of the specimens in pure shear was not observed. However, the performance with a realistic combination of shear and uplift indicated that the uplift component tended to govern the failure of the connections. The results clearly show that the hurricane clip connections have a significantly higher capacity for both uplift and shear than the toenailed connections. As was the case with the monotonic uplift loading, the residual strength of the hurricane clip connections tended to be similar to or greater than the 
ultimate capacity of the toe-nailed connections.

Tests with a cyclic lateral displacement were performed to assess the performance and behavior of the connections when subjected to seismic loads. While the toe-nailed connections failed after numerous cycles, the hurricane clips proved to be stronger than other components of the specimen. The hurricane clips were still intact when the wall studs and cladding began to separate from the base plate. As was the case with the monotonic loads, the behavior of both types of connections was nonlinear, which produced significant hysteresis in the response. Such hysteresis can provide significant energy dissipation during seismic events. The results indicated that the hurricane clip connections have a higher capacity to withstand seismic loading, but the magnitude of the increased capacity could not be determined.

Finally, tests were performed with combined uplift and lateral loading to determine the performance and behavior of the connections when subjected to strong winds. During the test with hurricane clip connections one of the connections failed at a relatively low load when the top plate of the wall split where the connection was anchored. The load at which this connection failed was still slightly larger than the loads at which the toe-nailed connections failed. The behavior of the other hurricane connections was similar to the behavior seen in other loading cases, with the hurricane clips providing a much greater capacity than the toe-nailed connections. This response highlights the great variability that can occur in the response of wood frame construction, due to both the variability in the materials and in the quality of workmanship. However, the overall strength of the hurricane clip specimen was not greatly compromised by the single weak connection. The com- bined strength of the other three hurricane clips on that wall of the specimen allowed the specimen to resist almost $45 \%$ more load than the specimen with toe-nailed connections.

The most important conclusion that can be reached from this effort is the great improvement in performance that was gained when using the hurricane clips instead of the toe-nailed connections. These simple clips tended to increase capacity by more than $40 \%$. As observed in the cyclic loading tests, the hurricane clip connections had strengths that were similar to the strength of the walls themselves. Further increases in the connection capacity would require clips or straps that connect the trusses directly to the wall studs, and should probably be paired with straps that anchor the studs directly to the foundation.

There is, unfortunately, a significant uncertainty associated with these results. Due to the limited number of tests and specimens, a statistical analysis of the results and an accurate determination of their uncertainty are not practical. In general, there is a large variation in the response of wood-frame housing components due to variations in the material properties of the wood members and inconsistencies in the quality of construction. The wood properties can vary considerably, and are dependent on the wood type, dryness, and density, as well as cracks or other physical defects. The quality of construction can vary considerably depending on the experience and skill of the builders. The uncertainty of the results between test specimens was minimized by purchasing all materials at the same time and from the same distributor, and having the walls and roof trusses pre-fabricated. In addition, the same two people performed the final assembly of all of the specimens. Although the individual results have some uncertainty, the general trends in the over- 
all performance were quite consistent and the uncertainty of the relative response between the specimens with toe-nailed connection and those with hurricane clips is estimated to be small.

The data obtained in these tests can provide the basis for limited analytical models of the connection response. Additional testing is required to fully quantify the response of roof to wall connections. Some gaps that still need to be filled include tests of additional types of connections and tests of specimens with longer wall lengths. Component tests of single, directly loaded connections would allow numerous tests with a particular load pattern and connection type, to determine the statistical mean, variance, and uncertainty of the response. Tests of wall-to-foundation and wall-to-wall connections are also necessary to fully determine the response of wood-frame construction. 
This page intentionally left blank. 


\section{REFERENCES}

Groom, K. M. and Leichti, R. J. (1991), “Finite-Element Model of a Nonlinear intercomponent connection in LightFramed Structures," Proceedings of the 1991 International Timber Engineering Conference, London, England, September, Vol. 4, pp. 4.346-4.353.

Groom, K. M. and Leichti, R. J. (1994), "Transforming a Corner of a LightFrame Wood Structure to a Set of Nonlinear Springs, Wood and Fiber Science, Vol. 26, No. 1, Society of Wood Science and Technology, pp. 28-35.

Krawinkler, H., Parisi, F., Ibarra, L., Ayoub, A., and Medina, R. (2001), "Development of a Testing Protocol for Wood Frame Structures," Technical Report W02, CUREE - Consortium of Universities for Research in Earthquake Engineering, Richmond, CA.

Polensek, A. and Schimel, B. D. (1986), “Rotational Restraint of Wood-Stud Wall Supports," Journal of Structural Engineering, Vol. 112, No. 6, American Society of Civil Engineers, NY, June, pp. 12471262.

Polensek, A. and Schimel, B. D. (1988), "Analysis of Nonlinear Connection Systems in Wood Dwellings," Journal of Computing in Civil Engineering, Vol. 2, No. 4, American Society of Civil Engineers, NY, October, pp. 365-379.

Rosowsky, D.V., Reed, T.D. and Tyner, K.G. (1998), “Establishing Design Values for Uplift Connections in Light-Frame Construction," Journal of Testing and Evaluation, ASTM, 26(4), pp. 426-433.

Reed, T., Rosowsky, D. and Schiff, S. (1997), “Uplift Capacity of Light-Frame Rafter to Top-Plate Connections," Journal of Architectural Engineering, ASCE, 3(4), pp. 156-163.

Reed, T.D., Rosowsky, D.V. and Schiff, S.D. (1996), “Roof Rafter-Top Plate Connection in Coastal Residential Construction," Proceedings: International Wood Engineering Conference, IWEC'96, New Orleans, LA.

Seible, F., Filiatrault, A., and Uang, C. M. (1999), Proceedings of the Invitational Workshop on Seismic Testing, Analysis and Design of Woodframe Construction, CUREe - California Universities for Research in Earthquake Engineering, Richmond, CA.

Yancey, C. W., Cheok, G. S., Sadek, F., and Mohraz, B. (1998), "A Summary of the Structural Performance of SingleFamily, Wood-Frame Housing," Technical Report NISTIR 6224, National Institute of Standards and Technology, Gaithersburg, MD. 